NUREG/CR-6429

PNL-10897

\title{
The Role of Organic Complexants and Microparticulates in the Facilitated Transport of Radionuclides
}

Manuscript Completed: October 1996

Date Published: December 1996

Prepared by

A. J. Schilk ${ }^{1}$, D. E. Robertson ${ }^{1}$, K. H. Abel ${ }^{1}$, E. L. Cooper ${ }^{2}$, R. W. D. Killey ${ }^{2}$, P. G. Hartwig' ${ }^{2}$, C. W. Thomas ${ }^{1}$,

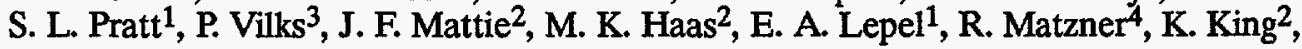

1Pacific Northwest National Laboratory

Richland, WA 99352

Subcontractors:

${ }^{2}$ Chalk River Laboratories

Chalk River, Ontario, Canada K0J1J0

${ }^{3}$ Whiteshell Laboratories

Pinawa, Manitoba, Canada R0E1LO

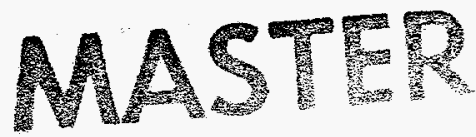

${ }^{4}$ Los Alamos National Laboratory

Los Alamos, NM 87545

E. O'Donnell, NRC Project Manager

\section{Prepared for}

Division of Regulatory Applications

Office of Nuclear Regulatory Research

U.S. Nuclear Regulatory Commission

Washington, DC 20555-0001

NRC Job Code L1935 


\begin{abstract}
This progress report describes the results of ongoing radiological and geochemical investigations of the mechanisms of radionuclide transport in groundwater at two low-level waste (LLW) disposal sites within the waste management area of the Chalk River Laboratories (CRL), Ontario, Canada. These sites, the Chemical Pit liquid disposal facility and the Waste Management Area $\mathrm{C}$ solid LLW disposal site, have provided valuable 30 - to 40-year-old field locations for characterizing the migration of radionuclides and evaluating a number of recent site performance objectives for LLW disposal facilities. This information will aid the NRC and other federal, state, and local regulators, as well as LLW disposal site developers and waste generators, in maximizing the effectiveness of existing or projected LLW disposal facilities for isolating radionuclides from the general public and thereby improving the health and safety aspects of LLW disposal.
\end{abstract}

These studies have focused on identifying the physicochemical species of mobile radionuclides in groundwater at these field locations and characterizing their behavior in the sub-surface environment. Field and laboratory studies have shown that the mobile radionuclide species, including ${ }^{55} \mathrm{Fe},{ }^{60} \mathrm{Co},{ }^{106} \mathrm{Ru},{ }^{125} \mathrm{Sb}$, and ${ }^{239,240} \mathrm{Pu}$, are generally anionic in nature and being sequestered by naturally occurring and/or man-made complexing materials, such as fulvic and humic substances. Ion chromatographic separations of contaminated groundwater have identified a number of individual mobile chemical species of ${ }^{60} \mathrm{Co}$ and ${ }^{106} \mathrm{Ru}$, indicating the presence of a complex mixture of these sequestered radionuclides being transported in the groundwater. Further physico-chemical characterization of these mobile radionuclides using large-volume hollow-fiber ultrafiltration techniques have confirmed that a significant fraction of the "soluble" radionuclides are present as

\section{Abstract}

intermediate molecular weight compounds corresponding to size ranges typical of fulvic and humic organo-metallic macromolecules. Optical spectroscopic techniques for characterizing the organo-metallic radionuclide species have also provided confirmatory evidence of complexation of radionuclides by humic materials.

These studies have shown, through the use of multiple state-of-the-art characterization methodologies, the consistent relationship between migrating radionuclides and naturally occurring humic and fulvic materials in CRL groundwater. Their ubiquitous presence in sampled waters, substantial capacity for the complexation of cationic radionuclides under the existing geochemical conditions, and general lack of attraction for most mineral surfaces in the aquifer medium suggest that these species are primarily responsible for the facilitated transport of radionuclides in this region. As the CRL site serves as a viable model for LLW disposal sites in humid environments, the results of this investigation have farreaching implications in the fields of facility design, maintenance, and remediation.

On-going field and laboratory studies are continuing to provide information on the degree of retardation of the mobile organo-radionuclide species as well as corresponding cationic forms by site soils. These measurements will allow more accurate and reliable modeling assessments of radionuclide transport in groundwater at CRL and similar humid sites. Work is also continuing on characterization of the movement of ${ }^{14} \mathrm{C}$ through the sub-surface environment, its release to the atmosphere as a gaseous species, and its uptake by vegetation growing in the immediate vicinity of the contaminated groundwater plume (by both root and foliative pathways). 
DISCLAIMER

Portions of this document may be illegible in electronic image products. Images are produced from the best available original document. 


\section{DISCLAIMER}

This report was prepared as an account of work sponsored by an agency of the United States Government. Neither the United States Government nor any agency thereof, nor any of their employees, make any warranty, express or implied, or assumes any legal liability or responsibility for the accuracy, completeness, or usefulness of any information, apparatus, product, or process disclosed, or represents that its use would not infringe privately owned rights. Reference herein to any specific commercial product, process, or service by trade name, trademark, manufacturer, or otherwise does not necessarily constitute or imply its endorsement, recommendation, or favoring by the United States Government or any agency thereof. The views and opinions of authors expressed herein do not necessarily state or reflect those of the United States Government or any agency thereof. 


\section{Contents}

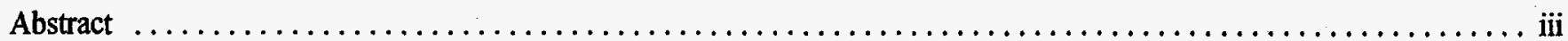

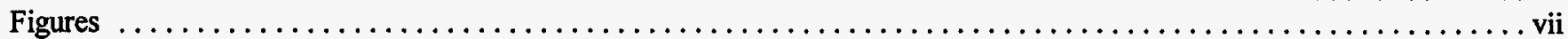

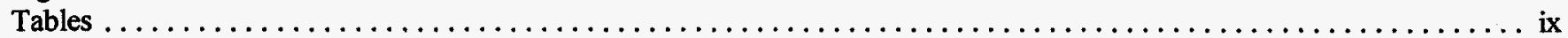

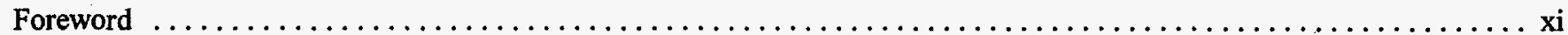

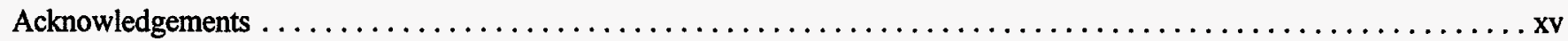

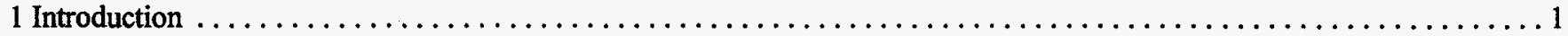

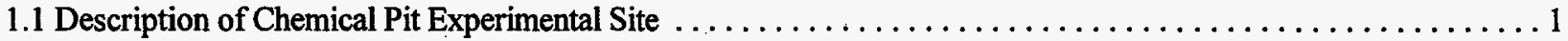

1.1.1 Previous Related Chemical and Radiological Characterizations . . . . . . . . . . . . . . . . . . 6

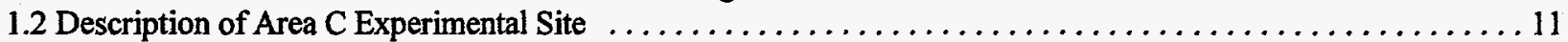

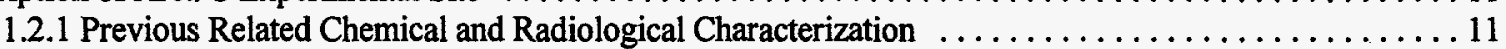

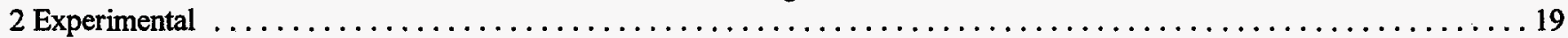

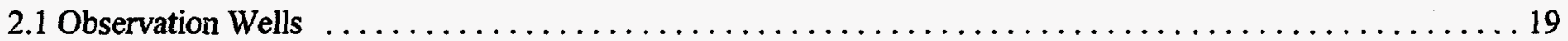

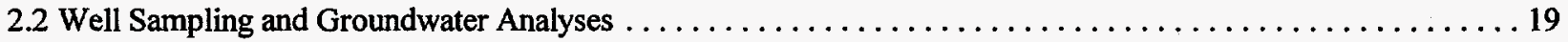

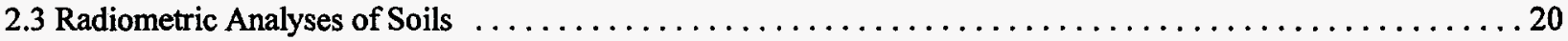

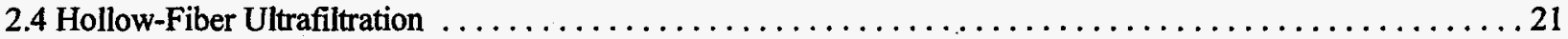

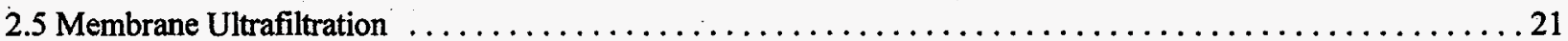

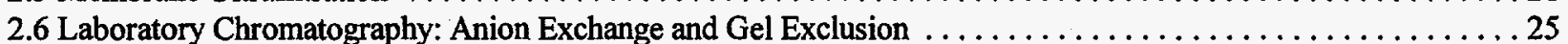

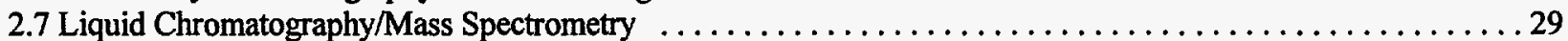

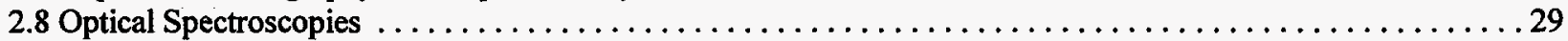

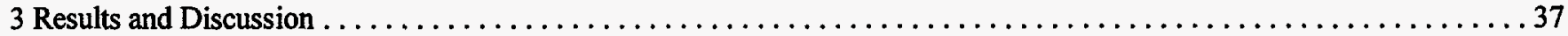

3.1 Well Sampling and Analyses of Chemical Constituents of Groundwater $\ldots \ldots \ldots \ldots \ldots \ldots \ldots \ldots \ldots \ldots \ldots \ldots$

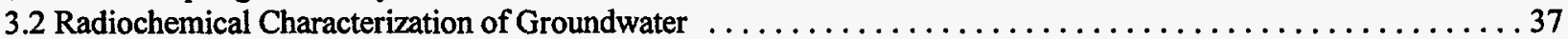

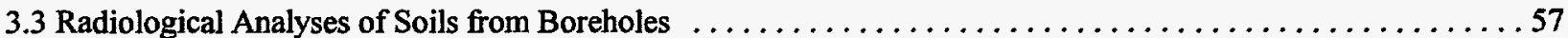

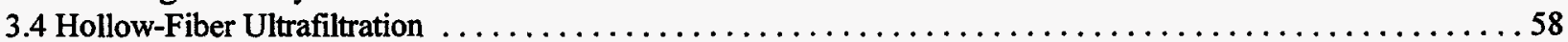

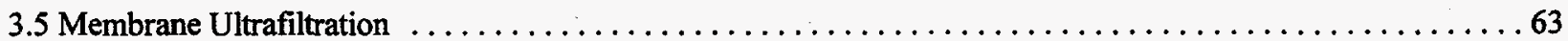

3.6 Laboratory Chromatography: Anion Exchange and Gel Exclusion $\ldots \ldots \ldots \ldots \ldots \ldots \ldots \ldots \ldots \ldots \ldots$

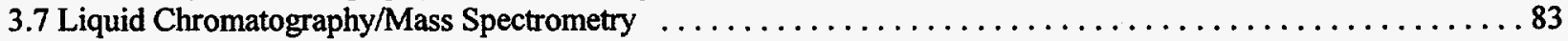

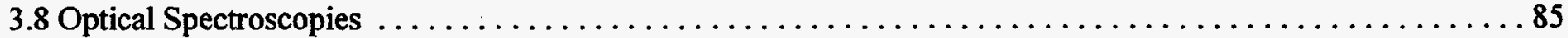

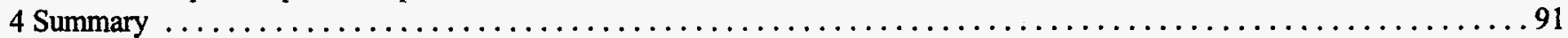

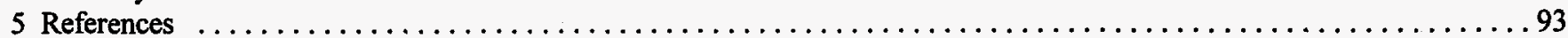





\section{Figures}

Chalk River Laboratories site location map

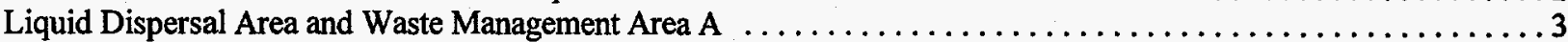

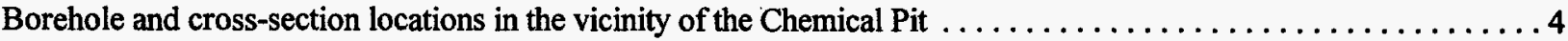

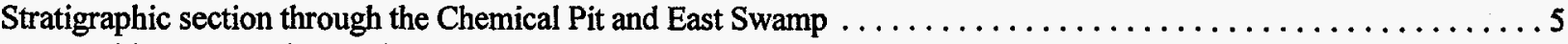

Water table contours in the vicinity of the Chemical Pit $\ldots \ldots \ldots \ldots \ldots \ldots \ldots \ldots \ldots \ldots \ldots \ldots$ Annual average concentrations of total beta-gamma activity and ${ }^{90} \mathrm{Sr}$ at the East Swamp

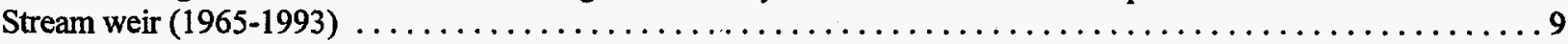
Annual average concentrations of ${ }^{60} \mathrm{Co}$ and ${ }^{106} \mathrm{Ru}$ at the East Swamp Stream weir $(1974-1993) \ldots \ldots \ldots \ldots \ldots 10$

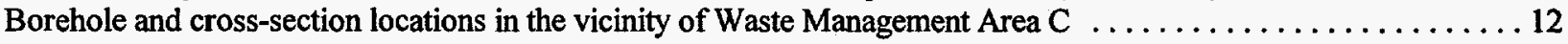
Stratigraphic section through Area $C$ and the Duke Swamp groundwater discharge area $\ldots \ldots \ldots \ldots \ldots \ldots$ Surface hydrology, water table contours, and areal extent of groundwater contamination by ${ }^{3} \mathrm{H}$

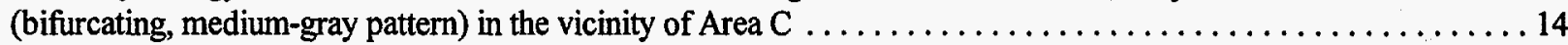

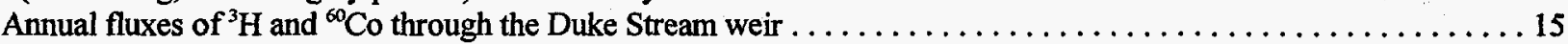

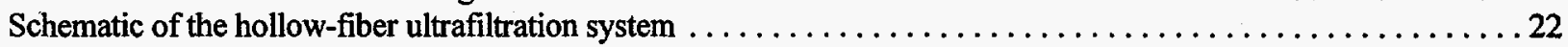

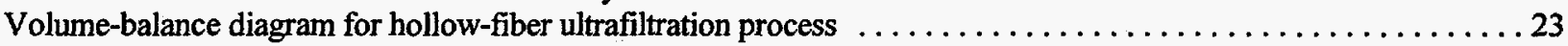

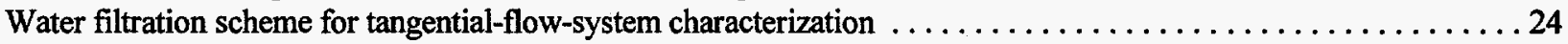

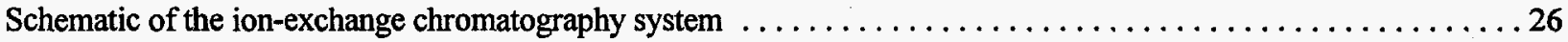

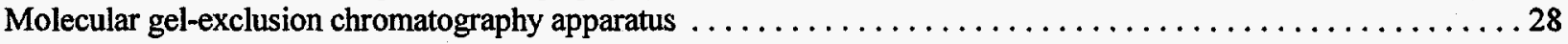

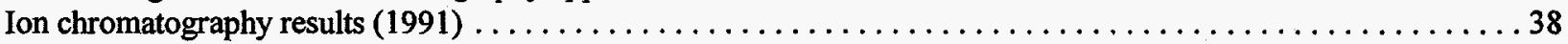

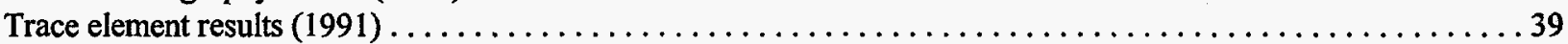

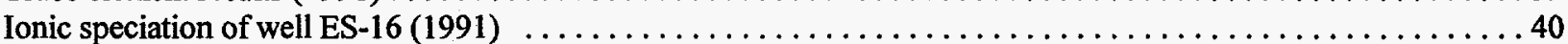

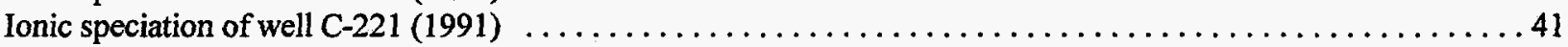
Relative proportions of ${ }^{60} \mathrm{Co}$ and ${ }^{106} \mathrm{Ru}$ at ES-16 with respect to particle size $(1991) \ldots \ldots \ldots \ldots \ldots \ldots \ldots \ldots \ldots$

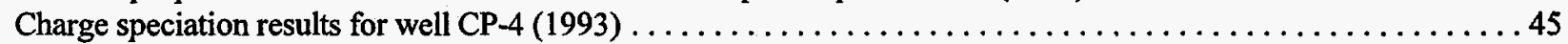

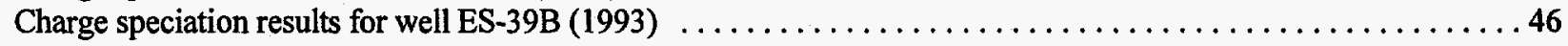

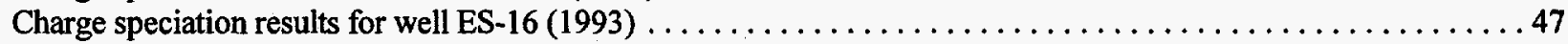

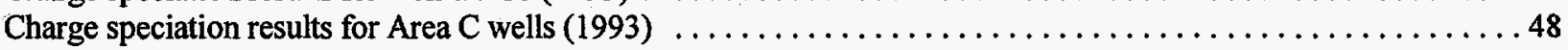
Cobalt-60 charge speciation as a function of distance from the Chemical Pit (1993) . . . . . . . . . . . . . 49 Ruthenium-106 charge speciation as a function of distance from the Chemical Pit (1993) . . . . . . . . . . 50 Antimony -125 charge speciation as a function of distance from the Chemical Pit (1993) $\ldots \ldots \ldots \ldots \ldots \ldots \ldots$. 51

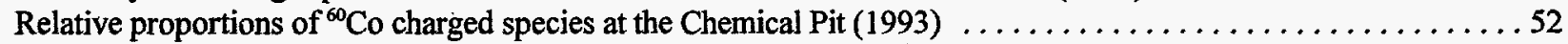

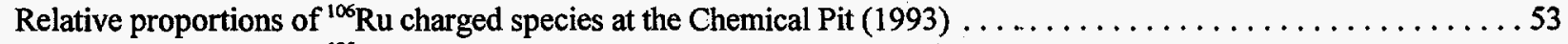

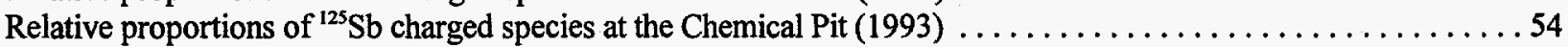

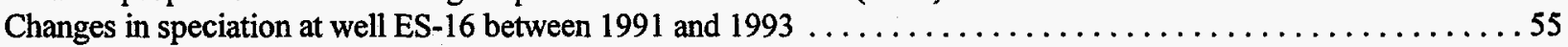
General size-fractionation trends for selected radionuclides at well ES-16 in 1993 (a) and 1994 (b) ........661 General size-fractionation trends for selected radionuclides at well CP-4 in 1993 (a) and 1994 (b) . . . . . . .6. 62 Cobalt-60 chromatograms for well ES-16, prior to (a) and following (b) installation of rotary valve (3/5/93 and

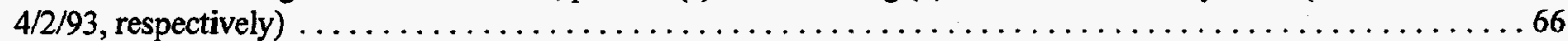
Ruthenium-106 chromatograms for well ES-16, prior to (a) and following (b). installation of rotary valve (3/5/93 and

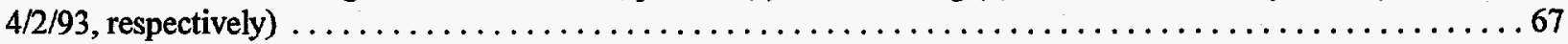

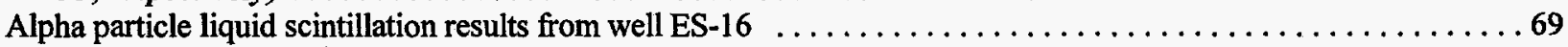

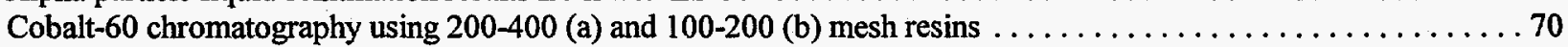
Ruthenium-106 chromatography using 200-400 (a) and 100-200 (b) mesh resins $\ldots \ldots \ldots \ldots \ldots \ldots \ldots \ldots$. 71

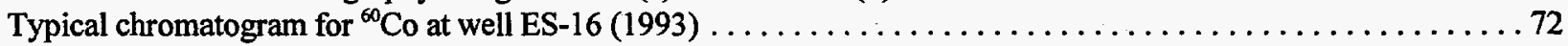
Cobalt-60 chromatograms for well ES-16 using $17-\mathrm{cm}$ (a) and $25-\mathrm{cm}$ (b) columns $\ldots \ldots \ldots \ldots \ldots \ldots \ldots \ldots \ldots$ Ruthenium-106 chromatograms for well ES-16 using $17-\mathrm{cm}$ (a) and $25-\mathrm{cm}$ (b) columns $\ldots \ldots \ldots \ldots \ldots \ldots 74$

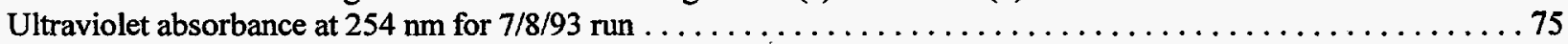
Cobalt-60 chromatogram for ultrafiltered water from well $\mathrm{CP}-4(8 / 13 / 93) \ldots \ldots \ldots \ldots \ldots \ldots \ldots \ldots \ldots \ldots 77$ Cobalt 60 chromatogram for ultrafiltered water from well ES-39 $(8 / 11 / 93) \ldots \ldots \ldots \ldots \ldots \ldots \ldots \ldots \ldots 78$ Cobalt-60 chromatograms for ultrafiltered (a) and $0.45-\mu \mathrm{m}$-filtered (b) waters from well ES-16

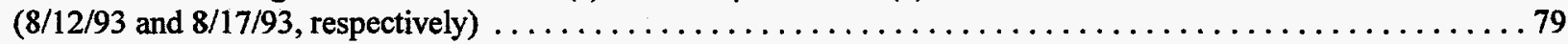

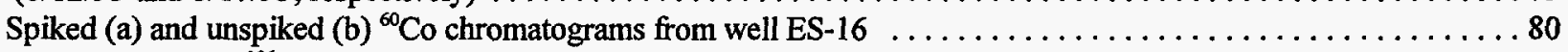

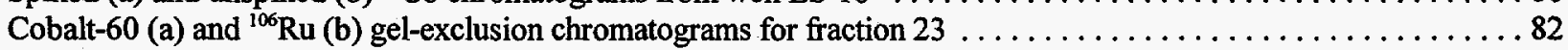


Cobalt-60 gel-exclusion chromatograms for fractions 22 (a), 26 (b), 27 (c), and 112 (d) .84 Absorption spectra of size-fractionated aqueous samples Emission spectra from well CP-4 $(<0.45 \mu \mathrm{m},>100,000 \mathrm{MW})$ as a function of the photon counter gate and delay $\ldots 89$ Emission spectra from well CP-4, aqueous $(<0.45 \mu \mathrm{m},>100,000 \mathrm{MW})$ and solid material, as a function of the photon counter gate and delay 


\section{Tables}

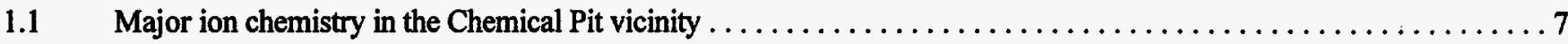

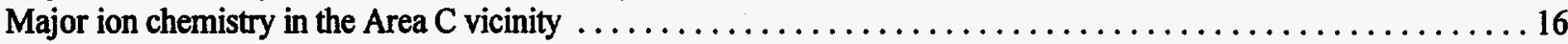

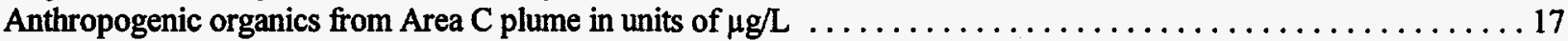

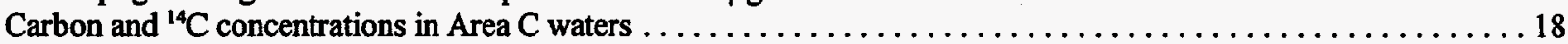

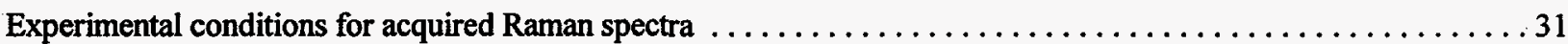

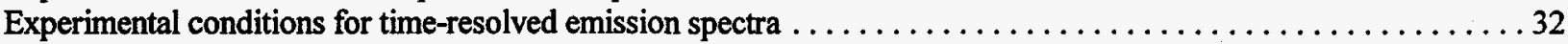

Experimental conditions for delay- and gate-dependent time-resolved emission spectra $\ldots \ldots \ldots \ldots \ldots \ldots \ldots 34$

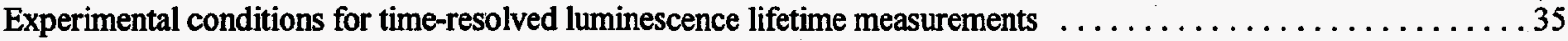

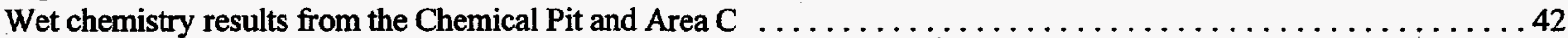

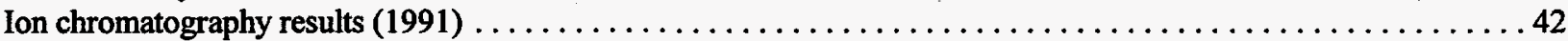

Trace element results via inductively-coupled argon plasma/atomic emission spectrometry $(1991) \ldots \ldots \ldots \ldots .42$

Charge speciation and particulate natures of selected radionuclides $(1991) \ldots \ldots \ldots \ldots \ldots \ldots \ldots \ldots \ldots 43$

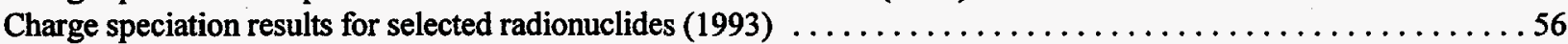

Dissolved radionuclide concentrations downgradient from the Chemical Pit (1993) . . . . . . . . . . . . . 57

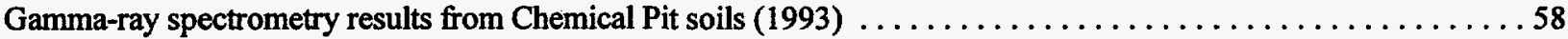

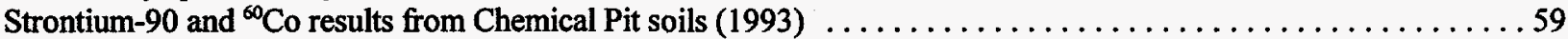

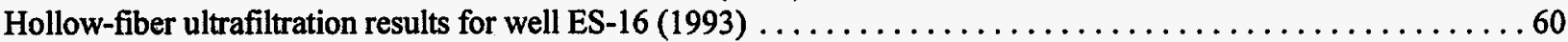

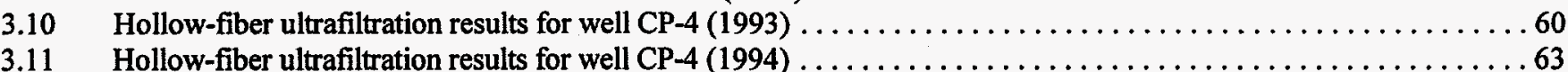

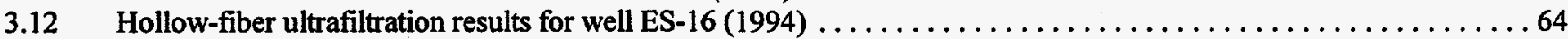

3.13 Results from gravimetric particle-size analyses at the Chemical Pit (1993) . . . . . . . . . . . . . . . 64

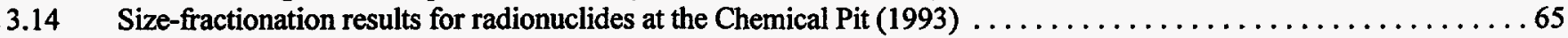

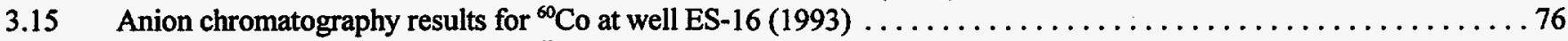

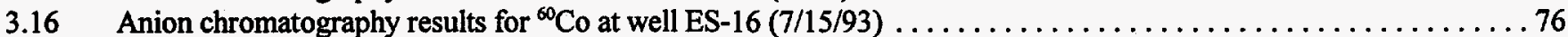

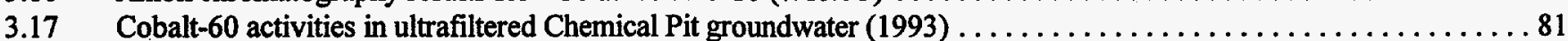

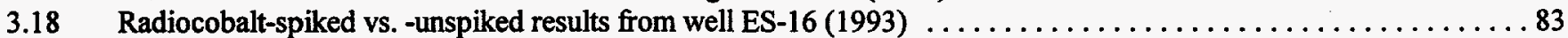

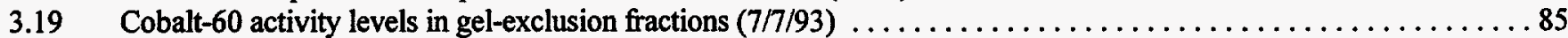

3.20 Fitting results for the time-resolved luminescence lifetime measurements $\ldots \ldots \ldots \ldots \ldots \ldots \ldots \ldots \ldots \ldots$ 



\section{Foreword}

Any candidate site intended for use as a facility for the shallow burial of low-level radioactive waste must satisfy the requirements of 10 CFR 61 (Licensing Requirements for Land Disposal of Radioactive Waste), subpart $D$, section 61.5(2). This regulation states that any proposed site must be capable of being characterized, modeled, analyzed, and monitored. When such facilities are licensed, the primary concern is the means (natural and/or enhanced) by which radionuclides migrate beyond site boundaries. A thorough understanding of these means could lead to the prevention or minimization of such transport, thereby sparing the general public from undue exposure. Furthermore, shallow land burial has been routinely used for the disposal of lowlevel radioactive wastes during which imperfect disposal practices, precipitation infiltration, and groundwater leaching of various waste forms have led to the contamination of many surface and subsurface waters (Riley and Zachara 1992). Despite current wastemanagement programs, which are intended to modify and/or reduce waste streams and to contain pollutants from past disposals, the active migration of radionuclides from many of the aforementioned sites is an almost ubiquitous phenomenon (e.g., McCarthy 1988; Olsen et al. 1986; and references therein). Whether one is concerned with projected or existing radioactive waste disposal sites, a clear and detailed understanding of the mechanisms of radionuclide transport (both natural and facilitated) is imperative and critical to any realistic performance assessment.

To ensure the compliance of proposed sites and to perform environmental assessments of existing ones, most investigators use predictive models of radionuclide transport that employ laboratory-derived values for a parameter referred to as the radionuclide distribution coefficient $\left(\mathrm{K}_{\mathrm{d}}\right)$. This parameter is essentially a ratio of the radionuclide activity per unit mass of soil (aquifer medium) to the radionuclide activity per unit volume of groundwater. The magnitude of this ratio is directly related to the extent to which the radionuclide in question is retarded (or retained by the stationary phase) with respect to the migrating fluid. A number of recent studies have identified significant discrepancies between actual migration rates and those predicted by models for some radionuclides in natural settings (Robertson et al. 1989; and references cited). It is generally acknowledged that transport models based on thermodynamic calculations of radionuclide speciation ${ }^{1}$ (Rai and Serne 1978) and laboratory analyses (e.g., studies involving "ideal" radiotracers that may be in some form other than those of the actual mobile species in natural groundwater) often fail to produce reliable results. This is, at least in part, because these procedures disregard the potential for radionuclide complexation by natural and man-made organic species as well as incorporation of radionuclides in microparticulate or dissolved colloidal material (Bondietti 1982; Champ et al. 1988; McCarthy 1988; McCarthy and Zachara 1989; Petit 1990; Warwick et al. 1991). Consequently, the current study supports the contention that to understand the mechanisms that determine the extent of radionuclide migration or retardation in an existing or proposed setting, it is imperative that species exhibiting facilitated transport be examined in actual field situations and subsequently compared with results from laboratory studies and calculated thermodynamic data. Fundamental information of this sort can then be incorporated into models for more accurate predictions of radionuclide movement from repositories and thereby enhance strategies for site planning or remediation by artificially manipulating retention or mobilization of these species.

Several mature low-level waste management and experimental dispersal sites exist at Chalk River Laboratories, Ontario, Canada, and are excellent analogues for shallow burial facilities in humid environments. These sites provide a unique and invaluable opportunity to study the long-term behavior and transport of a number of critical radionuclides (virtually all of those addressed in $10 \mathrm{CFR}$ 61), which have resided in a shallow groundwater flow system for nearly 40 years. The current study was initiated to sample groundwater from this natural setting, use multiple techniques to identify the speciation of the radionuclides migrating in this environment, and investigate the roles of organic complexation and microparticulates in facilitating migration.

Results of this study point to the existence of complex, heterogeneous, and highly variable chemical and redox environments that are controlled, at least in part, by the presence of natural organic material in the Chalk River groundwater. Anionic speciation of most radionuclides predominates in the areas studied, and particle-size and spectroscopic analyses indicate a correlation between these radionuclides and large organic macromolecules, lending support to the premise that naturally occurring humic and fulvic materials are facilitating the transport of radioactive contaminants in the subsurface. Additional evidence seems to suggest that multiple organo-radionuclide complexes are in these waters, and considerable conversion may be occurring between migrating species, both spatially and temporally. This has significant implications with regard to the potential for controlling radionuclide transport to either ensure contaminant retention or facilitate the extraction thereof. 


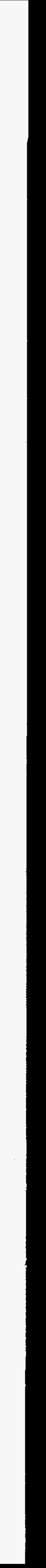




\section{References}

Bondietti, E.A. 1982. "Mobile Species of $\mathrm{Pu}, \mathrm{Am}, \mathrm{Cm}, \mathrm{Np}$, and Tc in the Environment." In: Environmental Migration of Long-Lived Radionuclides, IAEA-SM-257/42, International Atomic Energy Agency, Vienna, Austria.

Champ, D.R., J.L. Young, D.E. Robertson, and K.H. Abel. 1985. "Chemical Speciation of Long-Lived Radionuclides in a Shallow Groundwater Flow System." Water Poll. Res. J. Canada 19(2).

McCarthy, J.F. 1988. Role of Colloidal Particles in the Subsurface Transport of Contaminants. DOE/ER-0384, U.S. Department of Energy, Washington, D.C.

McCarthy, J.F., and J.M. Zachara. 1989. "Subsurface Transport of Contaminants." Environ. Sci. Technol. 23:496502.

Olsen C.R., P.D. Lowry, S.Y Lee, I.L. Larsen, and N.H. Cutshall. 1986. "Geochemical and Environmental Processes Affecting Radionuclide Migration from a Formerly Used Seepage Trench." Geochim. Cosmochim. Acta 44/45:165170.

Petit, J.C. 1990. "Migration of Radionuclides in the
Geosphere: What can we learn from Natural Analogues?" Radiochim. Acta 51:181-188.

Rai, D., and R.J. Serne. 1978. Solid Phases and Solution Species of Different Elements in Geologic Environments. PNL-2651, Pacific Northwest Laboratory, Richland, Washington.

Riley, R.G., and J.M. Zachara. 1992. Chemical Contaminants on DOE Lands and Selection of Contaminant Mixtures for Subsurface Science Research. DOE/ER0547T, U.S. Department of Energy, Washington, D.C.

Robertson, D.E., M.P. Bergeron, D. Holford, K.H. Abel, C.W. Thomas, D.A. Myers, D.R. Champ, R.W.D. Killey, D.L. Moltyaner, J.L. Young, and T. Ohnuki. 1989. Demonstration of Performance Modeling of a Low-Level Waste Shallow-Land Burial Site. NUREG/CR-4879 vol. 2, U.S. Nuclear Regulatory Commission, Washington, D.C.

Warwick, P., A. Hall, P. Shaw, J.J.W. Higgo, G.M. Williams, B. Smith, D. Haigh, and D. Noy. 1991. "The Influence of Organics in Field Migration Experiments (Part 2)." Radiochim. Acta 52/53:465-471. 


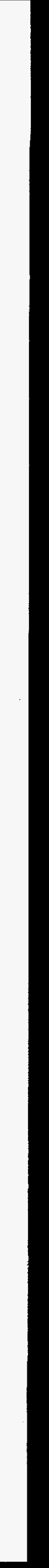




\section{Acknowledgments}

The authors wish to express their appreciation to Dr. Edward O'Donnell (Project Manager) of the Waste Management Branch, Division of Engineering, Office of
Nuclear Regulatory Research, U.S. Nuclear Regulatory Commission for helpful guidance and suggestions in conducting this work. 


\section{Introduction}

A major concern regarding the operation of existing and projected radioactive-waste disposal sites is the incidence of subterranean radionuclide transport by water. This phenomenon could potentially result in the contamination of public water-supply systems and uptake by overlying vegetation, thereby exposing the general public to such materials. Unfortunately, the physical and chemical processes that expedite such transport are still not well understood. For example, many of the radionuclides associated with waste management areas are often cationic in nature $\left({ }^{137} \mathrm{Cs}^{+},{ }^{60} \mathrm{Co}^{2+},{ }^{90} \mathrm{Sr}^{2+}\right.$, etc. $)$. Since many soil minerals are able to adsorb cationic species to some extent, these radionuclides would tend to migrate at a much slower rate than the accompanying groundwater. However, if the physico-chemical speciation of these radionuclides is modified by organic complexation and/or colloid formation, then the rate of migration may be dramatically enhanced. The formation of complexed or colloidal species can involve interactions between cationic radionuclides and organic or inorganic materials of both natural and manmade origins.

To more fully comprehend the mechanisms that determine the extent of radionuclide migration or retardation in existing or proposed natural settings, it is imperative that those species exhibiting transport be examined in actual field situations - due to the ready availability of various natural and/or anthropogenic complexing agents - and the results be subsequently compared to predictions from laboratory and thermodynamic data. Empirical data can then be incorporated into transport models for more accurate predictions of radionuclide migration from radioactive waste management facilities, thereby enhancing strategies for site planning or remediation by facilitating mobilization (for pump-and-treat methodologies) or deposition (for ensuring retention).

To assist in the characterization of these processes, a study has been initiated at Chalk River Laboratories (CRL) in Ontario, Canada, in an attempt to identify and quantify the mobile radionuclide species originating from two individual sites: 1) the Chemical Pit within the Liquid Dispersal Area, which has received aqueous wastes containing various radioisotopes, acids, alkalis, complexing agents, and salts since 1956, and 2) Waste Management Area C, a 30-yearold solid low-level waste storage facility consisting of a series of trenches containing radioactive wastes from CRL and various other facilities. These mature low-level waste management sites are excellent analogues for prospective shallow burial facilities located in environments where precipitation exceeds evapotranspiration, and they provide a unique and invaluable opportunity to study the long-term behavior and transport of a number of important radionuclides, many of which have resided in this shallow groundwater flow system for nearly $\mathbf{4 0}$ years.

Normally, it is difficult to effectively study migrating radionuclide species under natural conditions because the associated mass concentrations are quite low. The primary objective of this work, therefore, was to investigate a combination of methodologies that were intended to facilitate the study of radionuclide speciation in natural groundwater and shed some light on the issue of enhanced contaminant mobility.

\subsection{Description of Chemical Pit Experimental Site}

The Liquid Dispersal Area, which is located near the northern boundary of the Lower Perch Lake Basin (Figures 1.1 and 1.2), consists of a series of gravel-lined infiltration pits in a sandy, unsaturated horizon. This area is bounded to the southeast by a steep slope and the East Swamp, and to the southwest by a shallower grade that overlooks another wetland (South Swamp). The Chemical Pit, situated within this area, is composed of a pair of 5-m-deep, gravel-filled infiltration pits (Figure 1.3) that have accepted low-level liquid wastes since the mid-1950s. These wastewaters included a host of radionuclides (activation and fission products) and occasional discharges of small quantities of acids, alkalis, salts, and complexing agents originating from various research and development operations at CRL (Killey and Munch 1984). The disposal of anthropogenic complexing agents at this site has been discouraged since 1961 .

The local geology in the vicinity of the Chemical Pit (Figure 1.4) is made up of a variety of unconsolidated Quaternary sediments overlying a topographically irregular and locally fractured bedrock of Precambrian granitic to monzonitic gneiss, typical of much of the Canadian Shield. The bedrock is overlain by a sandy till of varying thickness that exhibits a low to moderate silt content with abundant gravel, cobbles, and boulders (often exceeding $3 \mathrm{~m}$ in diameter). Above the till is a thin ( $\leq 1 \mathrm{~m}$ ) layer of clayey silt, which is, in turn, overlain by silty to medium-grained sands with interbedded layers of clayey silt. These sands, generally less than $30 \mathrm{~m}$ in thickness, are composed largely of quartz and aluminosilicate minerals with associated alteration products and trace amounts of sulfides, carbonates, organic matter, and hydrated oxides of $\mathrm{Fe}$ and Mn (Champ et al. 1985; Killey and Munch 1984; Killey et al. 1984). The lower portion of these sands is probably composed of fluvial deposits, whereas the shallower materials are considered to be aeolian sheet deposits created from the reworking of the fluvial sands. Precipitation, 
Introduction

Figure 1.1 Chalk River Laboratories site location map
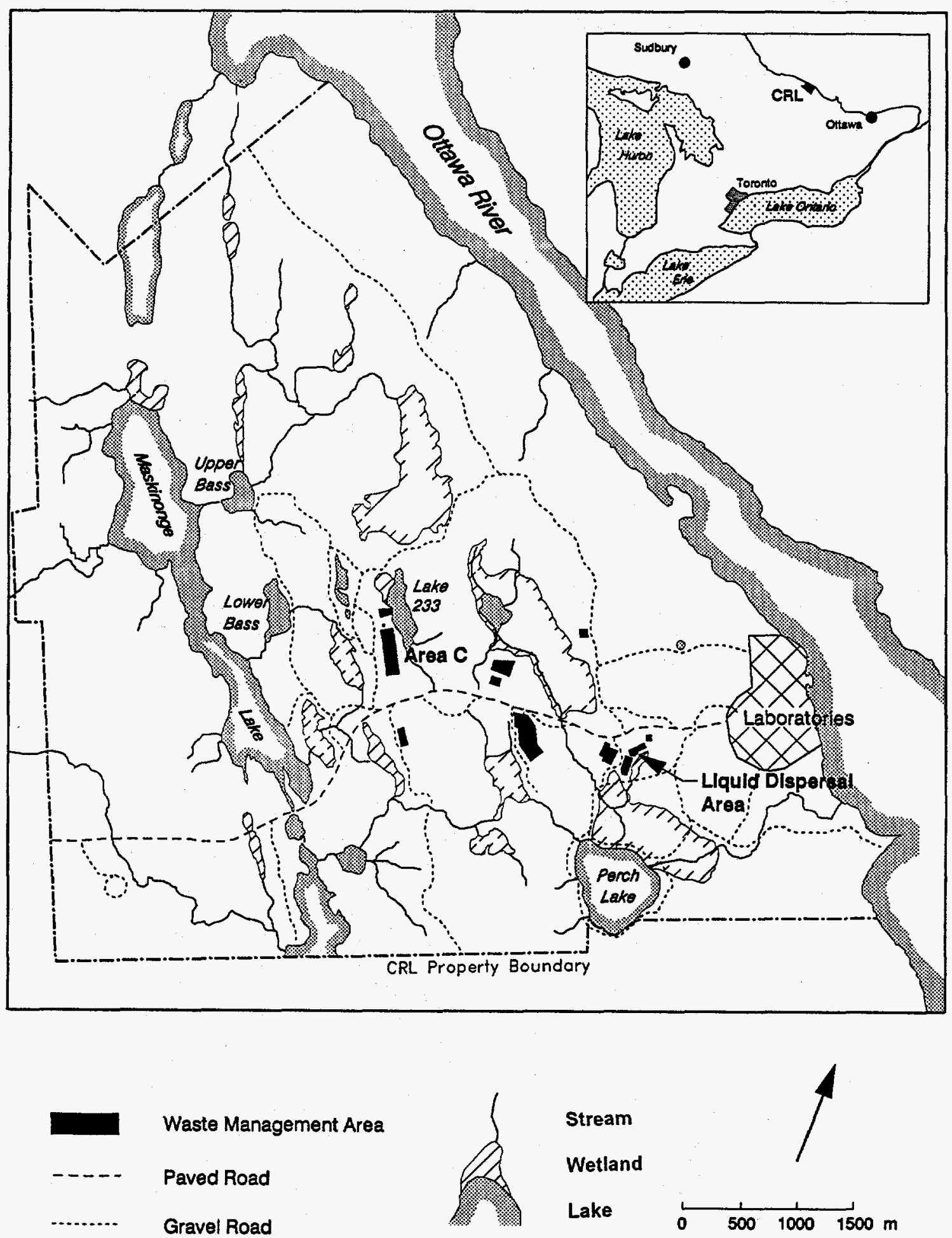

Stream

Wetland

Lake
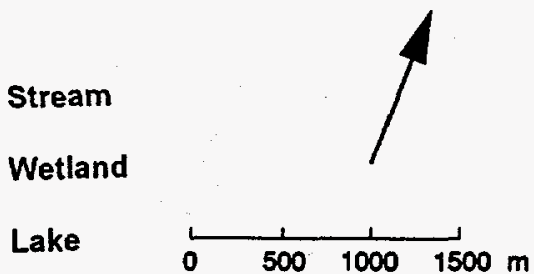
Figure 1.2 Liquid Dispersal Area and Waste Management Area A

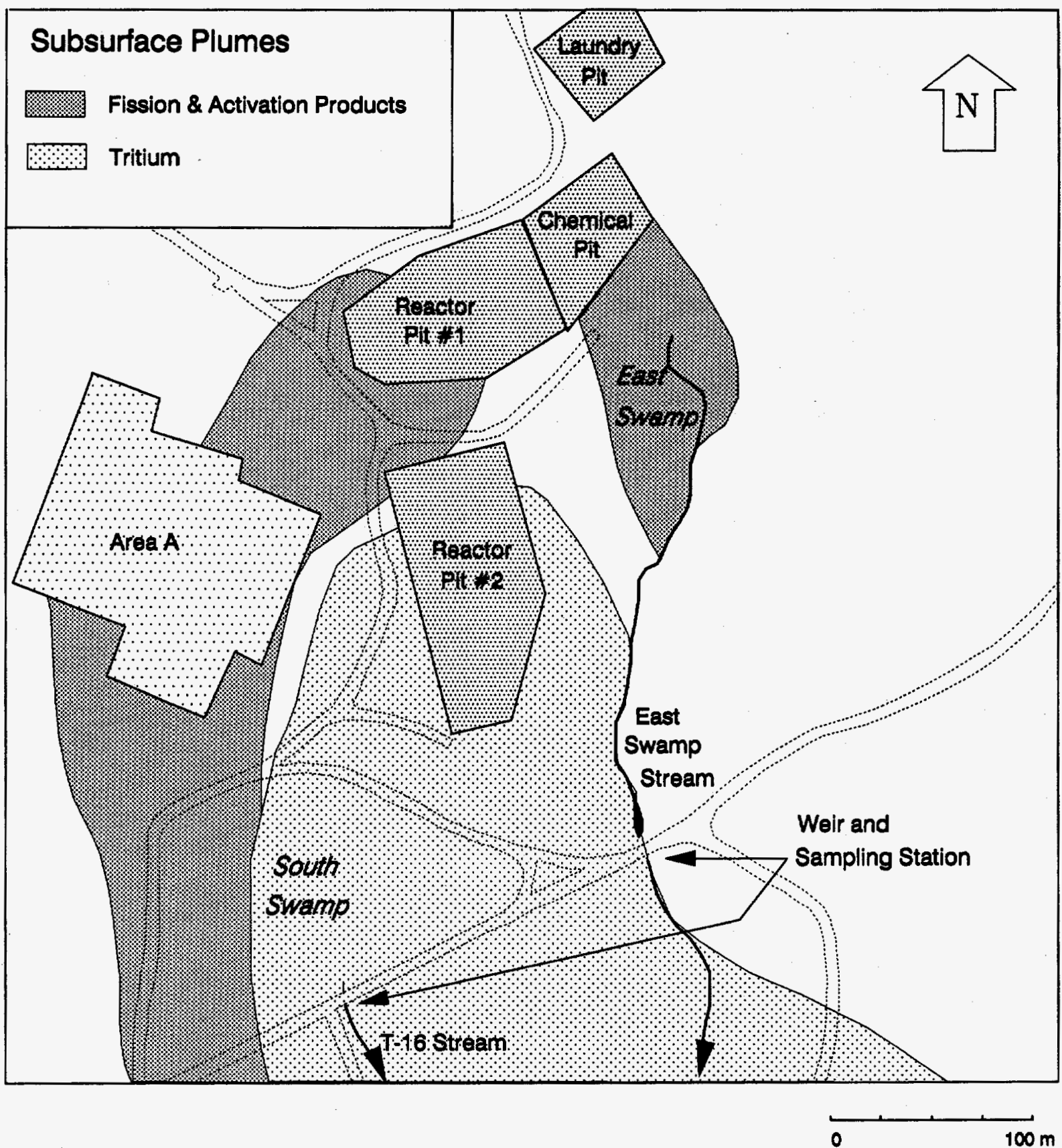


Introduction

Figure 1.3 Borehole and cross-section locations in the vicinity of the Chemical Pit

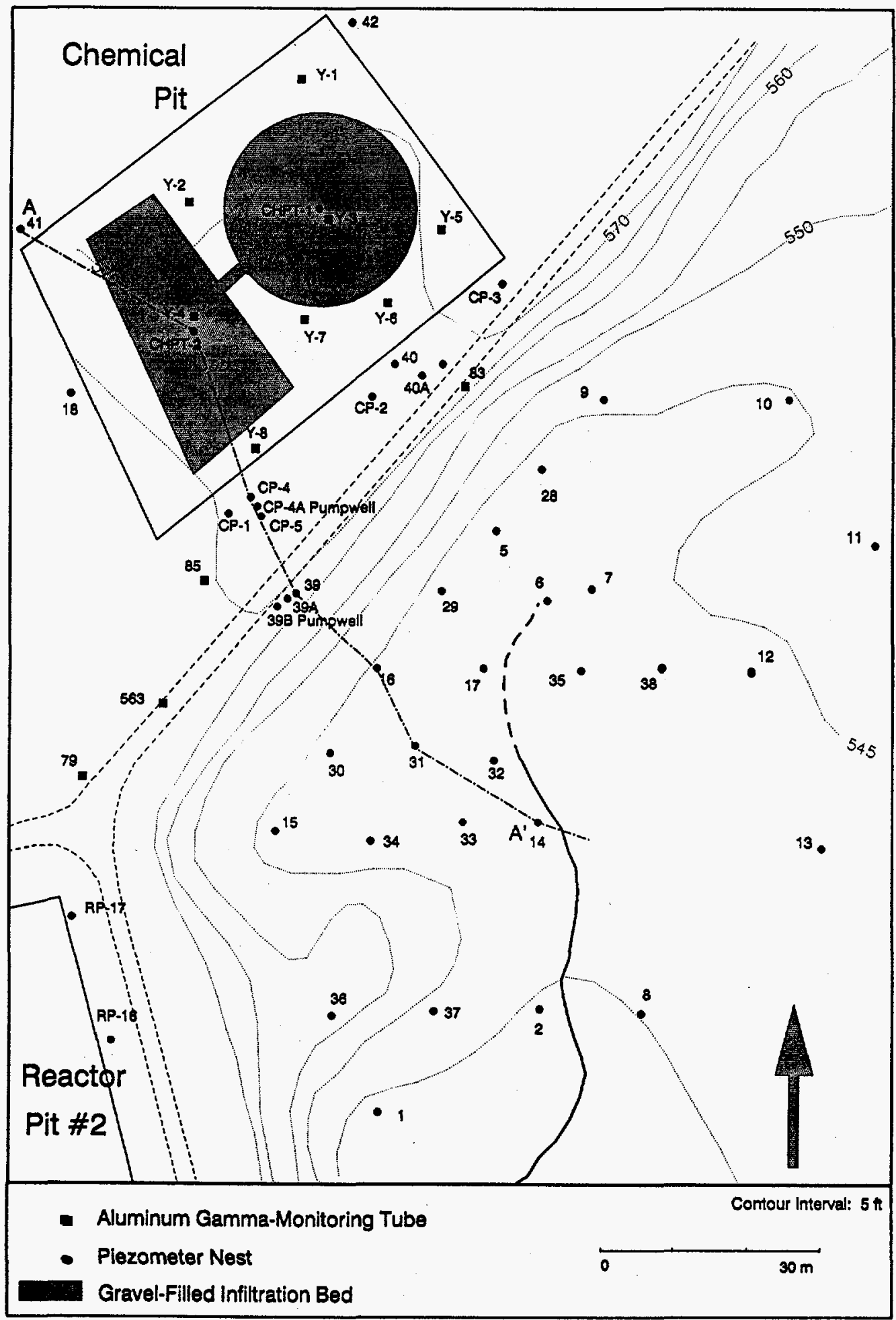


Introduction

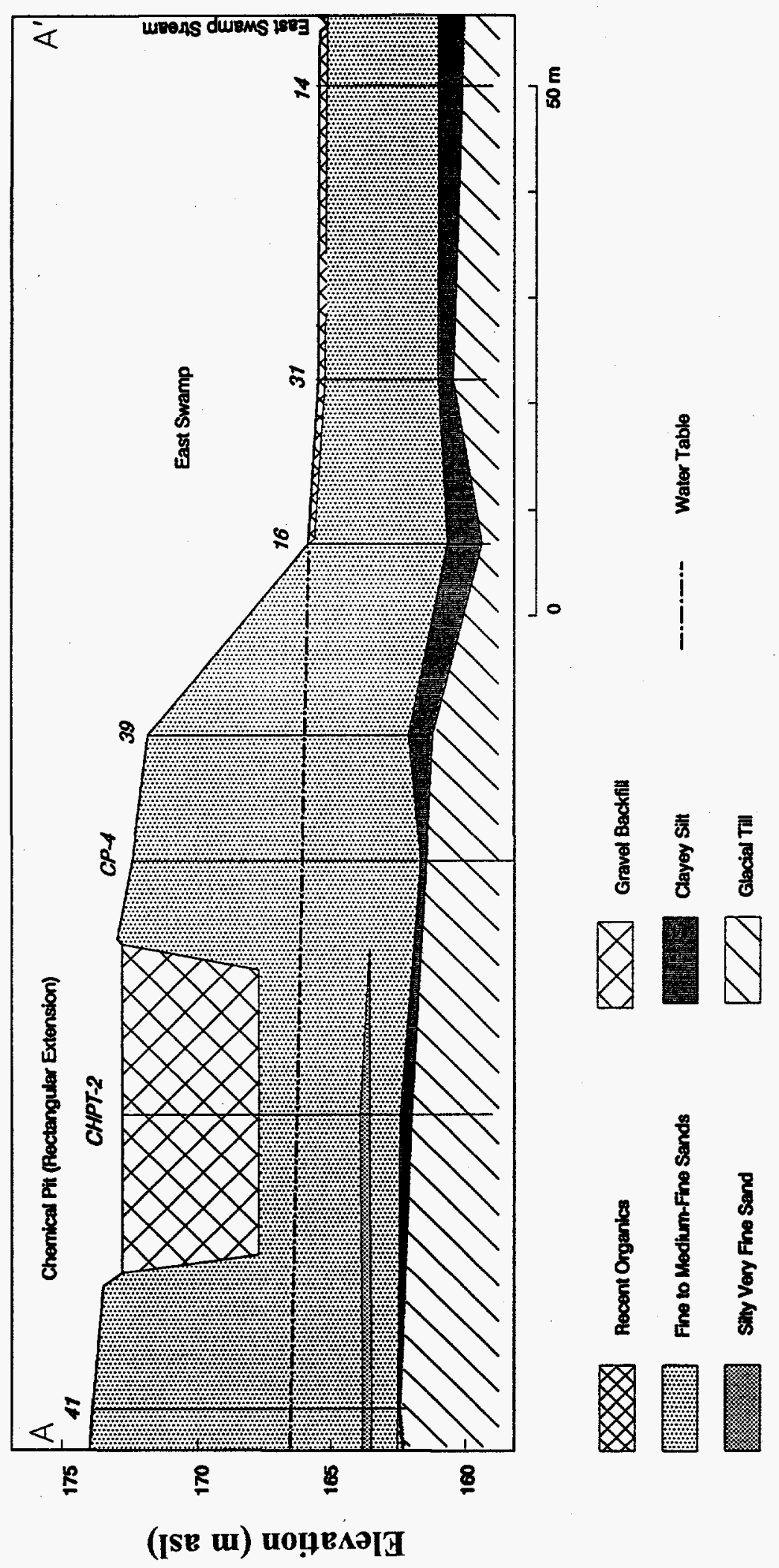

 
totaling approximately $75 \mathrm{~cm}$ per annum, is distributed evenly throughout the year and recharges a water table normally less than $5 \mathrm{~m}$ from the ground surface. This has led to the formation of swampy areas that contain bog deposits of peat and other organic matter (generally less than $0.5 \mathrm{~m}$ in thickness) throughout the region.

Existing boreholes in this area were used to determine hydraulic head distributions, and a subsurface flowpath was found to extend from this pit to the East Swamp (Figure 1.5 ), with a groundwater residence time of 6 months to 2 years and a mean flow rate of 5 to $25 \mathrm{~cm} /$ day.

Consequently, three wells along this gradient were selected for sampling near-field (CP-4), far-field (ES-16), and intermediate (ES-39) groundwater in the hopes of observing any temporal changes associated with the migrating radionuclide species (refer to Figures 1.3 and 1.4 for actual well locations).

\subsubsection{Previous Related Chemical and Radiological Characterizations}

\begin{abstract}
A previous sampling effort in July of 1980 (Killey and Munch 1984) indicated that the major ion loading at the Chemical Pit was rather low, and total dissolved solids in the contaminant plume were not substantially different from local uncontaminated groundwater (Table 1.1). The key distinguishing features of the plume, apart from the presence of radionuclides, were elevated $\mathrm{Na}$ and chloride concentrations, elevated $\mathrm{Eh}$, and lower dissolved iron $\left(\mathrm{Fe}^{2+}\right)$ concentrations compared to nearby groundwater. It was also noted during this study that sands within the Chemical Pit plume had significantly heavier surface coatings of iron oxyhydroxides than did equivalent sands outside of the plume boundaries. These coatings were interpreted to be a direct result of the more oxidizing conditions associated with the plume environment relative to the surrounding, uncontaminated waters, which led to the formation of insoluble ferric $\left(\mathrm{Fe}^{3+}\right)$ compounds.
\end{abstract}

Weekly records of streamflows and total beta-gammaemitter concentrations have been maintained for the East Swamp Stream, which provides a potential discharge path for the plume contaminants, since 1965. Radiochemical analyses and gamma-ray spectrometry were performed on quarterly composites of these waters from 1974 to 1992. Currently, these are done on a monthly basis, as are tritium and gross-alpha analyses. Since 1989, the average annual $\mathrm{pH}$ for stream inputs has ranged from 5.5 to 6.3 , and their conductivities have ranged between 300 and $600 \mu \mathrm{S} / \mathrm{cm}$.

Perhaps the most significant event in the operational history of the Chemical Pit occurred in 1961 when a solution containing appreciable quantities of citrate (and, possibly, a number of other complexing agents) was discharged to the pit. This event was followed $\sim 3$ months later by a marked increase in ${ }^{90} \mathrm{Sr}$ concentration and the first appearance of ${ }^{60} \mathrm{Co}$ in the East Swamp Stream. The presence of such complexing agents was apparently responsible for these phenomena and may have dissolved the previously adsorbed cationic species and facilitated their transport toward the discharge zone.

Another large increase in East Swamp Stream radionuclide concentrations occurred in 1990 (Figure 1.6). The total beta-gamma and ${ }^{90} \mathrm{Sr}$ concentrations were observed to rise dramatically throughout the year, resulting in average annual concentrations that were roughly an order of magnitude greater than those observed during the previous year. These were accompanied somewhat later by relatively smaller increases in the concentrations of ${ }^{60} \mathrm{Co}$ and ${ }^{106} \mathrm{Ru}$ (Figure 1.7). The reasons for this rise in radionuclide concentrations in the East Swamp Stream have not been determined, and sampling results since 1989 have provided no indications of appreciable changes in the conductivity or $\mathrm{pH}$ of the discharged wastewaters. Although these results do not include analyses for complexing agents, groundwater sampling during the summer of 1991 failed to detect any complexed forms of ${ }^{90} \mathrm{Sr}$. The presence of complexing agents, major shifts in groundwater $\mathrm{pH}$, or stable elements that might compete with radionuclides for sorption sites on the aquifer sands are expected to be observed at the East Swamp Stream within a few months of the discharge event, as indicated above. However, no such precursors to the enhanced contaminant concentrations have been identified.

It may be that the increases in radionuclide concentrations at the East Swamp Stream are the result of some much earlier perturbation in the Chemical Pit influent. The effects of such changes might not be evident in the discharge zone for many years if radionuclide migration rates were retarded by reversible or partially reversible sorption reactions. Records from the analyses of disposed waters show that the release of ${ }^{90} \mathrm{Sr}$ to the Chemical Pit in 1978 was approximately three times larger than releases in previous and subsequent years. A comparison between this 12-year delay (from the time of the ${ }^{90} \mathrm{Sr}$ release to the observed increase at the East Swamp Stream) and the 3month delay observed in the 1961 event leads to a ${ }^{90} \mathrm{Sr} \mathrm{K}$ of around $12 \mathrm{~mL} / \mathrm{g}$. This is in reasonable agreement with ${ }^{90} \mathrm{Sr}$ radioactivity distribution coefficients observed in other CRL aquifers (e.g., Robertson et al. 1987), making it tenable to propose that the observed increase in East Swamp Stream radiostrontium in 1990 is a direct result of the discharges in 1978. This hypothesis does not address the accompanying increases in ${ }^{60} \mathrm{Co}$ and ${ }^{106} \mathrm{Ru}$, yet these enhancements fall within the ranges of variability observed 
for these isotopes over the past decade. According to Champ et al. (1985), the total inventory of ${ }^{60} \mathrm{Co}$ on the aquifer matrix downgradient of the Chemical Pit is $10 \mathrm{Ci}$, while the quantity of alpha emitters disposed of at this site was estimated to be $5 \mathrm{Ci}$. Earlier investigations (Champ et al. 1985; Killey et al. 1984) identified radioisotopes of $\mathrm{Co}$, $\mathrm{Zr}, \mathrm{Ru}, \mathrm{Sb}, \mathrm{Cs}, \mathrm{Ce}, \mathrm{Eu}, \mathrm{Fe}, \mathrm{Sr}, \mathrm{Ni}, \mathrm{I}, \mathrm{Tc}, \mathrm{Pu}, \mathrm{Am}$, and $\mathrm{Cm}$ in downgradient water samples.

Table 1.1 Major ion chemistry in the Chemical Pit vicinity (refer to Figure 1.3 for well locations)

\begin{tabular}{|c|c|c|c|c|c|c|c|c|c|c|c|c|}
\hline \multirow{2}{*}{$\begin{array}{l}\text { Well No./ } \\
\text { Depth (m) }\end{array}$} & \multirow[t]{2}{*}{$\mathrm{pH}$} & \multirow{2}{*}{$\begin{array}{c}\mathrm{Eh} \\
(\mathrm{mV})\end{array}$} & $\mathrm{Ca}$ & Mg & $\mathrm{Na}$ & K & $\mathrm{Fe}$ & $\mathrm{Cr}$ & $\mathrm{SO}_{4}{ }^{2-}$ & $\mathrm{HCO}_{3}{ }^{-}$ & $\mathrm{F}^{-}$ & $\mathrm{NO}_{3}^{-}$ \\
\hline & & & \multicolumn{10}{|c|}{ Concentration (mg/L) } \\
\hline ES-9/1.0 & 5.98 & 130 & 3.7 & 0.85 & 2.2 & 1.34 & 6.3 & 0.8 & 5.7 & 15.4 & 0.21 & 0.0 \\
\hline ES-9/2.0 & 5.78 & 260 & 6.3 & 1.66 & 2.5 & 1.20 & 1.6 & 0.8 & 18.5 & 10.4 & 0.11 & 0.5 \\
\hline ES-9/3.0 & 5.85 & 100 & 5.5 & 1.87 & 2.6 & 1.26 & 2.5 & 0.7 & 8.8 & 21.2 & 0.13 & 0.0 \\
\hline ES-12/1.0 & 5.81 & 270 & 7.9 & 4.10 & 4.4 & 1.27 & 0.8 & 1.5 & 14.6 & 28.6 & 0.21 & 0.4 \\
\hline ES-12/1.5 & 6.40 & 160 & 21.2 & 6.70 & 4.5 & 2.23 & 1.1 & 1.0 & 11.3 & 84.8 & 0.17 & 0.3 \\
\hline ES-12/2.0 & 6.61 & 100 & 10.0 & 6.00 & 3.9 & 1.85 & 21.0 & 1.0 & 0.1 & 116.0 & 0.17 & 0.0 \\
\hline ES-13/1.0 & 5.82 & 80 & 7.4 & 3.40 & 4.3 & 1.10 & 4.2 & 2.5 & 16.2 & 23.6 & 0.23 & 0.0 \\
\hline ES-13/2.0 & 5.87 & 70 & 12.5 & 4.80 & 4.6 & 1.60 & 6.2 & 2.9 & 11.0 & 41.7 & 0.29 & 0.0 \\
\hline ES-5/0.6 & 5.15 & 660 & 2.4 & 0.70 & 3.0 & 1.15 & 0.1 & 2.3 & 9.2 & 10.0 & 0.25 & 1.0 \\
\hline ES-5/1.8 & 4.60 & 470 & 1.5 & 0.79 & 6.3 & 1.00 & 0.1 & 1.5 & 14.7 & 41.0 & 0.10 & 4.4 \\
\hline ES-5/24 & 5.70 & 330 & 3.7 & 2.30 & 3.8 & 1.65 & 3.0 & 0.5 & 12.5 & 21.8 & 0.20 & 0.0 \\
\hline ES. $14 / 1.0$ & 7.06 & 210 & 17.1 & 4.90 & 4.1 & 2.60 & 0.3 & 9.6 & 12.8 & 80.3 & 0.18 & 0.7 \\
\hline ES-14/2.0 & 7.32 & 230 & 31.2 & 9.00 & 3.0 & 1.00 & 0.1 & 13.5 & 28.0 & 97.5 & 0.13 & 4.0 \\
\hline ES-15/1.0 & 5.40 & 310 & 0.9 & 0.29 & 8.0 & 0.80 & 0.4 & 7.7 & 6.3 & 14.3 & 0.09 & 0.0 \\
\hline ES-15/2.0 & 5.50 & 310 & 4.4 & 0.81 & 11.1 & 1.90 & 0.3 & 9.3 & 5.8 & 24.9 & 0.25 & 0.0 \\
\hline ES-15/2.5 & 5.15 & 280 & 5.1 & 1.07 & 12.0 & 1.98 & 1.3 & 12.3 & 7.0 & 28.8 & 0.07 & 0.0 \\
\hline ES-1/1.06 & 5.40 & 650 & 0.7 & 0.52 & 13.0 & 0.86 & 0.3 & 12.8 & 10.7 & 14.5 & 0.15 & 3.0 \\
\hline ES-16/1.5 & 5.65 & 640 & 0.4 & 0.47 & 16.8 & 0.55 & 0.3 & 16.0 & 8.1 & 19.9 & 0.00 & 5.8 \\
\hline ES-16/2.0 & 6.28 & 540 & 1.0 & 4.40 & 16.2 & 0.49 & 0.5 & 16.4 & 11.4 & 83.4 & 0.39 & 0.0 \\
\hline ES-16/2.5 & 5.50 & 560 & 2.0 & 0.55 & 16.6 & 0.84 & 0.1 & 12.5 & 9.2 & 40.8 & 0.15 & 0.0 \\
\hline ES-17/1.0 & 4.75 & 360 & 1.7 & 0.49 & 7.3 & 1.04 & 0.1 & 0.6 & 12.5 & 10.0 & 0.12 & 2.5 \\
\hline ES-17/2.0 & 5.10 & 300 & 2.4 & 0.67 & 5.4 & 1.14 & 0.9 & 0.6 & 14.7 & 6.1 & 0.05 & 0.0 \\
\hline
\end{tabular}


Figure 1.5 Water table contours in the vicinity of the Chemical Pit

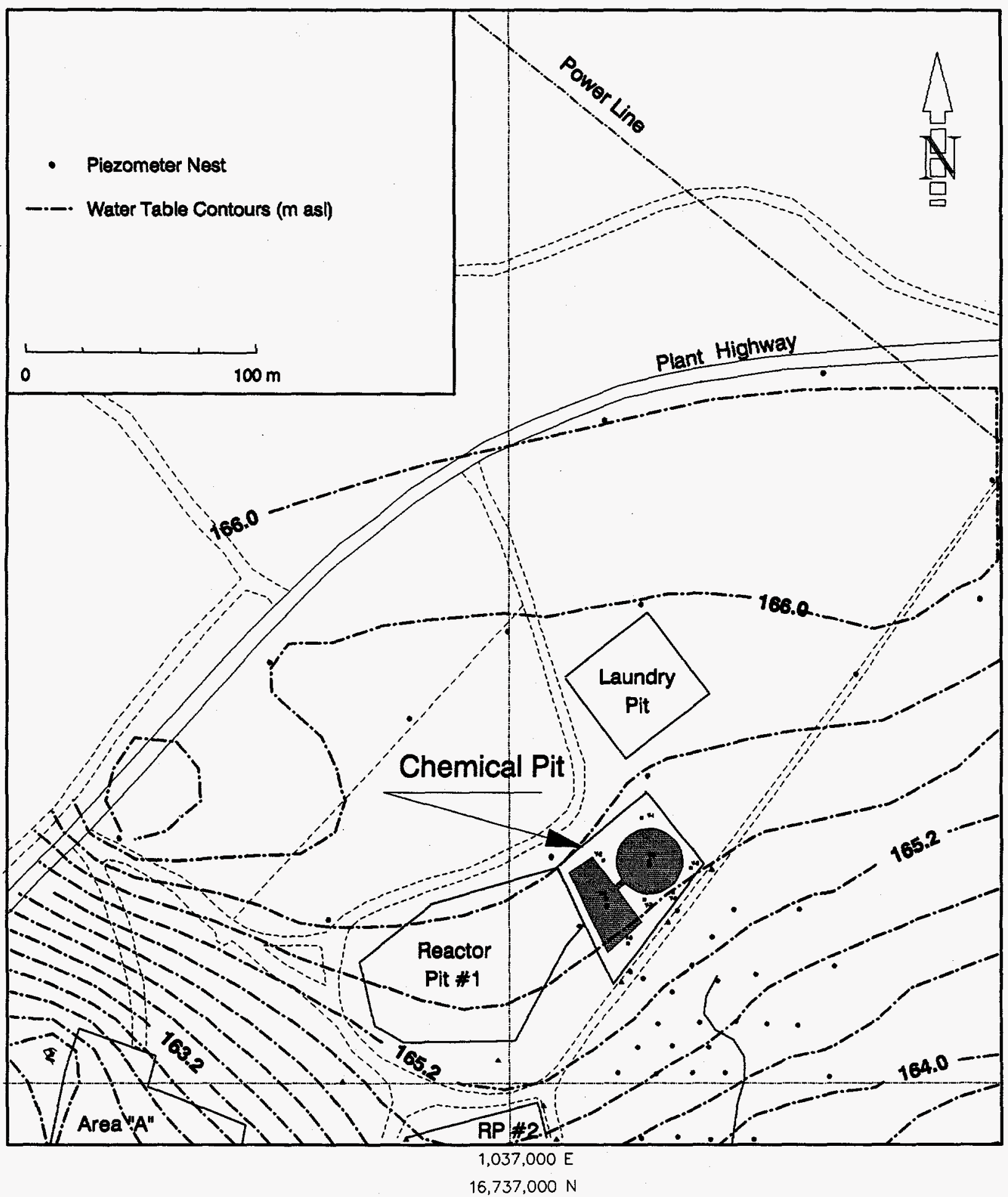


Introduction

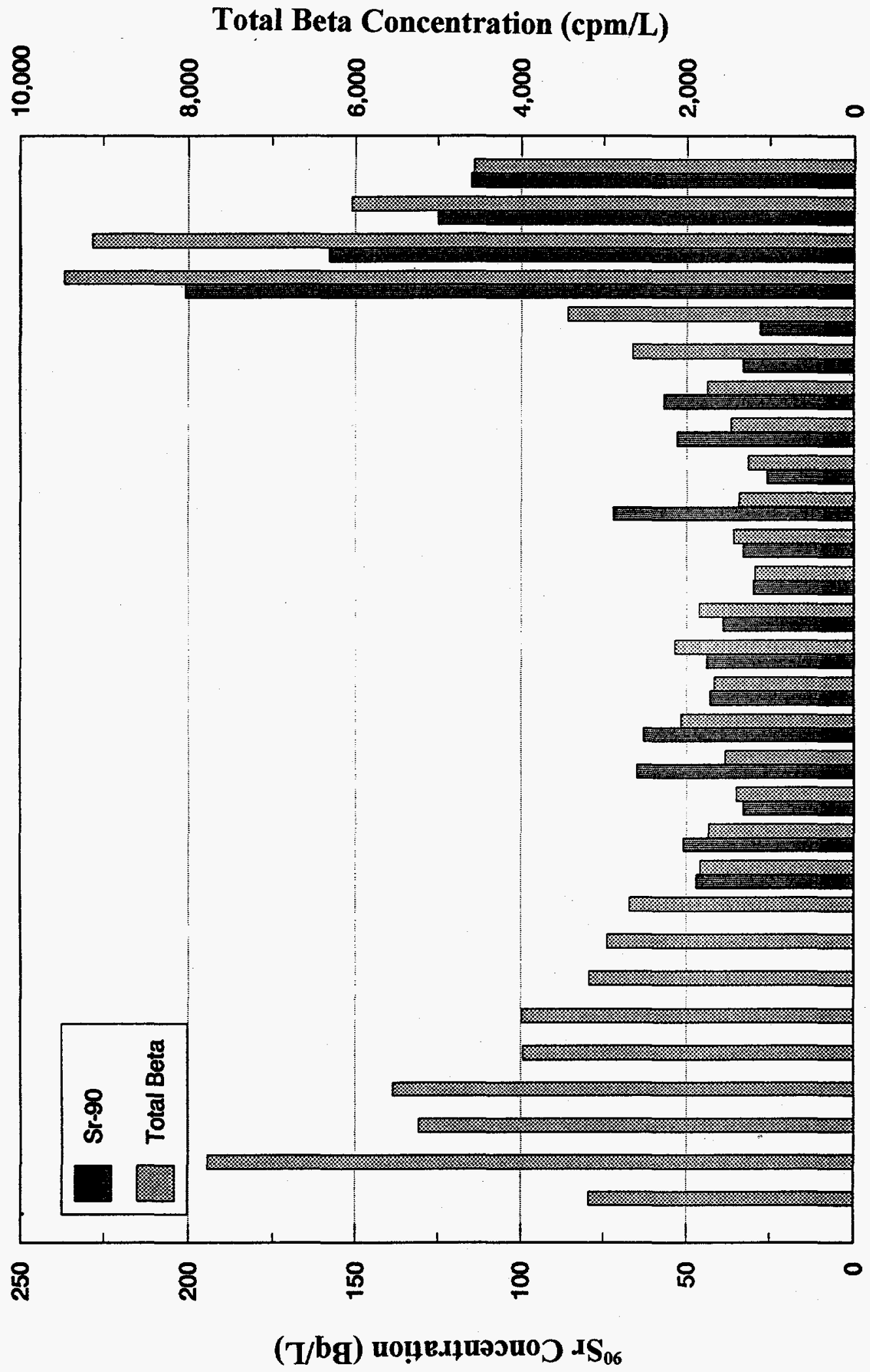

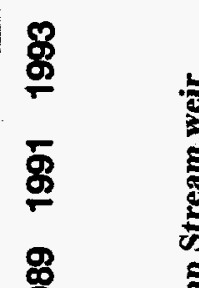

吕

这

5

怘

望

$\mathbb{8}$

:

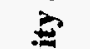

(2)

()

क हूँ

5

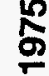

용

客

$\stackrel{8}{\circ}$

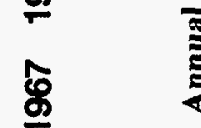

吕

$\underset{3}{0}$

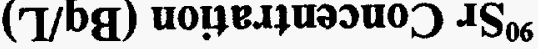




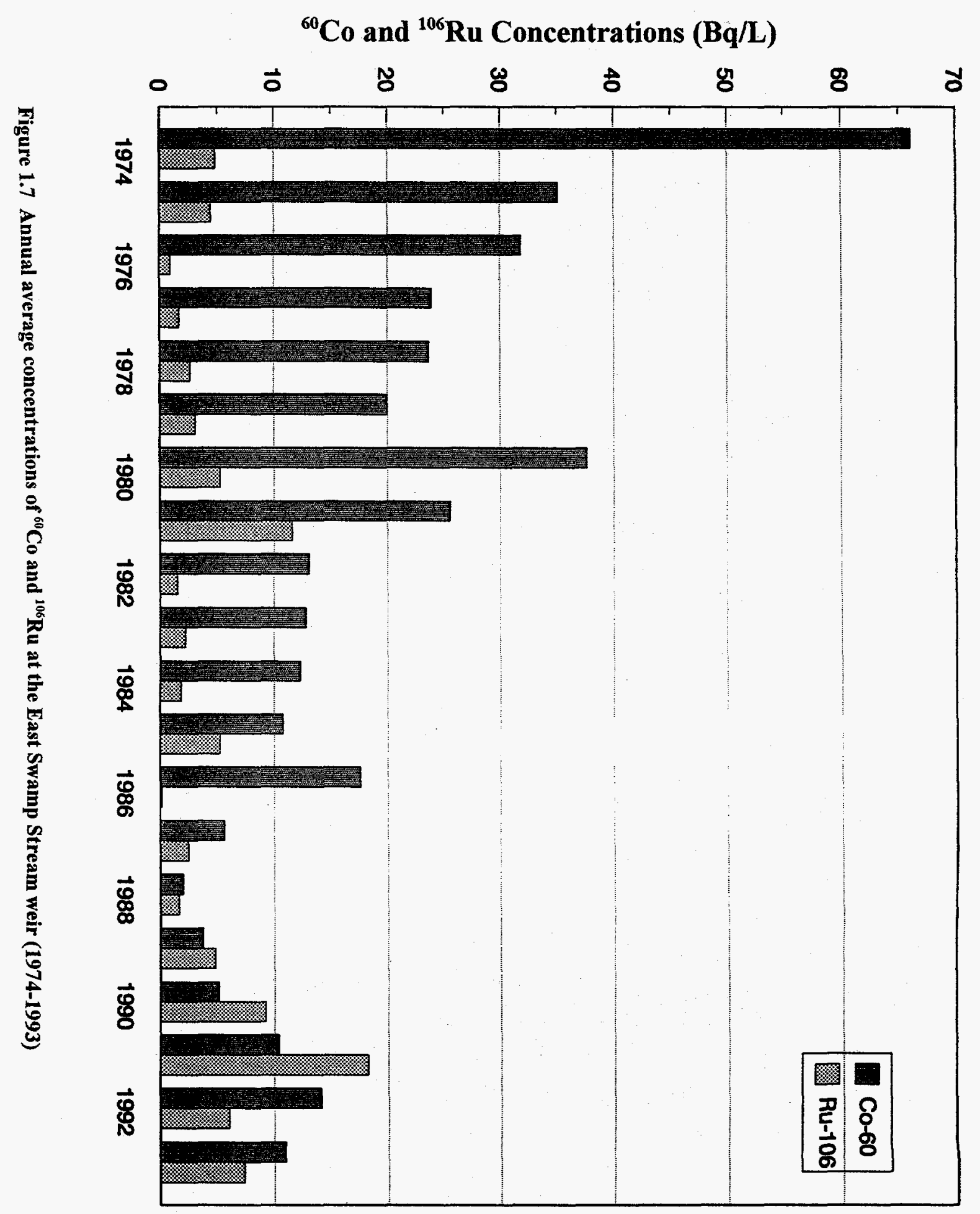




\subsection{Description of Area C Experimental Site}

\begin{abstract}
Waste Management Area C (Figures 1.1 and 1.8) includes a series of unlined trenches excavated from a large sand ridge that forms the southern margin of a nearby intermittent lake (Lake 233). This facility is still in operation and has received low-level radioactive wastes (paper, plastic, wood, metal, glass, liquid scintillation cocktails, organic and inorganic chemicals, etc.) from CRL, industry, hospitals, and universities throughout Canada since 1963. Until 1983, wastes were placed in trenches approximately 5 $\mathrm{m}$ deep (above the water table), $7 \mathrm{~m}$ wide, and $60 \mathrm{~m}$ long, oriented parallel to the short axis of the rectangular site. After being filled with low-level radioactive waste, the trenches were covered with $\sim 1$ $m$ of local sand and sandy topsoil. Since 1983, wastes have been placed within a large trench and covered with sand as the face of the fill advances. The southern portion of the site has been covered with a high-density polyethylene membrane and a tile drainage system to minimize precipitation infiltration (Figure 1.8).
\end{abstract}

Terrain to the northeast of Lake 233 is primarily bedrock with a thin, sandy till cover (see Figure 1.9). There is intermittent overland runoff from this area into Lake 233, which may contain up to $1 \mathrm{~m}$ of water in spring, but is normally almost dry in late summer. This lake has no surface drainage channel; therefore runoff that enters the lake from the northeast (as well as direct precipitation that exceeds evapotranspiration losses) drains by infiltration into the bed of the lake.

Apart from a basal wedge of bouldery till, the unconsolidated sediments in Area $\mathrm{C}$ consist of fine and medium-fine sands of fluvial origin overlain by a unit of interstratified, very-fine to fine sands and sandy silts. This interstratified unit is overlain by fine and medium-fine sands that make up the dune ridge hosting Area C. A unit of areally extensive, continuous, laminated clayey silts (generally less than $30 \mathrm{~cm}$ in thickness) is present along the margin of and beneath the wetland located about $250 \mathrm{~m}$ southwest of the waste-management facility. This wetland, known as Duke Swamp, contains up to $3 \mathrm{~m}$ of peaty organics. The southwest boundary of this wetland, as well as that of the groundwater flow system itself, is a bedrock ridge that trends roughly northwest-southeast.

As mentioned previously, much of the recharge from Lake 233 that passes beneath Waste Management Area C flows southwest (see Figure 1.10) through the unconsolidated sediments, and direct precipitation infiltration through Area $\mathrm{C}$ and downgradient sands is added to the aquifer en route. Groundwater from this flowpath discharges to Duke Swamp and subsequently drains by overland flow through Duke Stream to Maskinonge Lake. Groundwater flowrates range from 15 to $30 \mathrm{~cm} /$ day, leading to a total residence time of approximately 2 to 4 years between Area $\mathrm{C}$ and the wetland (Killey et al. 1993). Additionally, the groundwater flow downgradient of Area $\mathrm{C}$ bifurcates (Figure 1.10), such that those waters passing beneath the south end of the facility are diverted almost due south, flowing beneath the site highway and discharging to another wetland (which in turn drains through Bulk Storage Stream). This bifurcation is caused by a partially buried bedrock ridge that trends north-northwest and outcrops just east of the southern end of Duke Swamp.

\subsubsection{Previous Related Chemical and Radiological Characterization}

Some groundwater outside of the Area $\mathrm{C}$ plume is affected by salt used for road de-icing, but is otherwise uncontaminated. Table 1.2 summarizes the major ion chemistry for the surrounding groundwater and for samples collected from the Area $\mathrm{C}$ plume. Boreholes $\mathrm{C}-112$ and $\mathrm{C}-212$ (refer to Figure 1.8 for locations) were sampled for anthropogenic organic compounds in 1991, and Table 1.3 lists the compounds that were detected.

Tritium is the primary radionuclide of concern at this site in terms of quantity, although ${ }^{14} \mathrm{C}$ and ${ }^{60} \mathrm{Co}$ have also been detected in downgradient waters and vegetation. Area $\mathrm{C}$ began releasing ${ }^{3} \mathrm{H}$ to the aquifer before 1973 when routine monitoring of local surface waters was initiated (see Figure 1.11). Tritium in waters downgradient of the covered portion of Area $\mathrm{C}$ has virtually disappeared, however, since the fall of 1985 (Killey and Munch 1993), and this can be attributed to the impermeable polyethylene cover installed in 1983. Although this barrier appears to have eliminated the infiltration of precipitation and consequent release of tritiated water from this locale, ${ }^{14} \mathrm{C}$ apparently is still migrating from the area. Tritium releases continue from that portion of the site that has no cover, but analyses from the streams that drain the groundwater discharge areas that receive the Area $\mathrm{C}$ waters have shown a declining trend in ${ }^{3} \mathrm{H}$ releases since 1983 .

When regular measurements of Duke Stream were initiated in 1973, low concentrations of ${ }^{60} \mathrm{Co}$ were detected (Figure 1.11). The ${ }^{60} \mathrm{Co}$ flux peaked at $3.6 \mathrm{mCi}$ per annum in 1977 and has decreased in a roughly exponential fashion since that time. At present, this radionuclide is only marginally detectable in Duke Stream, exhibiting an annual flux of less than $81 \mu \mathrm{Ci}$. No program currently exists for mapping ${ }^{60} \mathrm{Co}$ distributions in the contaminated aquifer or the groundwater discharge area. 
Introduction

Figure 1.8 Borehole and cross-section locations in the vicinity of Waste Management Area C

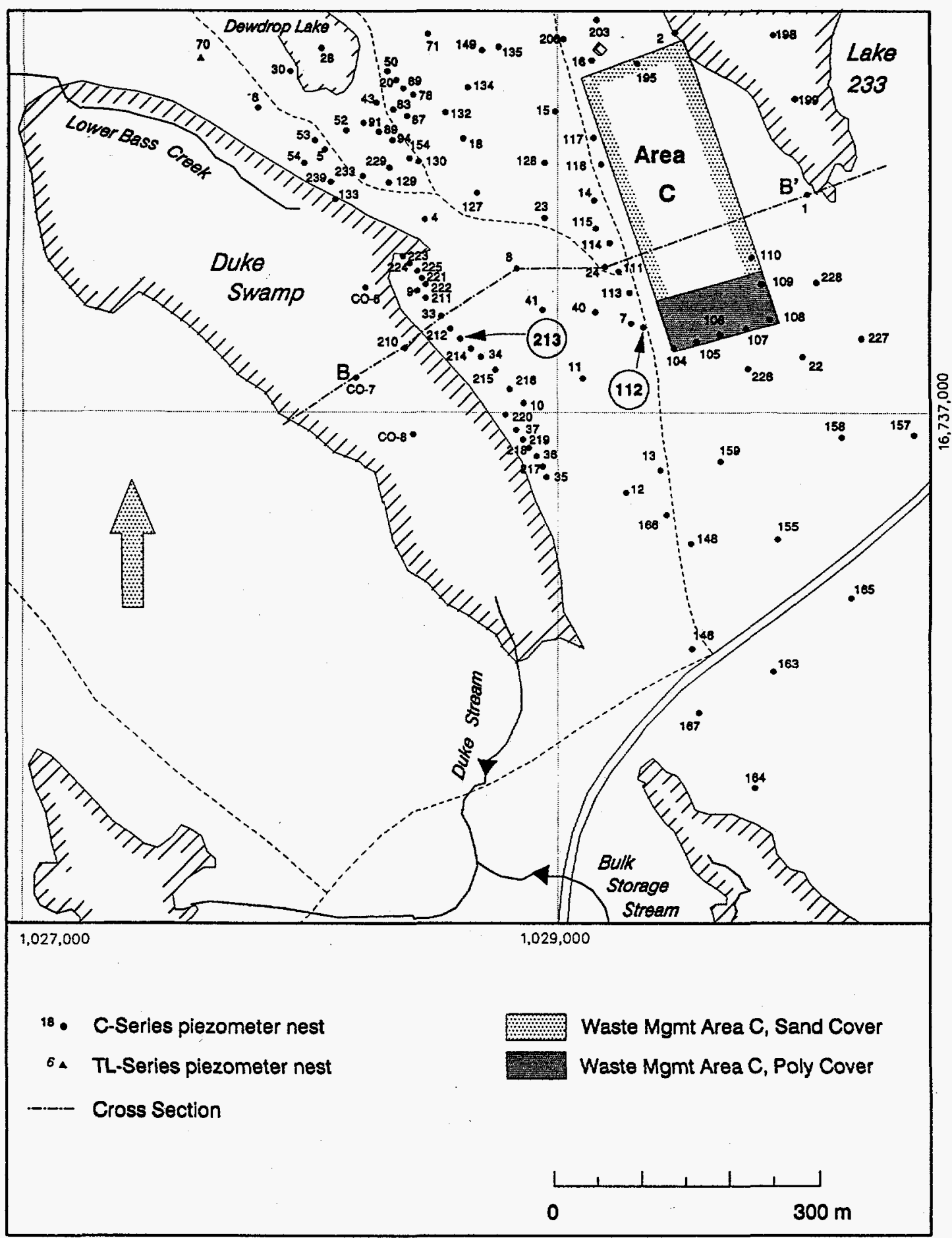


Introduction

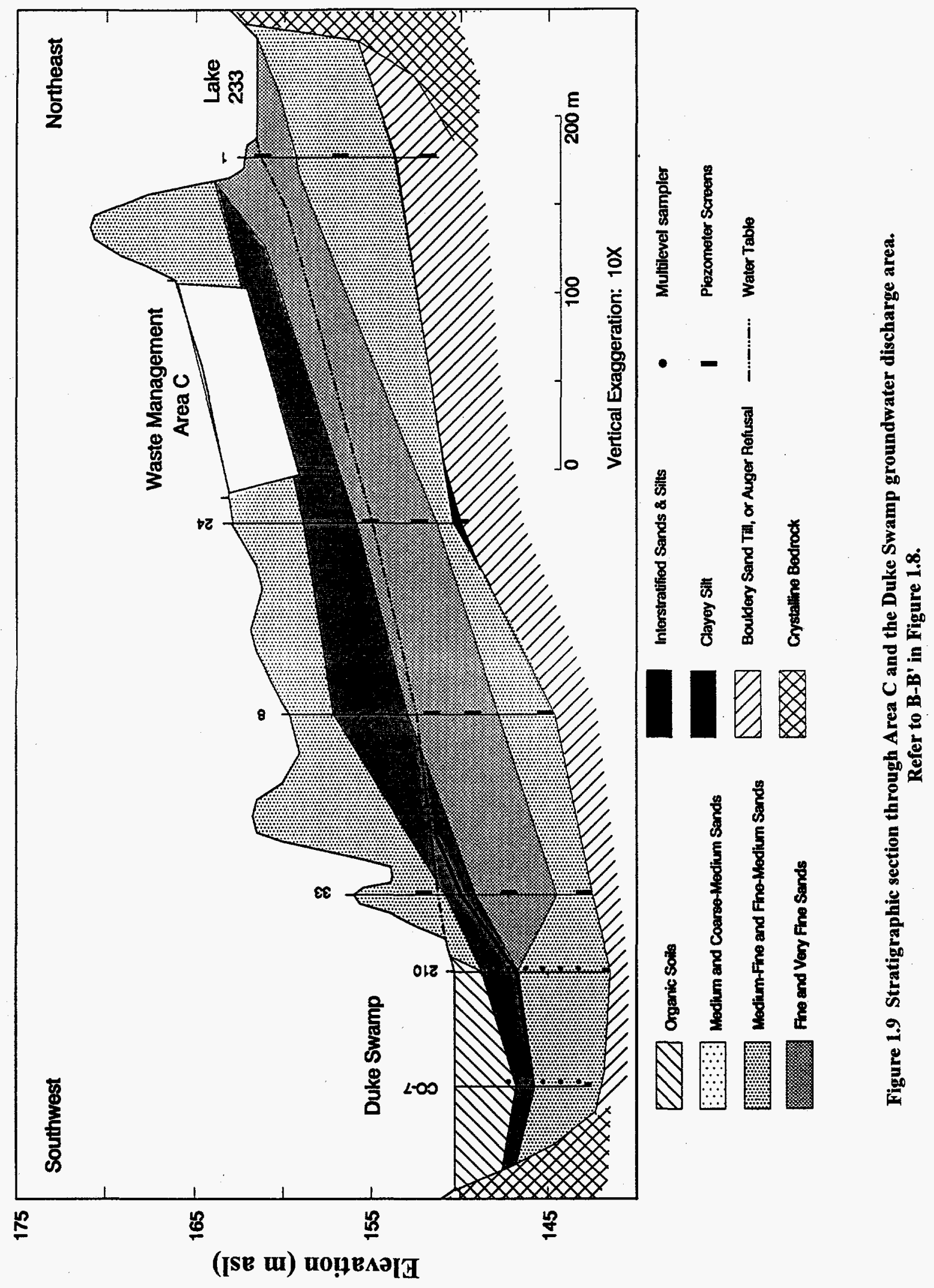


Introduction

Figure 1.10 Surface hydrology, water table contours, and areal extent of groundwater contamination by ${ }^{3} \mathbf{H}$ (bifurcating, medium-gray pattern) in the vicinity of Area $C$. Dots indicate piezometer nest locations (refer to Figure 1.8 for nest identifiers).

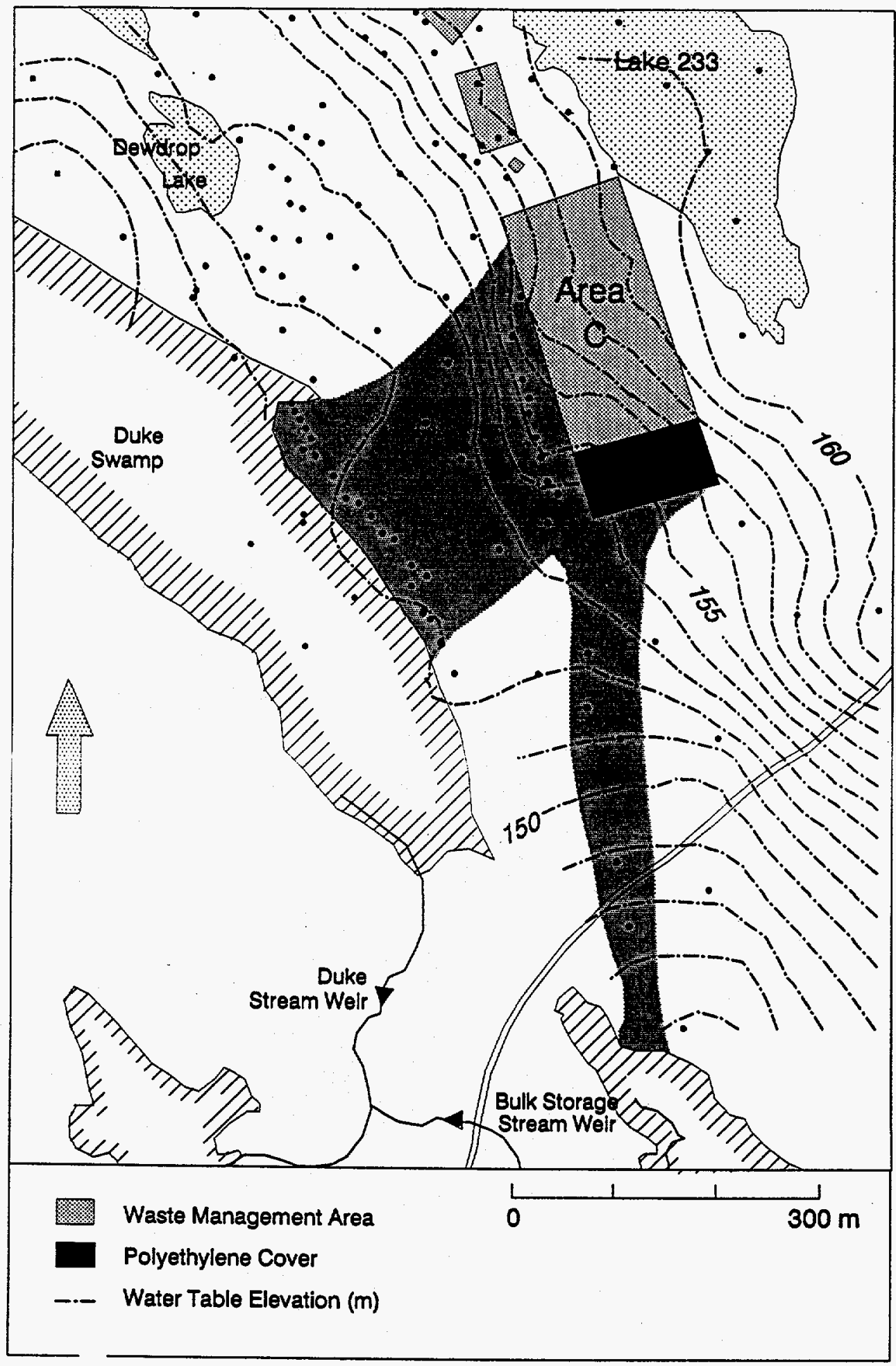


Figure 1.11 Annual fluxes of ${ }^{3} \mathrm{H}$ and ${ }^{60} \mathrm{Co}$ through the Duke Stream weir
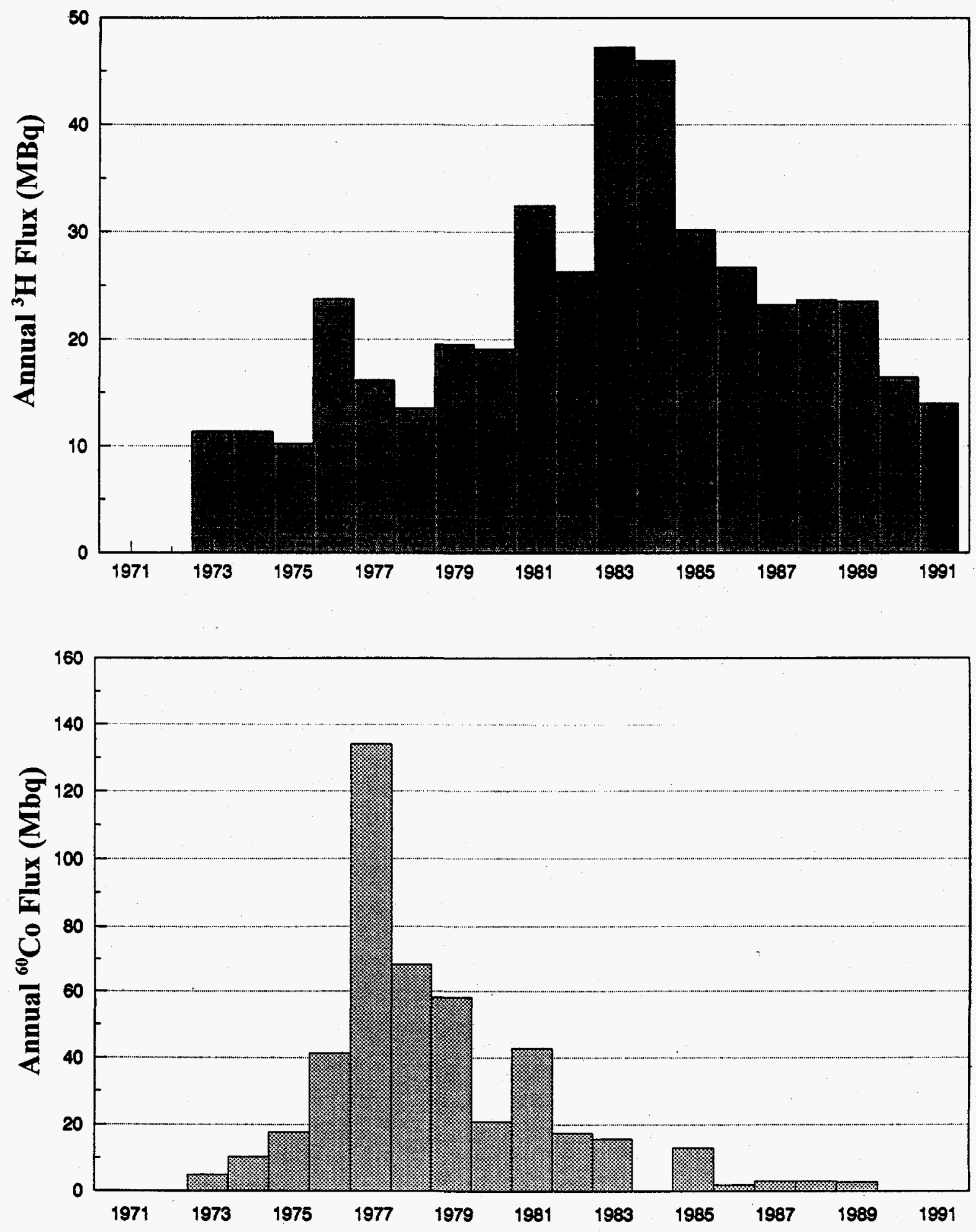
Introduction

Table 1.2 Major ion chemistry in the Area $\mathrm{C}$ vicinity (refer to Figure 1.8 for well locations)

\begin{tabular}{|c|c|c|c|c|c|c|c|c|c|c|c|c|}
\hline \multirow{2}{*}{$\begin{array}{c}\text { Well No./ } \\
\text { Depth } \\
\text { (m) }\end{array}$} & \multirow[t]{2}{*}{$\mathrm{pH}$} & \multirow{2}{*}{$\underset{(\mathrm{mV})}{\mathrm{Eh}}$} & $\mathrm{Ca}$ & Mg & $\mathrm{Na}$ & $\mathrm{K}$ & $\mathrm{Fe}$ & $\mathrm{SiO}_{2}$ & $\mathrm{HCO}_{3}^{-}$ & $\mathrm{Cl}$ & $\mathrm{SO}_{4}{ }^{2-}$ & $\mathrm{F}$ \\
\hline & & & \multicolumn{10}{|c|}{ Concentration (mg/L) } \\
\hline $1 / 10.4$ & 6.80 & 164 & 16.3 & 5.3 & 3.8 & 1.1 & 29.0 & 33.8 & 93.8 & 47.0 & 0.9 & - \\
\hline $1 / 5.4$ & 5.70 & 235 & 5.5 & 2.2 & 21.2 & 1.3 & 6.0 & 12.8 & 25.9 & 54.0 & 5.5 & - \\
\hline $2 / 9.2$ & 6.35 & 82 & 14.2 & 5.0 & 3.7 & 1.1 & 6.5 & 28.9 & 35.0 & 5.6 & 16.3 & - \\
\hline $2 / 2.5$ & 5.80 & 284 & 6.6 & 2.5 & 7.0 & 2.2 & 0.1 & 13.1 & 18.1 & 9.2 & 9.9 & - \\
\hline $3 / 11.0$ & 7.10 & 44 & 15.3 & 6.7 & 3.1 & 1.3 & 8.6 & 30.4 & 11.6 & 3.4 & - & - \\
\hline $3 / 4.1$ & 5.50 & 254 & 8.2 & 2.1 & 4.1 & 1.3 & 0.3 & 13.5 & 24.5 & 7.0 & 10.6 & - \\
\hline $4 / 9.4$ & 6.65 & 124 & 8.0 & 3.2 & 7.4 & 1.0 & 19.1 & 14.6 & 44.0 & 13.4 & 18.5 & 0.1 \\
\hline $7 / 15.6$ & 6.50 & 119 & 8.9 & 2.8 & 5.9 & 2.3 & 12.2 & 20.3 & 48.1 & 9.6 & 12.4 & - \\
\hline $7 / 11.8$ & 6.20 & 176 & 10.8 & 3.2 & 10.1 & 1.8 & 11.8 & 11.1 & 30.8 & 34.0 & 10.3 & 0.1 \\
\hline $8 / 14.5$ & 6.84 & 90 & 8.3 & 2.8 & 5.6 & 1.6 & 17.9 & 21.0 & 79.3 & 7.3 & 11.0 & - \\
\hline $8 / 14.5$ & 6.41 & 154 & 9.2 & 2.8 & 7.2 & 1.2 & 15.8 & 17.6 & 46.3 & 17.4 & 11.9 & 0.1 \\
\hline $8 / 10.3$ & 6.32 & 265 & 12.6 & 3.6 & 5.9 & 1.1 & 0.3 & 14.8 & 35.8 & 11.3 & 12.8 & 0.0 \\
\hline $8 / 8.1$ & 6.60 & 233 & 5.0 & 1.3 & 5.7 & 1.9 & 0.1 & 15.4 & 26.3 & 2.0 & 10.6 & - \\
\hline $8 / 8.1$ & 6.30 & 294 & 11.0 & 2.7 & 12.8 & 1.3 & 0.1 & 10.7 & 44.9 & 11.1 & 12.4 & 0.0 \\
\hline 9/14.1 & 6.30 & 239 & 17.9 & 7.1 & 16.7 & 1.7 & 0.7 & 12.0 & 93.0 & 15.5 & 20.0 & - \\
\hline $9 / 11.1$ & 6.00 & 374 & 32.1 & 9.1 & 37.1 & 2.9 & 0.5 & 19.1 & 77.1 & 47.0 & 41.4 & - \\
\hline 9/11.1 & 6.04 & 334 & 26.0 & 7.6 & 19.3 & 2.3 & 0.8 & 11.1 & 93.0 & 36.0 & 30.0 & - \\
\hline $9 / 7.2$ & 5.90 & 334 & 3.8 & 1.3 & 0.8 & 1.3 & 0.1 & 12.4 & 10.9 & 0.3 & 10.1 & - \\
\hline $9 / 7.2$ & 6.14 & 327 & 20.4 & 6.0 & 15.3 & 2.0 & 0.8 & 11.8 & 9.1 & 47.5 & 33.7 & - \\
\hline $10 / 4.8$ & 6.70 & 114 & 8.5 & 2.7 & 5.7 & 1.0 & 17.2 & 21.4 & 62.1 & 12.5 & 5.4 & 0.2 \\
\hline $10 / 2.6$ & 6.32 & 274 & 3.6 & 1.3 & 3.4 & 1.4 & 0.7 & 13.1 & 16.3 & 2.8 & 9.0 & - \\
\hline $14 / 9.5$ & 6.30 & 219 & 8.0 & 2.2 & 8.1 & 1.5 & 3.7 & 11.1 & 24.9 & 18.7 & 13.2 & 0.1 \\
\hline $14 / 7.1$ & 6.15 & 243 & 9.5 & 2.7 & 9.0 & 1.6 & 1.8 & 10.9 & 24.7 & 17.6 & 18.2 & 0.1 \\
\hline $14 / 10.5$ & 6.25 & 214 & 9.5 & 2.8 & 8.4 & 1.4 & 3.2 & 13.3 & 28.6 & 16.2 & 13.2 & 0.0 \\
\hline $15 / 13.3$ & 6.75 & 120 & 13.0 & 4.1 & 5.0 & 1.6 & 6.5 & 27.9 & 64.8 & 11.8 & 12.5 & 0.1 \\
\hline $15 / 8.8$ & 7.25 & 116 & 11.8 & 3.2 & 9.3 & 9.4 & 0.4 & 24.8 & 72.1 & 7.5 & 14.7 & - \\
\hline $15 / 8.8$ & 7.05 & 74 & 7.8 & 1.5 & 3.6 & 1.6 & 0.8 & 22.3 & 40.8 & 0.8 & 7.5 & 0.1 \\
\hline $16 / 14.1$ & 6.70 & 134 & 15.0 & 4.0 & 5.1 & 1.4 & 9.0 & 34.7 & 66.7 & 9.5 & 12.8 & 0.1 \\
\hline $23 / 11.6$ & 6.99 & 74 & 4.9 & 2.8 & 5.8 & 1.3 & 20.9 & 12.8 & 51.2 & 11.9 & 5.1 & 0.1 \\
\hline $24 / 12.8$ & 6.60 & 123 & 7.6 & 3.5 & 6.3 & 1.4 & 14.6 & 13.7 & 35.8 & 20.3 & 31.1 & 0.1 \\
\hline $24 / 10.5$ & 6.55 & 139 & 6.6 & 3.5 & 6.6 & 1.7 & 8.4 & 13.9 & 29.9 & 16.2 & 13.7 & 0.1 \\
\hline
\end{tabular}


Table 1.2 (continued)

\begin{tabular}{|c|c|c|c|c|c|c|c|c|c|c|c|c|}
\hline \multirow{2}{*}{$\begin{array}{c}\text { Well No./ } \\
\text { Depth } \\
(\mathrm{m})\end{array}$} & \multirow[t]{2}{*}{$\mathrm{pH}$} & \multirow{2}{*}{$\underset{(\mathrm{mV})}{\mathrm{Eh}}$} & $\mathrm{Ca}$ & Mg & $\mathrm{Na}$ & $\mathrm{K}$ & $\mathrm{Fe}$ & $\mathrm{SiO}_{2}$ & $\mathrm{HCO}_{3}^{-}$ & $\mathrm{Cl}^{-}$ & $\mathrm{SO}_{4}^{20}$ & $\mathrm{~F}$ \\
\hline & & & \multicolumn{10}{|c|}{ Concentration (mg/L) } \\
\hline $24 / 7.8$ & 7.00 & 86 & 7.8 & 2.9 & 6.6 & 3.7 & 2.0 & 14.1 & 29.9 & 13.0 & 12.2 & 0.1 \\
\hline $33 / 8.8$ & 5.90 & 266 & 18.0 & 5.8 & 9.5 & 1.9 & 10.2 & 17.1 & 27.2 & 59.0 & 16.9 & 0.1 \\
\hline $33 / 4.0$ & 6.95 & 15 & 10.4 & 3.5 & 2.7 & 2.0 & 7.6 & 19.6 & 34.5 & 5.7 & 1.3 & 0.1 \\
\hline $34 / 9.5$ & 6.59 & 191 & 6.5 & 2.1 & 7.3 & 1.3 & 6.0 & 18.4 & 32.2 & 16.8 & 11.3 & 0.2 \\
\hline $34 / 6.6$ & 6.28 & 194 & 4.4 & 1.7 & 2.4 & 0.8 & 6.9 & 18.2 & 32.2 & 5.7 & 1.3 & 0.1 \\
\hline $36 / 9.0$ & 7.70 & -104 & 10.2 & 3.4 & 9.4 & 2.3 & 2.9 & 10.1 & 66.2 & 6.9 & 4.5 & 0.7 \\
\hline $37 / 11.0$ & 6.93 & 169 & 7.6 & 3.3 & 10.6 & 1.9 & 3.4 & 37.2 & 51.7 & 5.5 & 3.4 & 0.3 \\
\hline Leste 233 & - & - & 4.2 & 1.6 & 21.3 & 0.6 & 0.2 & - & 3.9 & 41.2 & 3.1 & 0.0 \\
\hline
\end{tabular}

Table 1.3 Anthropogenic organics from Area C plume in units of $\mu \mathrm{g} / \mathrm{L}$

\begin{tabular}{|c|c|c|}
\hline Organic CompoundWell (sample depth) & C-112 $(11 \mathrm{~m}$ to $12.5 \mathrm{~m})$ & C-212 $(10 \mathrm{~m})$ \\
\hline 1,1-Dichloroethane & 32.0 & 55.9 \\
\hline 1,2-Dichloroethane & 4.0 & 7.4 \\
\hline Carbon Tetrachloride & 4.6 & 1.2 \\
\hline Chloroform & 39.4 & 6.0 \\
\hline Tetrachloroethene & 4.4 & 1.2 \\
\hline Trichloroethene & 409.0 & 182.0 \\
\hline trans-1,2-Dichloroethene & 1.4 & 257.0 \\
\hline Benzene & 1.7 & - \\
\hline 0-Xylene & - & 1.6 \\
\hline Naphthalene & - & 16.5 \\
\hline Bis(2-ethylhexyl)phthalate & 3.5 & 9.0 \\
\hline
\end{tabular}

Surveys in 1982 and 1983 detected elevated ${ }^{14} \mathrm{C}$ in vegetation growing in and adjacent to the Area $\mathrm{C}$ compound with specific activities approaching 1.1 nCi/gC. In 1990, a study of soil gas and groundwater around Area $\mathrm{C}$ found specific activities up to 1.3 $\mu \mathrm{Ci} / \mathrm{gC}$ in soil $\mathrm{CO}_{2}$ above the waste trenches and ${ }^{14} \mathrm{C}$ concentrations in downgradient waters of up to 34 $\mathrm{nCi} / \mathrm{L}$ (Killey and Mattie 1993).

Further studies from 1991 to 1993 addressed the distribution of ${ }^{14} \mathrm{C}$ in dissolved inorganic and organic forms (Killey et al. 1993). Dissolved organic carbon
(DOC) was generally found to account for less than $10 \%$ of the dissolved ${ }^{14} \mathrm{C}$ in these samples (Table 1.4). This is because the DOC in the ground and surface waters is less abundant than the dissolved inorganic carbon (DIC), and the specific activity of the former is generally lower than that of the latter. The variability in the distribution of ${ }^{14} \mathrm{C}$ between the two classes of compounds is attributed to variability in the source area. Although these data suggest that most of the ${ }^{14} \mathrm{C}$ inventory in Area $C$ is in inorganic forms, a portion of the dissolved inorganic ${ }^{14} \mathrm{C}$ most likely originates from $\mathrm{CO}_{2}$ produced during the bacterial degradation of radiocarbon-bearing organic materials. The DIC and DOC concentrations in the Area C 
Introduction

plume waters range from background levels to about 3 and 8 times background, respectively.

Table 1.4 Carbon and ${ }^{14} \mathrm{C}$ concentrations in Area $\mathrm{C}$ waters (refer to Figure 1.8 for well locations)

\begin{tabular}{|c|c|c|c|c|c|c|}
\hline \multirow{2}{*}{$\begin{array}{l}\text { Well } \\
\text { No. }\end{array}$} & \multicolumn{2}{|c|}{ Carbon Concentration } & \multicolumn{2}{|c|}{${ }^{14} \mathrm{C}$ Concentration } & \multicolumn{2}{|c|}{ Specific Activity } \\
\hline & DIC (mg/L) & $\mathrm{DOC}(\mathrm{mg} / \mathrm{L})$ & $\mathrm{DIC}(\mathrm{nCi} / \mathrm{L})$ & $\mathrm{DOC}(\mathrm{nCi} / \mathrm{L})$ & $\mathrm{DIC}(\mathrm{nCi} / \mathrm{gC})$ & $\mathrm{DOC}(\mathrm{nCi} / \mathrm{gC})$ \\
\hline 104 & 13.82 & 0.83 & 1.1 & 0.1 & 78.9 & 147.2 \\
\hline 105 & 12.10 & 2.45 & 2.8 & 0.7 & 232.5 & 294.1 \\
\hline 112 & 46.65 & 19.76 & 7.0 & 1.0 & 150.3 & 50.5 \\
\hline 114 & 44.47 & 7.84 & 4.6 & 0.9 & 103.1 & 111.5 \\
\hline 211 & 37.78 & 24.7 & 5.5 & 3.3 & 5390 & 134.7 \\
\hline 212 & 38.10 & 7.25 & 2.9 & 0.0 & 76.7 & 6.1 \\
\hline 213 & 52.96 & 9.12 & 28.6 & 0.7 & 540.5 & 78.0 \\
\hline 214 & 29.86 & 7.78 & 8.7 & 0.8 & 290.2 & 97.6 \\
\hline 216 & 23.22 & 5.29 & 8.3 & 0.1 & 358.5 & 22.9 \\
\hline 221 & 30.58 & 5.58 & 1.6 & 0.1 & 52.5 & 14.1 \\
\hline 222 & 55.30 & 21.6 & 1.9 & 0.3 & 34.6 & 11.4 \\
\hline Duke Stream & 7.66 & 3.57 & 0.1 & 0.0 & 17.9 & 4.5 \\
\hline $\begin{array}{c}\text { Bulk Storage } \\
\text { Stream }\end{array}$ & 7.77 & 1.97 & 0.1 & 0.3 & 9.3 & 159.1 \\
\hline
\end{tabular}




\section{Experimental}

The general intent of the experimental phase was to identify and quantify as many of the mobile radionuclide species as practical. This process is inherently difficult due to the invariably low radionuclide concentrations, the potential instability of the complexed species, the nature of their kinematics, changing physico-chemical conditions in the spatial and temporal domains, etc. Toward this end, a number of diverse procedures and methodologies were used to study the speciation of migrating radionuclides: 1 ) field sampling of groundwater and subsurficial sands, 2) radioanalytical techniques, 3) wet chemistry, 4) ion exchange, 5) hollow-fiber and membrane ultrafiltration, 6) size-exclusion and ion-exchange chromatography, 7) liquid chromatography/mass spectrometry, and 8) various optical spectroscopies.

\subsection{Observation Wells}

Wells were drilled at Area $\mathrm{C}$ and the Chemical Pit using a rotary drilling rig. When soil sampling and multilevel piezometer installation were the objectives of the borehole, 9.5-cm-ID hollow-stem augers were used. When installing the groundwater sampling wells, 15.2-cm-ID hollow-stem augers were employed. Portable equipment was deployed in the wetland downgradient of the Chemical Pit, and a gaspowered jackhammer was used for driving the flush-joint casing. While drilling, the casings were rinsed with water at a flow rate of approximately $50 \mathrm{~L} / \mathrm{min}$.

Cores of soil were collected with a fixed-piston sampler fitted with thin-wall, 5-cm-ID aluminum tubing. Core lengths were either $0.76 \mathrm{~m}$ or $1.52 \mathrm{~m}$, and the soil samples were collected ahead of the advancing borehole. Cores were checked for beta and gamma activities as they were retrieved, logged for visual features, and subsampled. These subsamples (except for soils collected from well CP4B) were subsequently oven dried and archived. Following a second screen for beta and gamma activities in the dried samples, composites from the contaminated portions of $\mathrm{CP}$ 4, ES-39, and ES-16 were prepared. Individual samples were subdivided using a mechanical splitter, and appropriate quantities of these subsamples were combined.

Sampling wells used to collect groundwater for speciation analyses were installed at borehole locations CP-4, ES-39, $\mathrm{C}-112$, and C-213 at depths selected to correspond with the maximum concentrations of radionuclides as defined by previous soil cores, borehole gamma scans, and groundwater samples from multilevel piezometers. The wells are constructed of 10-cm-ID, 1-m-long, stainless-steel well screens ( $0.15-\mathrm{mm}$ slot width) attached to $10-\mathrm{cm}$-ID stainless-steel pipe that extends $\sim 1 \mathrm{~m}$ above the water table. The remainder of the well casing consists of 10-cm-ID Schedule 40 PVC pipe. The local sands, which have no cohesive strength below the water table, slumped around the well screens as soon as the augers were withdrawn. Above the water table, the annular space around the well casing was backfilled with clean local sand, and a $0.6-\mathrm{m}$ seal of powdered bentonite was installed just below grade. The well at ES-16 consists of a 7.6-cm-ID, 0.91-m-long . stainless-steel screen with a 7.6-cm-ID Schedule 40 PVC casing to the surface.

\subsection{Well Sampling and Groundwater Analyses}

All of the sampling wells were developed after installation. Initially, the wells were pumped to dryness repeatedly (with the exception of $\mathrm{C}-112$, which sustained pumping at a rate of $40 \mathrm{~L} / \mathrm{min}$ ) and then pumped for a minimum of 1 hour at a sustainable rate $(>12 \mathrm{~L} / \mathrm{min})$ within 5 days of sample collection. A 4.6-cm-OD stainless-steel, variable-speed, submersible pump or a bellows-type metering pump with polypropylene wetted parts was used for drawing groundwater samples.

All water samples were collected after removing at least three column volumes of water or after pumping the well to dryness twice. Sample flow rates were maintained as low as possible to preclude resuspension of any microparticulates retained by the aquifer medium (generally less than $200 \mathrm{~mL} / \mathrm{min}$ ). During this process, groundwater temperature, $\mathrm{pH}$ and $\mathrm{Eh}$, dissolved oxygen, alkalinity (as $\mathrm{CO}_{3}^{2-}$ ), and $\mathrm{Fe}^{2+} / \mathrm{Fe}^{3+}$ ratios were determined. Aliquots were also drawn for analyses of trace metals (inductivelycoupled plasma/atomic-emission spectrometry), anions (ion chromatography), and organic carbon content (persulfate/ultraviolet-oxidation analysis). Samples were pressure filtered through sterile $0.2-\mu \mathrm{m}^{2}$ or $0.45-\mu \mathrm{m}$ membranes at the wellhead or suction filtered through 0.45 $\mu \mathrm{m}$ membranes in a CRL laboratory within 4 hours of sample collection. The purpose of this prefiltration step was to retain any undissolved or particulate matter. Waters were maintained on ice during transit and storage to hinder kinematic processes and mitigate against any physicochemical changes to the dissolved species.

A number of prefiltered groundwaters were passed through a large-volume water sampler (Robertson and Perkins 1975) to facilitate the removal of charged and uncharged soluble species. Generally, $\sim 200 \mathrm{~L}$ of groundwater were sampled at each well through this system. This modular unit is composed of six stacked resin or sorbent chambers $(2.5 \mathrm{~cm}$

\footnotetext{
${ }^{2}$ The $0.2-\mu \mathrm{m}$ cartridges also included a nominal $1.0-\mu \mathrm{m}$ gauze layer and $0.8-\mu \mathrm{m}$ membrane.
} 
thick by $20 \mathrm{~cm}$ in diameter) separated by glass-fiber filter sheets. Water enters the base of the unit and is directed to the first of two cation-exchange resin beds $\left(\mathrm{Na}^{+}\right.$form, 200 400 mesh), the redundant bed being present in case the first becomes compromised or saturated with ions. This resin was originally in the $\mathrm{H}^{+}$form, but was converted to the $\mathrm{Na}^{+}$ form to eliminate the potentially destructive or denaturing effects on existing radionuclide species that might have been caused by the resulting acidic solution. Following the cation beds are duplicate layers of anion-exchange resin ( $\mathrm{Cl}^{-}$form, $200-400$ mesh) for the retention of negatively charged species. Finally, a pair of activated aluminumoxide sorbent beds are used to remove those radionuclides that exist in soluble, non-ionic forms. Following this ionexchange groundwater-sampling procedure, the individual resin and sorbent beds (as well as the prefilters) were rinsed with $\sim 1 \mathrm{~L}$ of clean groundwater, dewatered, disassembled, and packaged for shipment and radiological characterization. Gamma-ray spectrometry was performed by placing the prefilters (or their component membranes), resins, and sorbent powders in standardized geometries and counting them with lithium-drifted or intrinsic germanium detectors for suitable periods of time. Aliquots of the above materials were then leached with appropriate acid mixtures, and the resulting solutions were subjected to various radiochemical separation procedures for quantifying radioisotopes that were not amenable to direct gamma-ray analyses.

Additional groundwater samples ( $100 \mathrm{~mL}$ each) were counted in $125-\mathrm{mL}$ polyethylene bottles with a high-purity germanium detector. An aqueous dilution of a multiisotope standard in an identical $125-\mathrm{mL}$ geometry was used for detector calibration. Only preliminary data regarding dissolved ${ }^{90} \mathrm{Sr}$ concentrations in the Chemical Pit plume groundwater from CP-4 and ES-39 are currently available. These have been determined by Cerenkov counting with a liquid-scintillation analyzer, using $10-\mathrm{mL}$ samples in 20 $\mathrm{mL}$ glass scintillation vials. The samples were stored for a minimum of 20 days before counting to ensure equilibrium between ${ }^{90} \mathrm{Sr}$ and ${ }^{90} \mathrm{Y}$. Cerenkov efficiency was determined by recounting after a spike addition of 20 to $40 \mu \mathrm{L}$ of a known amount of ${ }^{90} \mathrm{Sr}$. The spike solution consisted of commercial ${ }^{90} \mathrm{Sr}$ diluted in a $0.137-\mathrm{mg} / \mathrm{L} \mathrm{Sr}$ solution with 1$\underline{\mathrm{M}} \mathrm{HNO}_{3}$ and was calibrated against a commercial standard. This procedure does not provide a means for eliminating Cerenkov contributions from ${ }^{106} \mathrm{Ru}$; therefore, quantitative ${ }^{90} \mathrm{Sr}$ analyses must be performed by radiochemical separation (as was done for ES-16 samples).

Tritium and ${ }^{14} \mathrm{C}$ data were obtained via liquid scintillation counting, using a mix of $3 \mathrm{~mL}$ of water and $15 \mathrm{~mL}$ of scintillation cocktail in standard $20-\mathrm{mL}$ polyethylene scintillation vials. Energy windows on the analyzer were set to $0.5-11 \mathrm{keV}$ for ${ }^{3} \mathrm{H}$ and $18.6-156 \mathrm{keV}$ for ${ }^{14} \mathrm{C}$. Backgrounds (distilled Ottawa River water) were prepared in the same fashion and run with each sample set. Counting efficiencies were determined by spike additions to a subset of the samples. Between 20 and $40 \mathrm{mg}$ of a standardized tritiated water solution was added to samples to determine ${ }^{3} \mathrm{H}$ counting efficiency. Radiocarbon counting efficiency (and spillover into the ${ }^{3} \mathrm{H}$ window) were determined following additions of $15-45 \mathrm{mg}$ of ${ }^{14} \mathrm{C}$-dextrose in $0.1-\underline{\mathrm{M}}$ dextrose solution, which was calibrated against a commercial ${ }^{14} \mathrm{C}$-glucose standard.

\subsection{Radiometric Analyses of Soils}

Radionuclide analyses of sands collected along the Chemical Pit flowpath were conducted. Borehole CHPT-2 (see Figures 1.3 and 1.4), which is within the rectangular infiltration pit and best reflects the source term, was also included in this phase of the study. Dried soil samples were mechanically split into $\sim 30 \mathrm{~g}$ fractions and sealed in 60 $\mathrm{mm}$ by $15-\mathrm{mm}$ polystyrene containers. Replicate blank sands were similarly prepared, and the samples were counted on a high-purity germanium detector. The detector was calibrated for energy and efficiency using a commercial multi-isotope standard in a $1.5-\mathrm{g} / \mathrm{cm}^{3}$ solution of $\mathrm{CaCl}_{2}$ and in a geometry identical to that of the soil samples.

When high-resolution spectrometry of composite soil samples had established that only a limited suite of gamma emitters was present in a particular borehole, individual soil samples were counted for specific radionuclides (e.g., ${ }^{60} \mathrm{Co}$ and ${ }^{137} \mathrm{Cs}$ ) with a 7.5 -cm well-type $\mathrm{NaI}(\mathrm{Tl})$ detector.

Thirty-gram subsamples were mechanically split and placed in standard $20-\mathrm{mL}$ scintillation vials. Replicate blanks were similarly prepared and analyzed before and after each group of samples. The counter was calibrated for energy and monitored for instrument background and peak shape using software provided by the manufacturer. Instrument efficiency for the specific sample geometry was determined by spiking blank sands with known amounts of a ${ }^{50} \mathrm{Co}$ or ${ }^{137} \mathrm{Cs}$ standard solution that had been calibrated against a commercial standard on a high-resolution germanium detector. The only gamma emitter present in these sediments in appreciable concentrations was ${ }^{60} \mathrm{Co}$.

Strontium-90 analyses of these soils were limited to those samples collected from CP-4, ES-39, and ES-16.

Mechanically split subsamples ( $0.5 \mathrm{~g}$ each) were mounted on stainless-steel planchettes with collodion and counted using a gas-flow proportional counter. Blanks of uncontaminated sands were run with each sample set, as were standards consisting of spiked sands. These standards, composed of $\mathrm{Co}$ and $\mathrm{Sr}$, ranged in weight from 
$0.100 \mathrm{~g}$ to $0.750 \mathrm{~g}$. Results from the gas-flow proportional counting were converted to ${ }^{90} \mathrm{Sr}$ concentrations following corrections for sand background and the ${ }^{60} \mathrm{Co}$ contribution, the latter of which was based on earlier gamma-ray analyses.

Borehole scanning to map gamma-radiation fields employed a CRL-constructed winch for positioning a 2.5$\mathrm{cm}-\mathrm{OD}$ probe that contained a $\mathrm{NaI}(\mathrm{Tl})$ detector, a stabilized high-voltage supply, and a signal preamplifier. Data were collected via a multichannel analyzer operated in multiscaling mode with a full-energy window. The analyzer was linked to the winch so that one channel in the record corresponded to a predefined depth interval traversed by the winch ( $5 \mathrm{~cm}$, in this case).

\subsection{Hollow-Fiber Ultrafiltration}

The microparticulate contents of the Chemical Pit groundwaters (CP-4 and ES-16) were characterized using hollow-fiber ultrafiltration technology. A commercially available system with four individual size-cutoff filter cartridges was used in an attempt to fractionate migrating radionuclide species as a function of particulate/molecular size (Figure 2.1). The hollow-fiber cartridges each contain hundreds of $0.6-\mathrm{m}-\mathrm{long}, 0.5-\mathrm{mm}$-ID polysulfone fibers. The combined surface area within these bundles is on the order of $1 \mathrm{~m}^{2}$ and thereby allows filtration rates as high as $10 \mathrm{~L} / \mathrm{min}$. This methodology was chosen over stirred-cell membrane ultrafiltration due to its ability to process larger volumes of groundwater in a shorter period of time. In addition, minimization of the natural tendency toward concentration polarization and surface-adsorption phenomena at the membrane/solution boundary (commonly associated with the stirred-cell technique) is afforded by the accompanying intra-fiber shear forces within the retentate flow.

Waters were drawn with a variable-speed submersible pump at rates less than $\sim 200 \mathrm{~mL} / \mathrm{min}$ (to minimize resuspension of adsorbed species), passed through sterile prefilters $(0.2 \mu \mathrm{m}$ or $0.45 \mu \mathrm{m})$, and retained in 1) plasticlined drums that were open to the atmosphere (1993 field season) or 2) a large plastic tank provided with positive $\mathrm{N}_{2}$ pressure to preclude the disturbance of oxidation/reduction equilibria by atmospheric $\mathrm{O}_{2}$ (1994 field season). The decision to maintain an oxygen-free environment during the 1994 sampling effort was based on observations from the previous year in which the ultrafiltered waters took on a slight green tint upon concentration. The cause for this coloration is uncertain, although iron oxidation due to air exposure may have played a role. This effect was not observed during the 1994 ultrafiltration effort, but could have been present and gone unnoticed since these waters were moderately colored to begin with. Samples were light- to medium-amber in color (ES-16 and CP-4, respectively), possibly due to an abundance of humic and fulvic materials made available as a result of two recent high-volume discharges to the Chemical Pit (note: late in 1993, a batch of high-conductivity, high-pH water was directed to this pit and may have disturbed the equilibria of adsorbed organo-radionuclide complexes; a second discharge containing low-ionic-strength, high-pH water occurred in early 1994, and may have served to flush any previously mobilized species into the aquifer).

Sampled waters were incrementally transferred to the ultrafiltration reservoir and pumped through separate pairs of hollow-fiber filter cartridges, and filtrates from each step were directed into secondary reservoirs. During the 1994 sampling effort, all reservoirs were maintained under a $\mathrm{N}_{2}$ blanket. Original sample volumes ranged from $\sim 50 \mathrm{~L}$ (1994) to $\sim 180 \mathrm{~L}$ (1993). The first pair of filter cartridges had a nominal molecular weight (MW) cutoff of 100,000 daltons (roughly equivalent to a 10 -nm-diameter molecule, based on globular protein analogues). When the total volume of the retentate in each step dropped to $\sim 5 \mathrm{~L}$, the concentrated solution was flushed with double-distilled water for desalting. This step was incorporated into the procedure to mitigate against any induced flocculation or disruption of chemical equilibria upon sample concentration. Resulting filtrates were subsequently passed through a pair of 30,000-MW filters $(-5-\mathrm{nm}$ molecular diameter) as above. The process was then repeated with 10,000-MW ( $\sim 3-\mathrm{nm}$ molecular diameter) and 3,000-MW ( 1-nm molecular diameter) filter cartridges. Final filtrates were passed through large-volume water samplers to determine the charge speciation of those species that were $<1 \mathrm{~nm}$ in size.

The end result of these procedures was a series of aliquots from CP-4 and ES- 16 with the following size ranges: 0.2 $\mu \mathrm{m}$ or $0.45 \mu \mathrm{m}$ to $\geq 10 \mathrm{~nm}, 10 \mathrm{~nm}$ to $25 \mathrm{~nm}, 5 \mathrm{~nm}$ to $\geq 3 \mathrm{~nm}$, $3 \mathrm{~nm}$ to $\geq 1 \mathrm{~nm}$, and $<1 \mathrm{~nm}$. A volume-balance diagram for these analyses is shown in Figure 2.2. Aliquots were split, sealed in amber glass bottles, and chilled before and during shipment and analysis.

\subsection{Membrane Ultrafiltration}

Tangential-flow ultrafiltration systems were used to produce 2-L-to-6-L particle concentrates from groundwater samples to provide enough material for colloid characterization and size analysis (Figure 2.3). Chemical and radiochemical analyses of the resulting particle concentrates and filtrates were performed to obtain information on the association of various elements and radionuclides with colloids and suspended particles. The 


\section{Experimental}

Figure 2.1 Schematic of the hollow-fiber ultrafiltration system

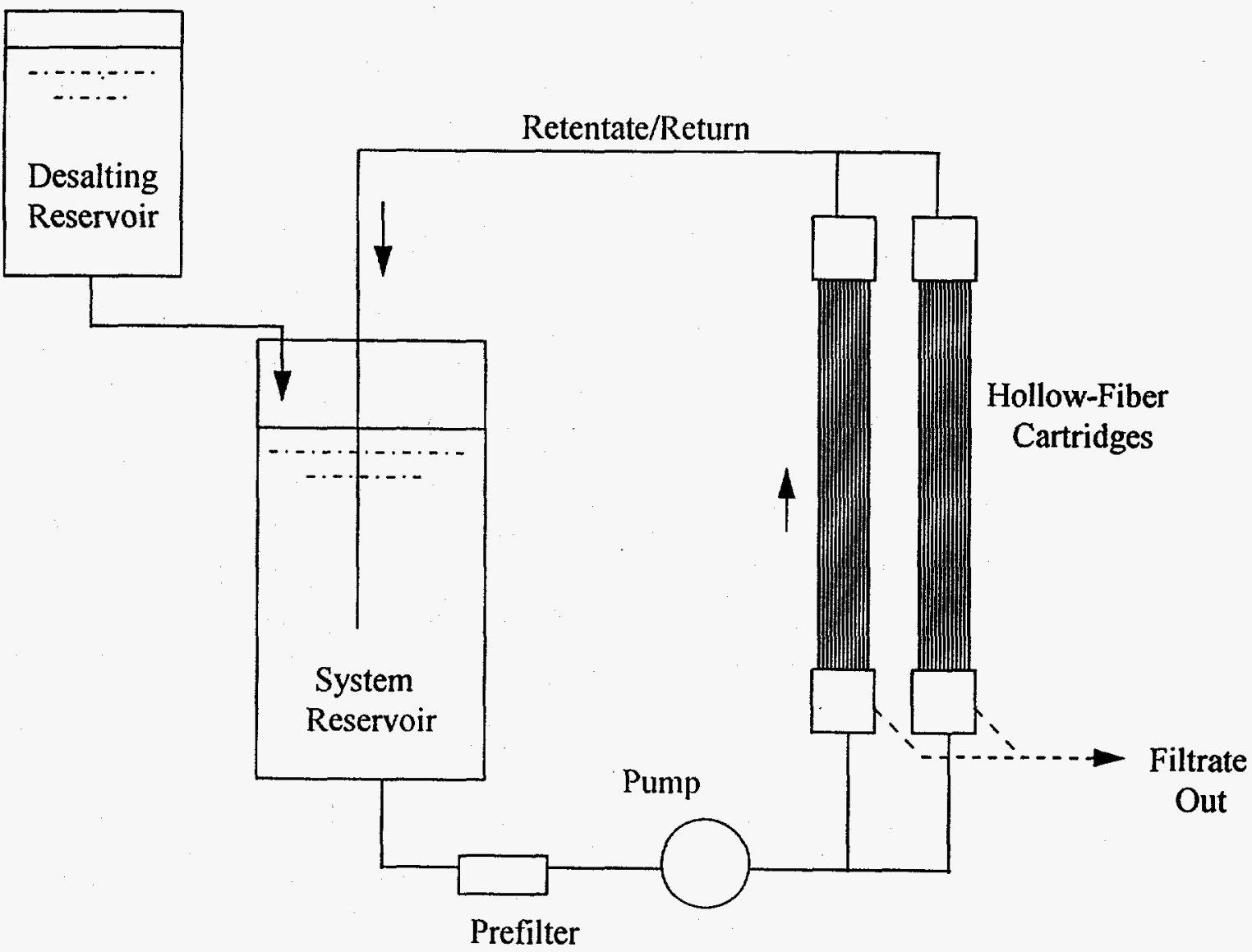


Figure 2.2 Volume-balance diagram for hollow-fiber ultrafiltration process

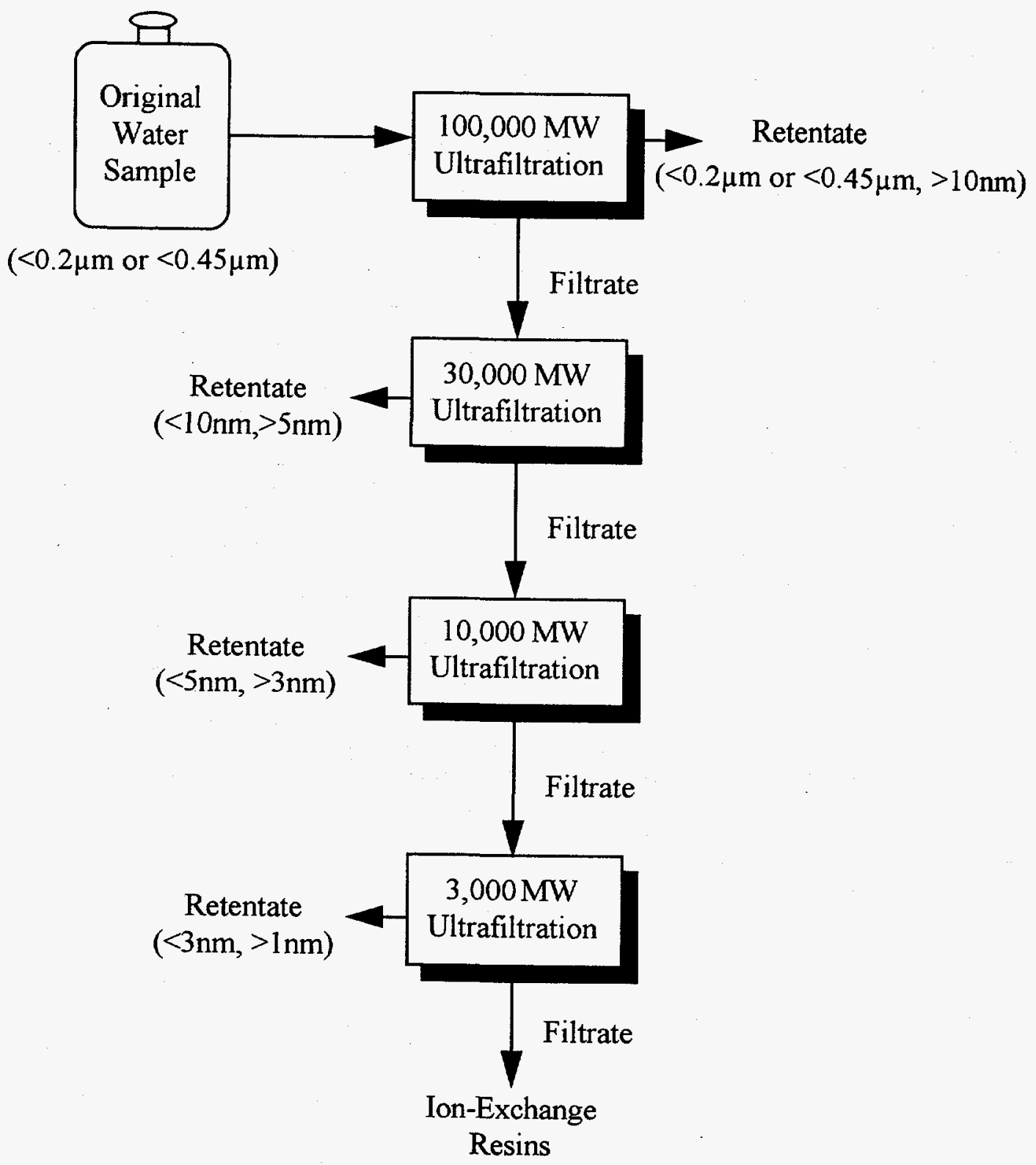




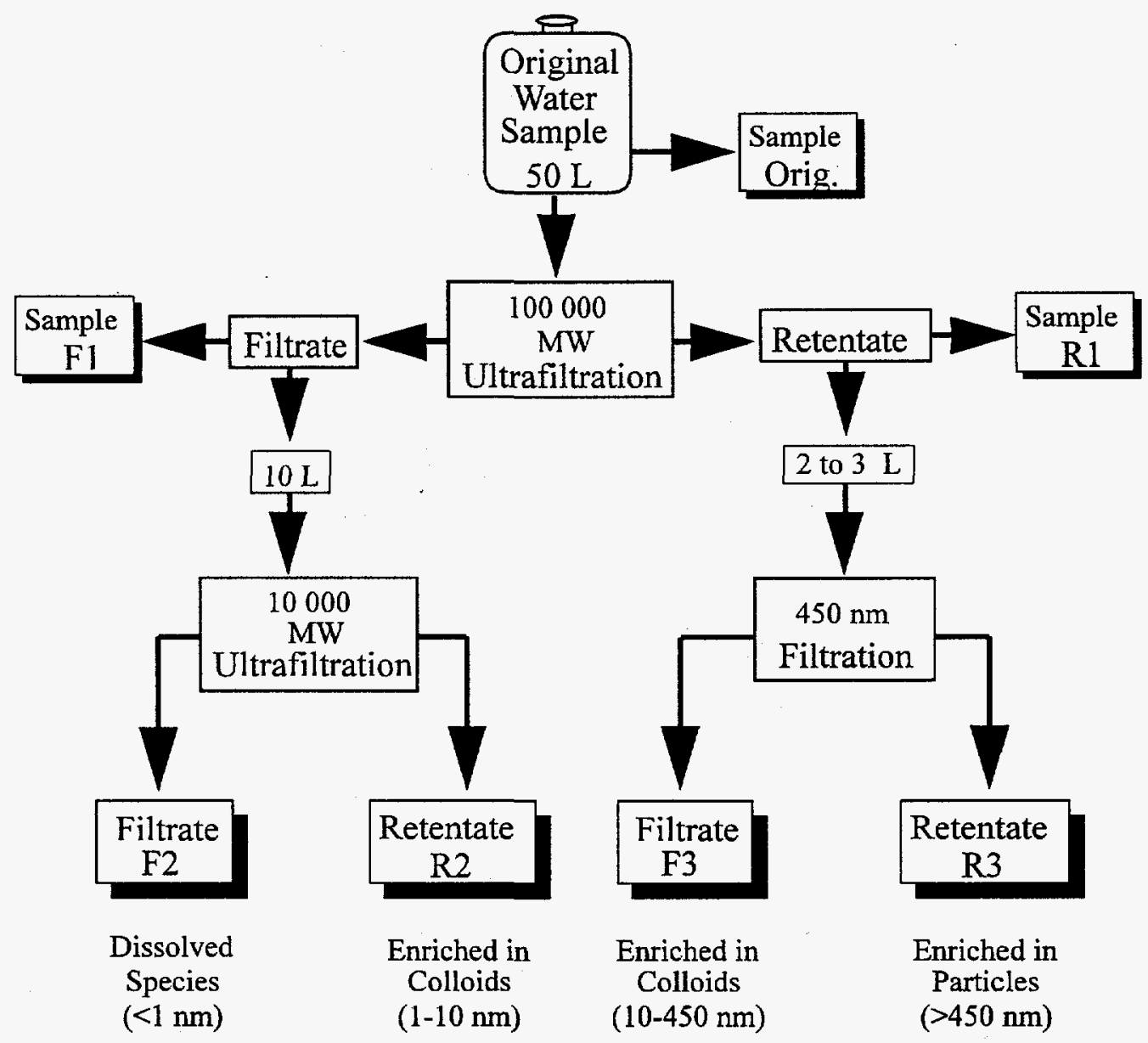


groundwater was not prefiltered before the ultrafiltration step to avoid loss of colloids and suspended particles on the prefilter medium. In the first step, particles larger than about $10 \mathrm{~nm}$ were concentrated by filtering groundwater through a commercial system equipped with 100,000-MW polysulfone membrane packets separated by retentate screens. The concentrate produced by the $100,000-\mathrm{MW}$ membrane was then filtered further with a tangential-flow filtration system equipped with a $0.45-\mu \mathrm{m}$ cutoff membrane. This produced a filtrate containing colloids between $10 \mathrm{~nm}$ and $0.45 \mu \mathrm{m}$, and a concentrate enriched in suspended particles that were larger than $\sim 0.45 \mu \mathrm{m}$. Approximately $20 \mathrm{~L}$ of water retained from the initial 100,000-MW filtration step were passed through another system equipped with a 10,000-MW polysulfone filter cassette. This produced a sample of filtered water containing only species smaller than $\sim 3 \mathrm{~nm}$ in size and a concentrate enriched in colloids with a size range between $10,000 \mathrm{MW}(\sim 3 \mathrm{~nm})$ and 100,000 MW ( 10 nm).

Particle concentrations and size distributions were measured by pressure filtering $25 \mathrm{~mL}$ of particle concentrates through a series of 25 -mm-diameter polycarbonate filters with the following cutoff sizes: 10,000 $\mathrm{nm}, 5,000 \mathrm{~nm}, 1,000 \mathrm{~nm}, 400 \mathrm{~nm}, 100 \mathrm{~nm}, 50 \mathrm{~nm}$, and 15 $\mathrm{nm}$. Particle concentrations were determined by measuring the total weight of the material deposited on each filter. The presence of colloidal material in the 1-nm-to-10-nm size range was determined by comparing the chemical composition of colloid concentrates with that of filtered water.

Particle-size analyses were also carried out with an ultrafine particle-size analyzer (UPA), which used backscattered laser light to measure the Brownian motion of particles with sizes between $6 \mathrm{~nm}$ and $2.5 \mu \mathrm{m}$. Brownian motion was used to calculate particle-size distributions. In addition, an aliquot of the $<10,000-\mathrm{MW}$ filtrate was retained from each sample for speciation analysis via anion exchange.

\subsection{Laboratory Chromatography: Anion Exchange and Gel Exclusion}

The groundwater used in this phase of the study was collected from the Chemical Pit plume. Results from earlier studies of ${ }^{60} \mathrm{Co}$ in this plume were reported in Killey et al. (1984) and Champ et al. (1985), which indicated that dissolved ${ }^{60} \mathrm{Co}$ was primarily anionic in form and that these species were nearly as mobile as tritiated water (i.e., essentially unretarded by the aquifer medium). A variety of techniques were used to study these apparently stable, inert, organically complexed species. Ion-exchange resins were used to differentiate between anionic and cationic species, and it was found that the dominant anionic species were strongly bound by Bio-Rad AG1x8 resin when groundwater was passed through packed columns of this material. Since the concentrations of ${ }^{60} \mathrm{Co}$ in the groundwater were naturally low, the AGlx8 resin was used to preconcentrate the anionic species. It was further determined that the anionic Co species could be stripped from the resin using acidic solutions or higher-ionic-strength salt solutions. These preliminary results suggested that the mobility of anionic radionuclides vis-à-vis anion-exchange resins could allow their chromatographic separation using selective elution, thereby facilitating the study of such species. Further work at that time indicated that AGMP1 resin, a macroporous form of $\mathrm{AG} \mathrm{x} 8^{3}$, was even more efficient for retaining anionic species and that ${ }^{60} \mathrm{Co}$ could be concentrated from a few liters of groundwater using a fairly small resin column. The results reported below are a continuation of these earlier studies.

Throughout a 6-month period beginning in March of 1993, groundwaters were intermittently drawn from wells ES-16, ES-39, and CP-4 at the Chemical Pit. Using a peristaltic pump and clean plastic tubing, these waters were collected and passed through a $0.45-\mu \mathrm{m}$ prefilter, retained in $20-\mathrm{L}$ polyethylene carboys, and stored in a coldroom until the chromatographic analyses could be performed. Generally, initial experiments were started on the day of collection, and subsequent experiments were performed over periods ranging up to several weeks.

The laboratory equipment used for the ion-exchange chromatography is shown schematically in Figure 2.4. A rotary valve was used to connect the inlet of a microprocessor-controlled, dual-piston pump to various eluent solutions that were stored in 4-L polyethylene bottles. Salt gradients were generated using a piston pump and an acrylic mixing chamber with a magnetic stirrer. The conductivity of the eluent solution was monitored downstream of the microprocessor-controlled pump with a conductivity flow cell and meter, the output from which was recorded on a strip chart. A $10-\mathrm{m}$ length of plastic capillary tubing (a $0.51-\mathrm{mm}[0.020 \mathrm{inch}] \mathrm{ID}$ ) between this pump and the conductivity cell provided the necessary back pressure for the pump. Gamma-ray emitters in the separation column effluents were monitored by a $7.6-\mathrm{cm}$ by-7.6-cm well-type $\mathrm{NaI}(\mathrm{Tl})$ detector. The resulting gamma-ray spectra were recorded with a multichannel analyzer and the region-of-interest data were transferred to a personal computer for storage and display. Effluent volume splits (nominally $6 \mathrm{~mL}$ each) were collected with a programmable fraction collector, which was also used to

\footnotetext{
${ }^{3} \mathrm{AGMP1}$ resin has a nominal size exclusion of $100,000 \mathrm{MW}$, compared to only 1,000 MW for AGlx8.
} 


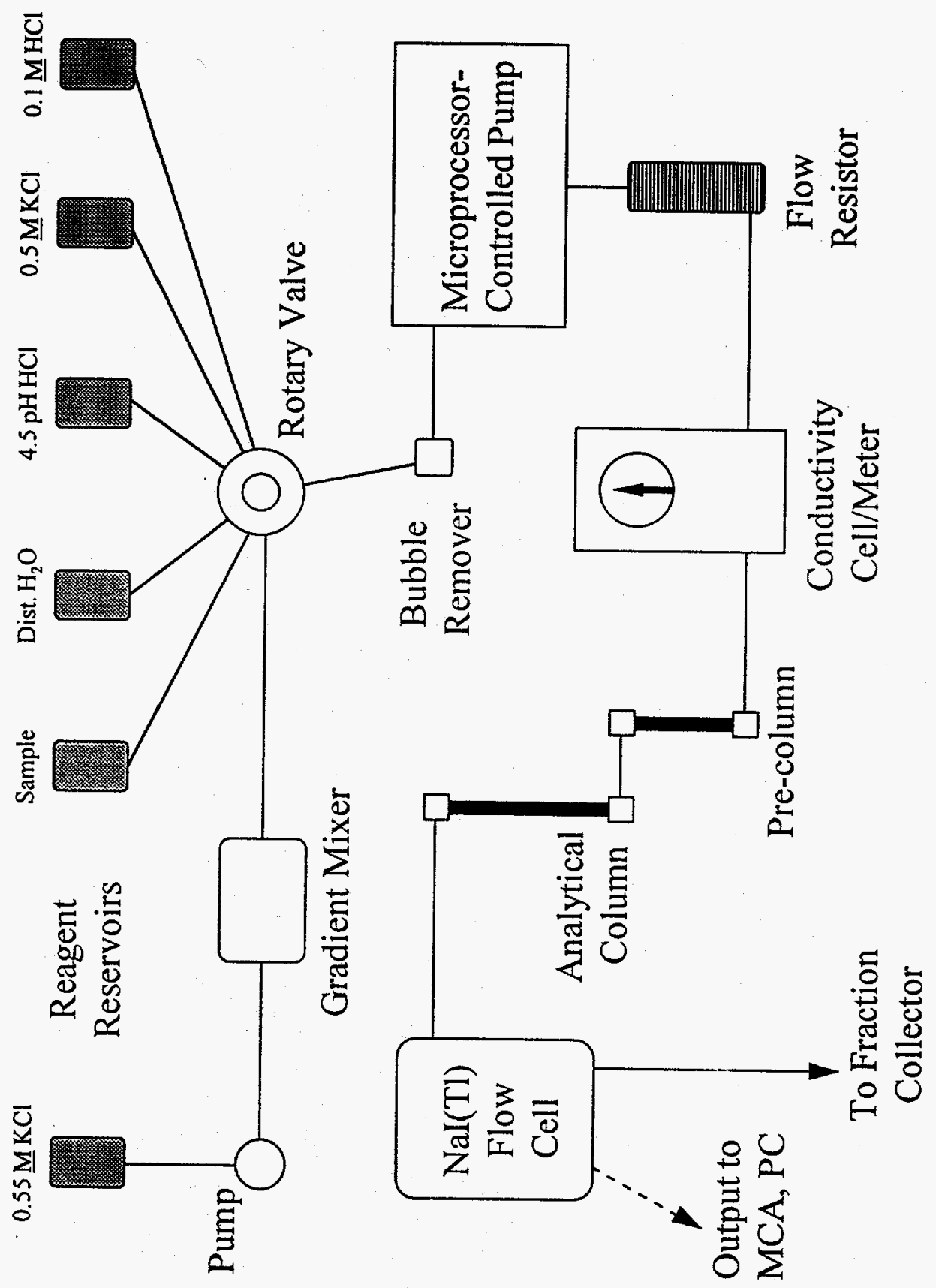

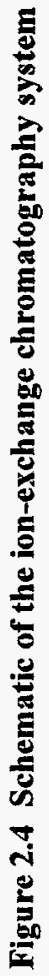


control the multichannel analyzer unit for displaying results and initiating the data acquisitions for each effluent fraction. Chromatographic resin columns were constructed from $6.35-\mathrm{mm}(0.25 \mathrm{inch})-\mathrm{ID}$ polyethylene tubing and $9.525-\mathrm{mm}(0.375$ inch) stainless-steel fittings. Porous polyethylene frits were used to retain the resins at each end of the columns. Adapters between the stainless-steel unions and the chromatography fittings were custom fabricated from plastic rod, and Teflon tubing was used for all system connections.

Gamma-ray emitters ${ }^{60} \mathrm{Co}$ and ${ }^{106} \mathrm{Ru}$ were analyzed in each fraction using 7-mL scintillation vials and an automatic gamma counter. Selected samples were analyzed by a gamma-ray spectrometry unit consisting of a 30\%-efficient Ge detector and a spectrum analyzer. Larger-volume liquid samples were either counted in a 400 -g geometry in a polyethylene bottle or dried on polyethylene film and pressed into a plastic pillbox. Alpha and beta emitters from a selected set of samples were analyzed with a liquid scintillation counter. Alpha spectrometry was performed with spectrometers interfaced to a multichannel buffer unit. The spectrometers were calibrated with traceable standards.

The presence of organic material in selected volume fractions was determined by observing the ultraviolet absorbance of the samples at $254 \mathrm{~nm}$. Target fractions were monitored in $1-\mathrm{cm}$-wide quartz cells using a commercial spectrophotometer. The concentrations of dissolved cationic and anionic species were established by passing $~ 0.5-\mathrm{L}$ groundwater aliquots through $1.5-\mathrm{cm}-\mathrm{ID}-$ by-15-cm-long columns of AG50Wx8 and AG1 18 ionexchange resins, respectively, and measuring the radionuclide concentrations in the column effluents following elution.

Chromatographic columns using AGMP1 resin were prepared with a suitable length of tubing that was cut and straightened by heating in an oven. Frits of $6.35 \mathrm{~mm}(0.25$ inch) and $9.525 \mathrm{~mm}$ (0.375 inch) were fitted on the lower end and held with a stainless-steel union, which was fitted with a chromatography adapter and a two-way valve. The top end was fitted with a lone $9.525-\mathrm{mm}$ ( $0.375 \mathrm{inch})$ frit and union connector. After swaging the ferrules, the upper union was removed and replaced with a 9.525-mm $(0.375$ inch) tube and $12.7-\mathrm{mm}$ ( $0.5 \mathrm{inch}$ ) adapter, which served as a filling reservoir. The resin was then slurried in distilled water and added to the column using gravity flow. The 200-400-mesh resin drained slowly, however, and required the use of suction for quicker loading. Additional slurry was added as necessary to accommodate the settling of the resin bed. The adapter was then removed from the top of the column and replaced with the original union. This was attached to the line at the outlet of the chromatography pump, and several hundred $\mathrm{mL}$ of distilled water were pumped at $10 \mathrm{~mL} / \mathrm{min}$ to pack the bed. The pump was then shut off, and the union on the top of the column was removed. If significant compression of the bed had occurred, more resin was added. Finally, a $6.35-\mathrm{mm}(0.25$ inch)-diameter frit was fitted into the top of the column, and the union was filled with distilled water and replaced. The column was then connected to the chromatographic system and covered with aluminum foil to exclude light.

Next, $4 \mathrm{~L}$ of groundwater were transferred to an opaque polyethylene container and purged with $\mathrm{He}$ gas. The sample was then pumped from the container through the AGMP1 column at $\sim 3$ to $6 \mathrm{~mL} /$ minute for 8 to 16 hours. The following day, loading was ceased and the columns were rinsed with distilled water. The total volume of groundwater loaded on the column was determined by weighing the container before and after loading. The column was then eluted with $30 \mathrm{~mL}$ of $\mathrm{pH}-4.5 \mathrm{HCl}$, followed by $500 \mathrm{~mL}$ of a $0-\underline{\mathrm{M}}$ to $0.5-\mathrm{M} \mathrm{KCl}$ linear gradient. This was followed by $100 \mathrm{~mL}$ of $0.5-\underline{\mathrm{M} \mathrm{KCl}}$ and $100 \mathrm{~mL}$ of $0.1-\mathrm{M} \mathrm{HCl}$. Fractions with a nominal $6-\mathrm{mL}$ volume were collected during the elution, which occurred at the rate of $\sim 3 \mathrm{~mL} /$ minute. Following the elution step, the columns were flushed with distilled water.

Equipment used for the gel-exclusion chromatography is shown in Figure 2.5. A tubing pump was used to load and elute four columns simultaneously. Three of the columns were 16-mm ID, while the fourth was 15-mm ID. A suitable quantity of Bio-Rad P2 gel, which has a fractionation size range of $100 \mathrm{MW}$ to $1,800 \mathrm{MW}$, was soaked in distilled water for at least 5 hours to allow the resin to swell to its full capacity. The columns were then packed with P2 slurry until bed lengths of $25 \mathrm{~cm}$ were obtained. These were further packed by passing up to 200 $\mathrm{mL}$ of distilled water under gravity flow. The three larger columns were fitted with flow adapters that allowed the inlets to be adjusted to the tops of the gel beds, and $50 \mathrm{~mL}$ of distilled water was pumped through each at a nominal flow rate of $20 \mathrm{~mL} / \mathrm{h}$. If compaction was observed, then the flow adapter was adjusted to the top of the column. Six-mL fractions from the AGMP1 separations were loaded onto the gel columns at a nominal $20-\mathrm{mL} / \mathrm{h}$ flow rate and then eluted with several column volumes $(50 \mathrm{~mL})$ of distilled water at the same flow rate. Nominal 6-mL fractions were collected during elution with a commercial collector, and a number of fractions were weighed to determine the actual pumping rates in individual channels. After use, the columns were rinsed with distilled water. The total column volumes were determined with tritiated water, which was measured with a liquid scintillation counter. The void volumes were determined with blue dextran, which was detected visually. 
Experimental

Figure 2.5 Molecular gel-exclusion chromatography apparatus

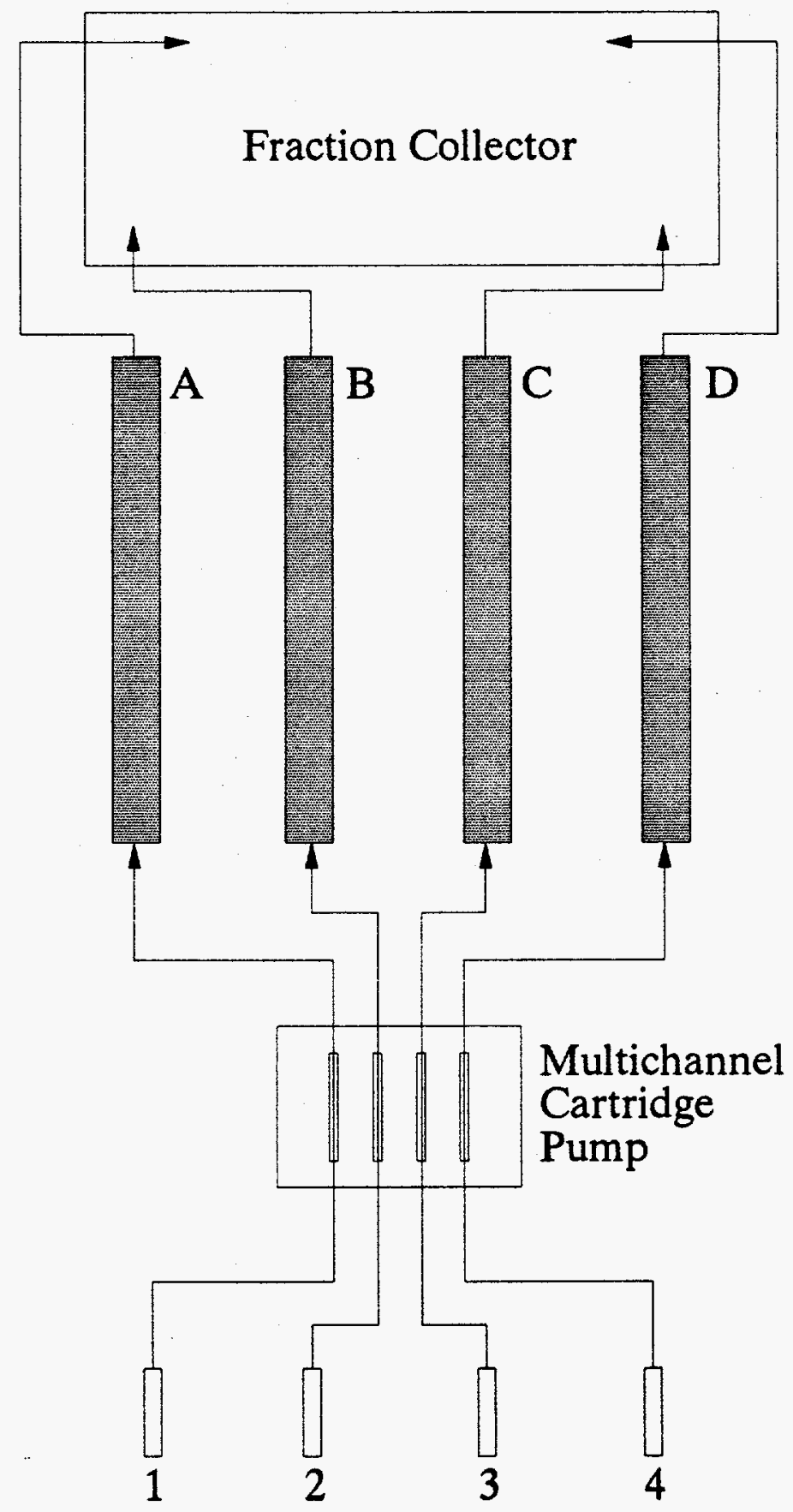




\subsection{Liquid Chromatography/Mass Spectrometry}

Initially, size-fractionated groundwater from wells $\mathrm{CP}-4$ and ES-16 (1994) was analyzed for total organic carbon (TOC) content using a hot persulfate method to determine which samples had the highest levels of carbon (Section 2.2). Only one sample (the largest size fraction from well $\mathrm{CP}-4$ ) exhibited a sufficient TOC concentration to allow subsequent analysis. This sample was concentrated by lyophilization, $1 \mathrm{~mL}$ of doubly-distilled water was added to the dried sample, and the resulting solution was analyzed via thermospray liquid chromatography/mass spectrometry (LC/MS) for the detection of nonvolatile, higher-molecularweight materials (e.g., humic and fulvic acids).

Thermospray LC/MS is an analytical technique that is applicable to a wide range of species (volatile and nonvolatile, polar and nonpolar, labile and stable) under a variety of chromatographic conditions. The thermospray technique serves as both an ionization and enrichment process. Although ions may be generated by a number of conventional ionization methods, ion evaporation was utilized in this investigation since it is a solution-phase ionization technique that is particularly appropriate for most nonvolatile compounds. In this method, a volatile buffer is added to the LC mobile phase (typically, 0.1- $\underline{M}$ ammonium acetate), which can result in a statistical charging of the micrometer-size droplets from the vaporizer. These droplets can have a mean surface field strength as high as $10^{7} \mathrm{~V} / \mathrm{m}$, which will increase as the droplets continue to desolvate. In the presence of volatile ammonium buffers, $\mathrm{NH}_{4}{ }^{+}$and other adducts are desorbed from the droplets, which can subsequently react in the gas phase with the analyte. In the absence of such buffer ions, highly polar or ionic compounds can generate a field to ionize themselves.

This method involves a controlled, partial vaporization of the liquid chromatography effluent before it enters the ion source of the mass spectrometer. This is accomplished by heating a capillary tube, which allows the liquid to be nebulized and partially vaporized, and any unvaporized solvent and sample are thereby carried into the ion source as microdroplets or in a supersonic vapor jet. Nonvolatile samples may be ionized by direct ion evaporation from highly charged droplets or particles, and more volatile samples may be ionized directly or by ion-molecule reactions in the gas phase.

\subsection{Optical Spectroscopies}

Size-fractionated samples from wells CP-4 and ES-16
(1994) were analyzed via three optical spectroscopy methods in an attempt to elucidate the nature of the complexing species in solution. The individual methods used were Raman, ultraviolet-visible absorption, and timeresolved luminescence spectroscopies. Raman spectroscopy was used to study the dissolved material to detect changes in the functional groups that are most likely to be involved in interactions with the sorbed species. This technique was also used to probe for the individual metals and ligands that may be responsible for the formation of the complexed species. The ultraviolet-visible absorption and luminescence spectroscopies were used to detect specific complexes that normally exhibit these optical properties. The latter technique was also used to investigate the existence of multiply adsorbed species and/or species adsorbed at sites with different physical and chemical properties.

The size-fractionated samples were kept refrigerated, and all work was performed inside a nitrogen-purged glovebox to preclude any oxidation and potential denaturation of the dissolved species. Additional preparation was performed on the largest size fractions from CP-4 $(<0.45 \mu \mathrm{m}, \geq 10 \mathrm{~nm})$ and ES-16 $(<0.2 \mu \mathrm{m}, \geq 10 \mathrm{~nm})$, which were suspected of having the highest concentrations of colloidal material. These aliquots $(\sim 0.5 \mathrm{~L})$ were centrifuged at 60,000 revolutions per minute for 8 hours, the supernatant was discarded, and the remaining solids were removed for spectroscopic analysis (insufficient solid material was obtained from the ES-16 aliquot to allow further study).

The Raman spectra were obtained via laser excitation at $16,793 \mathrm{~cm}^{-1}$ or $27,473 \mathrm{~cm}^{-1}$ (Table 2.1 ). The $27,473 \mathrm{~cm}^{-1}$ excitation was generated by an $\mathrm{Ar}^{+}$laser, and the 16,793 $\mathrm{cm}^{-1}$ excitation was provided by $\mathrm{Ar}^{+}-$laser pumping of a dye laser containing a suitable ethylene glycol mixture. Plasma and fluorescent lines from the latter beam were removed with a 3-nm bandpass filter. The spectrographic unit consisted of a double monochromator as the filter stage (600 grooves $/ \mathrm{mm}$ holographic grating) and a second monochromator as the spectrographic stage ( 1200 grooves $/ \mathrm{mm}$ holographic grating). Final detection was afforded by a cooled charge-coupled device containing 1152 columns by 298 rows of pixels, each $22.5 \mu \mathrm{m}$ on a side.

The excitation-energy-dependent time-resolved luminescence spectra (Table 2.2) were collected with a spectrofluorometer equipped with a Xe flash lamp for excitation. The spectrofluorometer consisted of a $0.22-\mathrm{m}$ spectrometer for excitation (1200 grooves/mm holographic grating blazed at $330 \mathrm{~nm}$ ), a $0.22-\mathrm{m}$ double spectrometer for emission (1200 grooves/mm holographic grating blazed at $500 \mathrm{~nm}$ ), and a photomultiplier tube in a thermoelectrically 


\section{Experimental}

cooled housing for detection.

The remainder of the time-resolved luminescence spectra (Table 2.3) and lifetime measurements (Table 2.4) were collected with a system that included a Nd:YAG pulsed laser, a 1.8- $\mathrm{m}$ monochromator, a photomultiplier tube, a fast preamplifier, and a dual-channel gated photon counter. The second harmonic of the laser $\left(28,169 \mathrm{~cm}^{-1}\right)$ was used for excitation in all of the time-resolved measurements. For lifetime determinations, the gate-scanning capability of the photon counter was used, and the data were analyzed via a double exponential function:

$$
P(t)=A_{0} \exp \left(-k_{0} t\right)+A_{1} \exp \left(-k_{1} t\right)
$$

where $\mathrm{k}_{0}=1 / \tau_{0}$ and $\mathrm{k}_{1}=1 / \tau_{1}$ are the unimolecular rate constants for radiative and nonradiative decay for two different emissive species, $t$ is time, and $A_{0}$ and $A_{1}$ are the pre-exponential factors for the emissive species.

The absorption spectra were collected with an ultravioletvisible spectrophotometer using a double-beam, doublemonochromator ratio-recording spectrometer (1440 grooves $/ \mathrm{mm}$ holographic grating). The scan region was from $40000 \mathrm{~cm}^{-1}$ to $15000 \mathrm{~cm}^{-1}$ and detection was via a photomultiplier tube. 
Experimental

Table 2.1 Experimental conditions for acquired Raman spectra

\begin{tabular}{|c|c|c|}
\hline $\begin{array}{c}\text { Sample } \\
\text { Identification }\end{array}$ & $\begin{array}{l}\text { Scan Region } \\
\left(\mathrm{cm}^{-1}\right)\end{array}$ & $\begin{array}{l}\text { Excitation } \\
\left(\mathrm{cm}^{-1}\right)\end{array}$ \\
\hline \multirow{7}{*}{$\underset{(<1 \mathrm{~nm})}{\mathrm{CP}-4}$} & $332-732$ & 16793 \\
\hline & $528-928$ & 16793 \\
\hline & $906-1306$ & 16793 \\
\hline & $1267-1667$ & 16793 \\
\hline & $1441-1841$ & 16793 \\
\hline & $2847-3247$ & 16793 \\
\hline & $165-1524$ & 27473 \\
\hline \multirow{7}{*}{$\begin{array}{c}\text { CP-4 } \\
(<0.45 \mu \mathrm{m}, \geq 10 \mathrm{~nm})\end{array}$} & $332-732$ & 16793 \\
\hline & $528-928$ & 16793 \\
\hline & 906-1306 & 16793 \\
\hline & 1267.1667 & 16793 \\
\hline & 1441-1841 & 16793 \\
\hline & $2847-3247$ & 16793 \\
\hline & $165-1524$ & 27473 \\
\hline \multirow{6}{*}{$\begin{array}{c}\mathrm{CP}-4 \\
\text { (solids from above) }\end{array}$} & $332-732$ & 16793 \\
\hline & $528-928$ & 16793 \\
\hline & $820-1220$ & 16793 \\
\hline & $1160-1560$ & 16793 \\
\hline & $1487-1887$ & 16793 \\
\hline & $285-1726$ & 27473 \\
\hline \multirow{2}{*}{$\begin{array}{l}\text { ES-16 } \\
(<1 \mathrm{~nm})\end{array}$} & $1441-1841$ & 16793 \\
\hline & 901-2088 & 27473. \\
\hline \multirow{4}{*}{$\begin{array}{c}\text { ES-16 } \\
(<0.2 \mu \mathrm{m}, \geq 10 \mathrm{~nm})\end{array}$} & $332-732$ & 16793 \\
\hline & $528-928$ & 16793 \\
\hline & $1611-2011$ & 16793 \\
\hline & $165-1524$ & 27473 \\
\hline
\end{tabular}


Experimental

Table 2.2 Experimental conditions for time-resolved emission spectra

\begin{tabular}{|c|c|c|}
\hline $\begin{array}{c}\text { Sample } \\
\text { Identification }\end{array}$ & $\begin{array}{l}\text { Scan Region } \\
\left(\mathrm{cm}^{-1}\right)\end{array}$ & $\begin{array}{l}\text { Excitation } \\
\left(\mathrm{cm}^{-1}\right)\end{array}$ \\
\hline \multirow{9}{*}{$\begin{array}{c}\mathrm{CP}-4 \\
(<1 \mathrm{~nm})\end{array}$} & $30769-17094$ & 33003 \\
\hline & 27778-15624 & 31008 \\
\hline & $27778-15624$ & 29412 \\
\hline & $26316-14286$ & 27778 \\
\hline & $25000-14286$ & 26316 \\
\hline & $23810-14286$ & 25000 \\
\hline & $22727-14286$ & 23810 \\
\hline & $21739-14286$ & 22727 \\
\hline & 20833-14286 & 21739 \\
\hline \multirow{9}{*}{$\begin{array}{c}\mathrm{CP}-4 \\
(<0.45 \mu \mathrm{m}, \geq 10 \mathrm{~nm})\end{array}$} & $30769-17094$ & 33003 \\
\hline & 27778-15624 & 31008 \\
\hline & 27778-15624 & 29412 \\
\hline & $26316-14286$ & 27778 \\
\hline & $25000-14286$ & 26316 \\
\hline & $23810-14286$ & 25000 \\
\hline & $22727-14286$ & 23810 \\
\hline & 21739-14286 & 22727 \\
\hline & 20833-14286 & 21739 \\
\hline \multirow{9}{*}{$\begin{array}{c}\text { ES-16 } \\
(<1 \mathrm{~nm})\end{array}$} & $30769-17094$ & 33003 \\
\hline & 27778-15624 & 31008 \\
\hline & 27778-15624 & 29412 \\
\hline & $26316-14286$ & 27778 \\
\hline & $25000-14286$ & 26316 \\
\hline & $23810-14286$ & 25000 \\
\hline & $22727-14286$ & 23810 \\
\hline & $21739-14286$ & 22727 \\
\hline & 20833-14286 & 21739 \\
\hline
\end{tabular}


Experimental

Table 2.2 (continued)

\begin{tabular}{|c|c|c|}
\hline $\begin{array}{c}\text { Sample } \\
\text { Identification }\end{array}$ & $\begin{array}{c}\text { Scan Region } \\
\left(\mathrm{cm}^{-1}\right)\end{array}$ & $\begin{array}{c}\text { Excitation } \\
\left(\mathrm{cm}^{-1}\right)\end{array}$ \\
\hline \multirow{2}{*}{$\begin{array}{c}\text { ES-16 } \\
(<0.2 \mu \mathrm{m}, 210 \mathrm{~nm})\end{array}$} & $30769-17094$ & 33003 \\
\cline { 2 - 3 } & $27778-15624$ & 31008 \\
\cline { 2 - 3 } & $27778-15624$ & 29412 \\
\cline { 2 - 4 } & $26316-14286$ & 27778 \\
\cline { 2 - 4 } & $25000-14286$ & 26316 \\
\cline { 2 - 4 } & $23810-14286$ & 25000 \\
\hline & $22727-14286$ & 23810 \\
\hline & $21739-14286$ & 22727 \\
\hline
\end{tabular}


Experimental

Table 2.3 Experimental conditions for delay- and gate-dependent time-resolved emission spectra. Excitation (28,169 $\left.\mathrm{cm}^{-1}\right)$ and scan region $\left(25,000-14,706 \mathrm{~cm}^{-1}\right)$ were the same for all samples.

\begin{tabular}{|c|c|c|}
\hline $\begin{array}{c}\text { Sample } \\
\text { Identification }\end{array}$ & $\begin{array}{l}\text { Delay } \\
(\mu \mathrm{s})\end{array}$ & $\begin{array}{l}\text { Gate } \\
(\mu \mathrm{s})\end{array}$ \\
\hline \multirow{2}{*}{$\underset{(<1 \mathrm{~nm})}{\mathrm{CP}-4}$} & 5.0 & 5.0 \\
\hline & 10.0 & 10.0 \\
\hline \multirow{12}{*}{$\begin{array}{c}\mathrm{CP}-4 \\
(<0.45 \mu \mathrm{m}, \geq 10 \mathrm{~nm})\end{array}$} & 0.0 & 0.5 \\
\hline & 0.0 & 1.0 \\
\hline & 0.0 & 2.0 \\
\hline & 0.0 & 5.0 \\
\hline & 0.0 & 10.0 \\
\hline & 0.0 & 20.0 \\
\hline & 0.0 & 50.0 \\
\hline & 0.0 & 100.0 \\
\hline & 0.5 & 0.5 \\
\hline & 1.0 & 1.0 \\
\hline & 5.0 & 5.0 \\
\hline & 10.0 & 10.0 \\
\hline \multirow{4}{*}{$\begin{array}{c}\mathrm{CP}-4 \\
\text { (solids from above) }\end{array}$} & 0.0 & 0.5 \\
\hline & 0.0 & 1.0 \\
\hline & 0.5 & 0.5 \\
\hline & 1.0 & 1.0 \\
\hline \multirow{2}{*}{$\begin{array}{l}\text { ES-16 } \\
(<1 \mathrm{~nm})\end{array}$} & 5.0 & 5.0 \\
\hline & 10.0 & 10.0 \\
\hline \multirow{2}{*}{$\begin{array}{c}\text { ES- } 16 \\
(<0.2 \mu \mathrm{m}, 210 \mathrm{~nm})\end{array}$} & 5.0 & 5.0 \\
\hline & 10.0 & 10.0 \\
\hline
\end{tabular}


Table 2.4 Experimental conditions for time-resolved luminescence lifetime measurements. Same excitation for all samples $\left(28,169 \mathrm{~cm}^{-1}\right)$.

\begin{tabular}{|c|c|c|c|c|}
\hline $\begin{array}{c}\text { Sample } \\
\text { Identification }\end{array}$ & $\begin{array}{c}\text { Emission } \\
\left(\mathrm{cm}^{-1}\right)\end{array}$ & $\begin{array}{c}\text { Fitting Region } \\
(\mu \mathrm{s})\end{array}$ & $\begin{array}{c}\text { Gate } \\
(\mu \mathrm{s})\end{array}$ & $\begin{array}{c}\text { Step Size } \\
(\mu \mathrm{s})\end{array}$ \\
\hline $\begin{array}{c}\text { CP-4 } \\
(<1 \mathrm{~nm})\end{array}$ & 21739 & $0.9-30$ & 0.1 & 0.1 \\
\cline { 2 - 5 } & 18315 & $0.7-10$ & 0.1 & 0.1 \\
\hline $\begin{array}{c}C P-4 \\
(<0.45 \mu \mathrm{m}, 210 \mathrm{~nm})\end{array}$ & 21739 & $0.8-10$ & 0.1 & 0.1 \\
\hline $\begin{array}{c}\text { CP-4 } \\
(s o l i d s \text { from above })\end{array}$ & 18315 & $0.7-10$ & 0.1 & 0.1 \\
\hline $\begin{array}{c}\text { ES-16 } \\
(<1 \mathrm{~nm})\end{array}$ & 18315 & $1.5-25$ & 0.5 & 0.5 \\
\hline $\begin{array}{c}\text { ES-16 } \\
(<0.2 \mu \mathrm{m}, 210 \mathrm{~nm})\end{array}$ & 21739 & $0.6-10$ & 0.1 & 0.1 \\
\hline
\end{tabular}





\section{Results and Discussion}

\subsection{Well Sampling and Analyses of Chemical Constituents of Groundwater}

Groundwater samples were drawn from the Chemical Pit and Waste Management Area C plumes during 1991, 1993, and 1994. These waters are observed to be slightly acidic, relatively oxidizing, and of moderate bicarbonate content (Table 3.1). The dissolved $\mathrm{O}_{2}$, Eh, and $\mathrm{Fe}^{2+} / \mathrm{Fe}^{3+}$ data indicate that the redox conditions in these waters are highly variable in both a spatial and temporal sense. These parameters do not appear to follow the general trend in which elevated $\mathrm{O}_{2}$ contents and higher Eh values are associated with lower $\mathrm{Fe}^{2+} / \mathrm{Fe}^{3+}$ ratios. In both the Chemical Pit and Area C plumes (1993), total-Fe concentrations increased and dissolved- $\mathrm{O}_{2}$ levels decreased along the groundwater gradient, whereas the $\mathrm{Fe}^{2+} / \mathrm{Fe}^{3+}$ ratios remained relatively constant (excluding the data from well ES-39B). The reasons for such apparent discrepancies are unknown, although it is speculated that the above data are simply manifestations of the heterogeneous and variable redox environments associated with these complex groundwater flow systems, which contain appreciable amounts of natural organic complexing agents (i.e., humic and fulvic acids).

Ion chromatography data from 1991 (Table 3.2; Figure 3.1) indicate that sulfate and chloride are the primary anions in solution at these sites, while nitrate is also prevalent at the Chemical Pit. These results are reasonable when one considers that two of the primary anthropogenic and meteoric inputs to this region are sodium chloride (from dissolved road salt) and acid precipitation (composed largely of sulfate, nitrate, and chloride components). The third major input to the Chemical Pit plume - namely, liquid radioactive waste, which often contained nitric acid in various concentrations - most likely contributed to the local elevated nitrate concentration in this region.

Trace element behavior in the 1991 waters (Table 3.3; Figure 3.2) appears to reflect the local geologic/mineralogic environment, most notably with regard to the abundance of the major rock-forming elements: $\mathrm{Si}, \mathrm{Na}, \mathrm{Ca}, \mathrm{Mg}$, and $\mathrm{Fe}$. The iron content in Area $\mathrm{C}$ waters is particularly elevated as, indeed, are most of the elements at this site with respect to those at the Chemical Pit. The elevated iron concentration may be a function of the less oxidizing nature of the Area $\mathrm{C}$ groundwater, which could have led to a predominance of the more soluble ferrous species. In any case, the above groundwater data are not significantly different from those reported for this region by Champ et al. (1985). This suggests that despite non-steady-state disposal practices, which often varied both temporally and in chemical content, the local groundwater is apparently quite stable in terms of its geochemical conditions.

\subsection{Radiochemical Characterization of Groundwater}

In 1991, a number of gamma-emitting radionuclides were detected in waters sampled downgradient from the Chemical Pit and Waste Management Area C (Table 3.4). Anionic species predominated in nearly every case (the exception is cationic ${ }^{55} \mathrm{Fe}$ at $\mathrm{C}-221$ ), most often followed by nonionic, cationic, and particulate species in order of decreasing concentrations (Figures 3.3 and 3.4). It was suspected that the negatively charged complexes were primarily organic macromolecules of natural humic and fulvic acids originating from the decomposition of plant and animal residues ${ }^{4}$ and anthropogenic organic chelating agents such as ethylenediamminetetraacetic acid (EDTA). ${ }^{5}$ In theory, such anionic organo-radionuclide species would be relatively unretarded in a groundwater flow scenario (assuming kinetic stability) due to the paucity of attractive forces within the aquifer medium. The silicate mineral surfaces in common soil matrices are negatively charged (although edge planes in some phyllosilicates may be locally positive) and do not attract anionic species in the aqueous phase, thereby ensuring the continued migration of the latter. Other potential forms of these migrating, radionuclide-bearing anions may include inorganic colloidal materials (mineralogically equivalent to the aquifer matrix, bearing negatively charged surface sites favorable for the retention of cationic radionuclides) and inorganic radionuclide complexes composed of common aquo-anion ligands (e.g., sulfato, chloro, hydroxo, or combinations thereof). Stable forms of these species would behave in a fashion analogous to that described above for the organo-radionuclide complexes. The nature of the cationic species is harder to predict, however, since by virtue of their overall charge, the aquifer medium would be expected to have retarded their migration and precluded their presence downgradient from the site of dispersal. Many positively charged radionuclides may have been mobilized by previous discharges to the Chemical Pit that contained complexing agents or waters that otherwise could have disrupted the existing equilibria (recall discussion in Section 2.4). If these cationic species were displaced downgradient, readsorption would occur after the equilibria between the solid and liquid phases became re-established.

\footnotetext{
${ }^{4}$ These molecules contain deprotonated alcoholic, phenolic, and carboxylic functional groups that may complex metal cations.

${ }^{5} \mathrm{~A}$ number of these chelators are known to have been disposed of within the Chemical Pit throughout its operational history.
} 
Results

Figure 3.1 Ion chromatography results (1991)

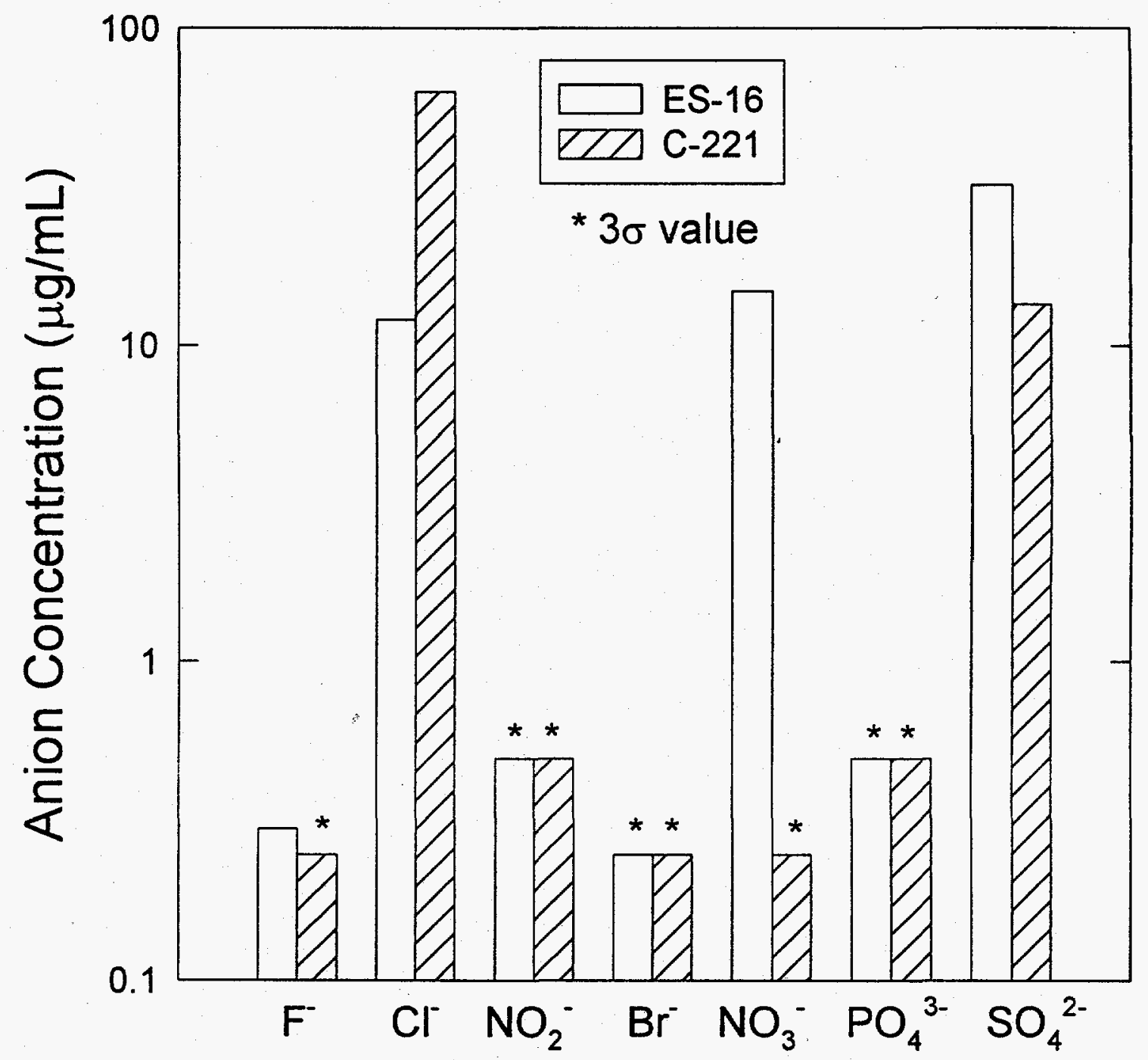


Figure 3.2 Trace element results (1991)
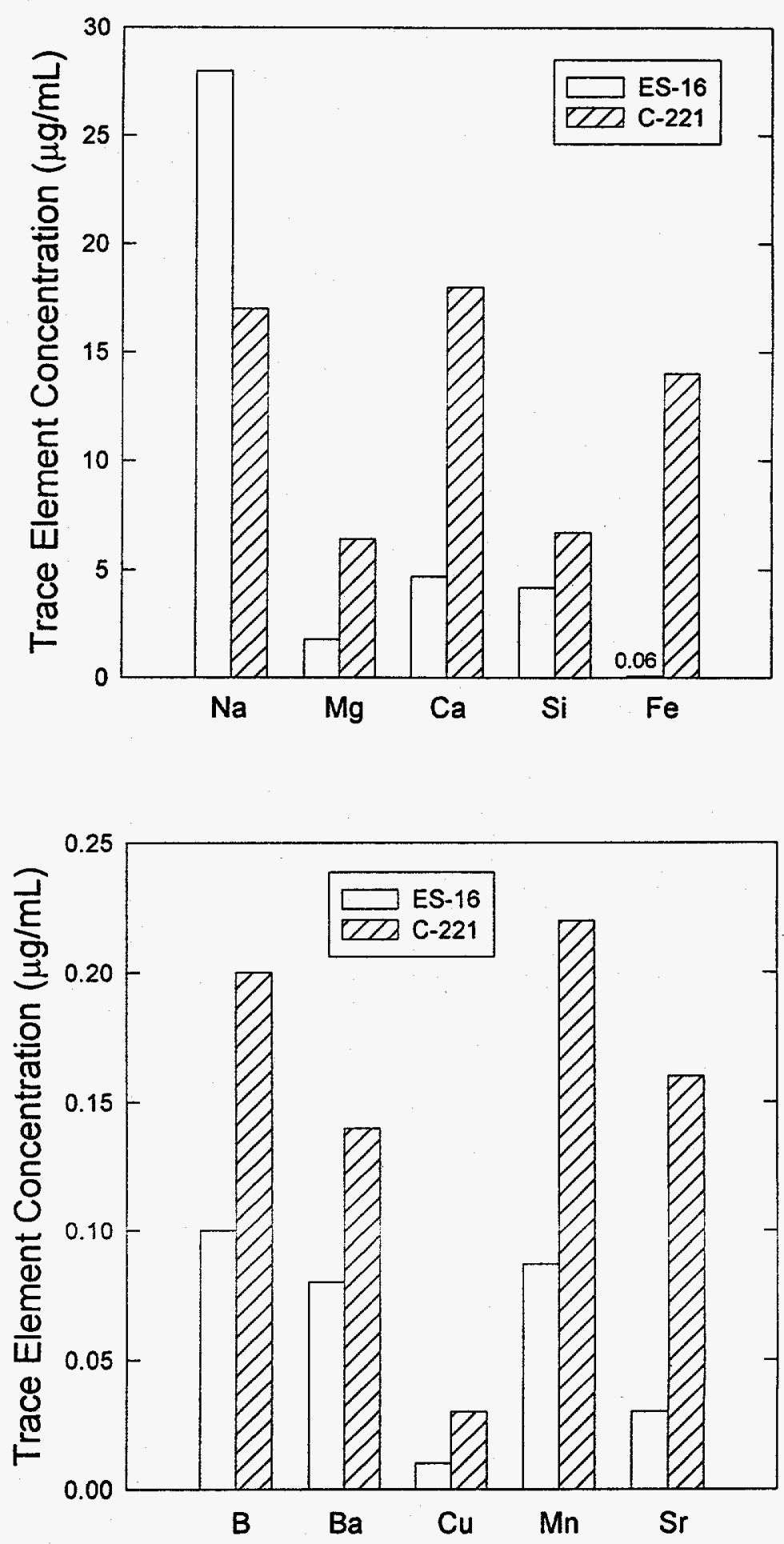
Figure 3.3 Ionic speciation of well ES-16 (1991)

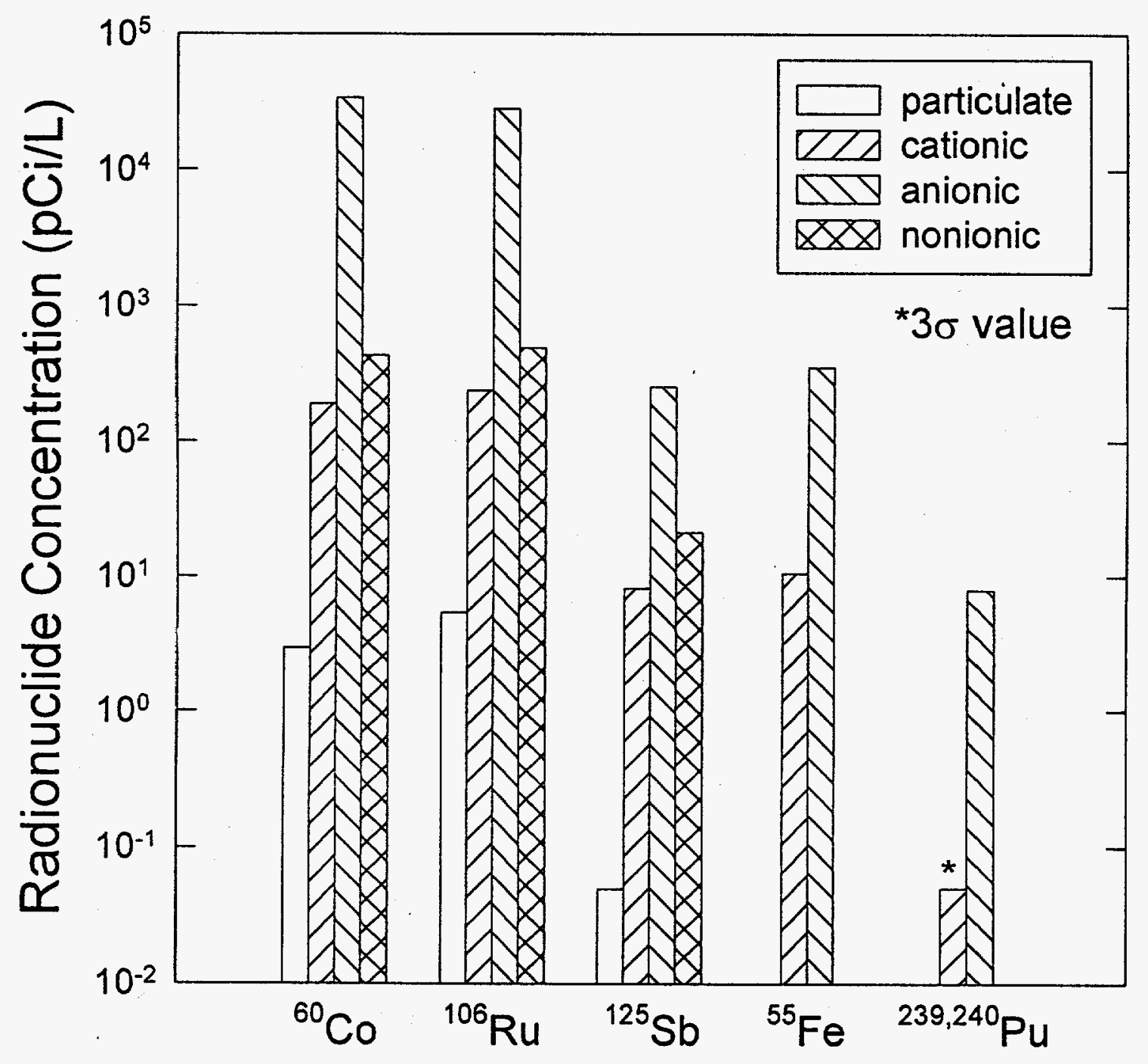


Figure 3.4 Ionic speciation of well C-221 (1991)

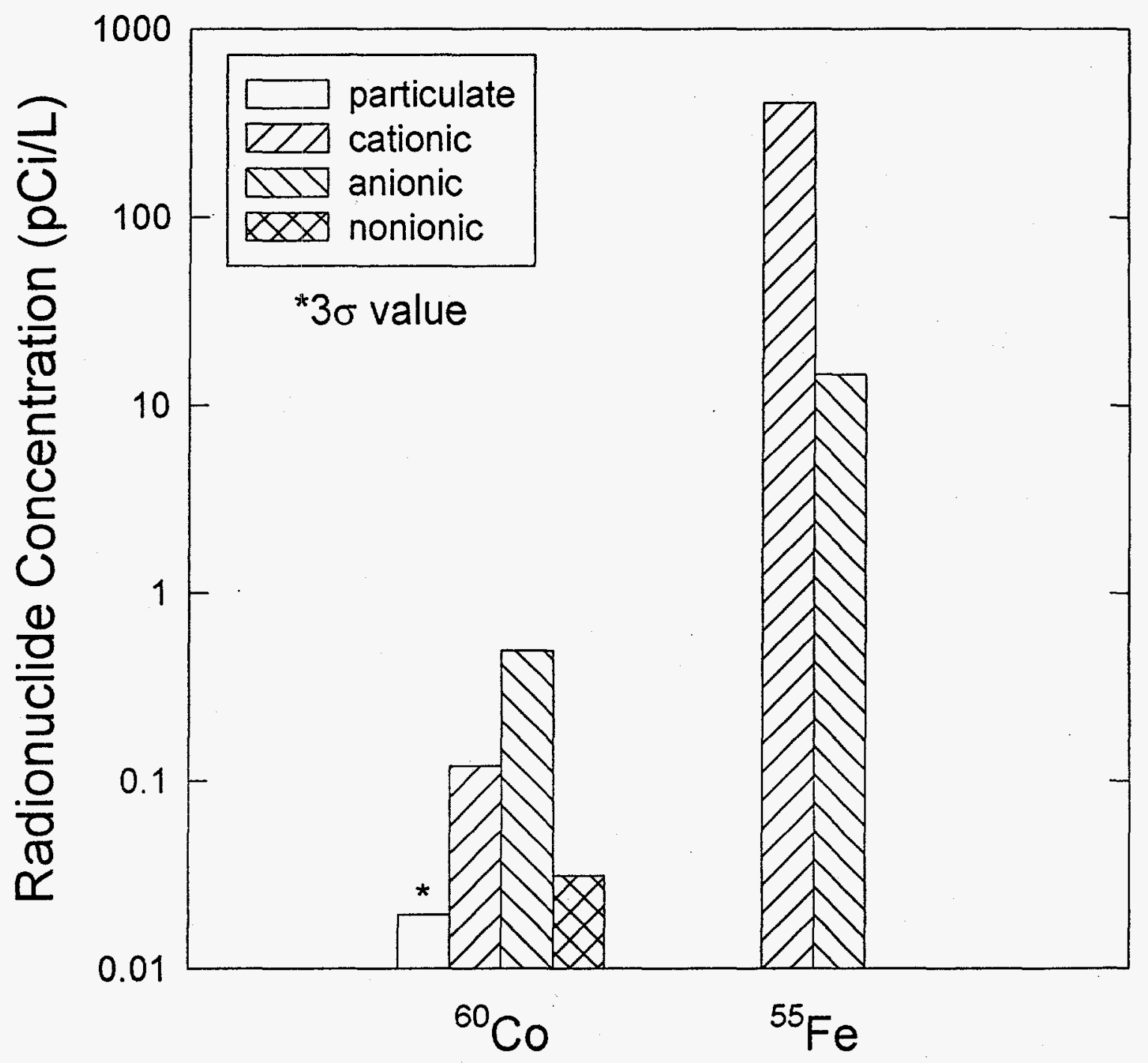


Table 3.1 Wet chemistry results from the Chemical Pit and Area C

\begin{tabular}{|c|c|c|c|c|c|c|c|}
\hline $\begin{array}{c}\text { Well } \\
\text { No. }\end{array}$ & $\begin{array}{c}\text { Sampling } \\
\text { Date }\end{array}$ & $\mathrm{pH}$ & $\begin{array}{c}\text { Eh } \\
(\mathrm{mV})\end{array}$ & $\begin{array}{c}\text { Dissolved } \mathrm{O}_{2} \\
(\mathrm{mg} / \mathrm{L})\end{array}$ & $\begin{array}{c}\text { Alkalinity } \\
(\mathrm{mg} / \mathrm{L})\end{array}$ & $\mathrm{Fe}^{2+} / \mathrm{Fe}^{3+}$ & $\begin{array}{c}\text { Total Fe } \\
(\mu \mathrm{g} / \mathrm{L})\end{array}$ \\
\hline $\mathrm{CP}-4$ & $8 / 30 / 93$ & 6.20 & 385 & 3.93 & 13.5 & 1.92 & - \\
\hline CP-4 & $10 / 18 / 94$ & 6.28 & 255 & 1.88 & 37.5 & - & 7.6 \\
\hline ES-39B & $8 / 29 / 93$ & 5.90 & 435 & 4.90 & 15.0 & 0.21 & 1.6 \\
\hline ES-16 & $9 / 30 / 91$ & 5.83 & 501 & 7.26 & 9.2 & 0.33 & 1.33 \\
\hline ES-16 & $8 / 30 / 93$ & 6.00 & 550 & 0.64 & 14.2 & 1.71 & 95 \\
\hline ES-16 & $10 / 18 / 94$ & 6.30 & 278 & 2.42 & 11.2 & - & - \\
\hline C-112 & $9 / 1 / 93$ & 6.00 & 355 & 1.45 & 75.0 & 1.45 & 27 \\
\hline C-221 & $10 / 2 / 91$ & 6.00 & 360 & 0.22 & 29.0 & 65.0 & 1320 \\
\hline C-213 & $8 / 31 / 93$ & 5.90 & 325 & 0.42 & 44.0 & 2.0 & 135 \\
\hline
\end{tabular}

Table 3.2 Ion chromatography results (1991)

\begin{tabular}{|c|c|c|r|r|r|r|r|}
\hline \multirow{2}{*}{$\begin{array}{c}\text { Well } \\
\text { No. }\end{array}$} & $\mathrm{F}$ & $\mathrm{Cr}$ & $\mathrm{NO}_{2}{ }^{-}$ & $\mathrm{Br}$ & $\mathrm{NO}_{3}{ }^{-}$ & $\mathrm{PO}_{4}{ }^{3 *}$ & $\mathrm{SO}_{4}{ }^{2 *}$ \\
\cline { 2 - 8 } & \multicolumn{7}{|c|}{ Concentration $(\mu \mathrm{g} / \mathrm{mL})$} \\
\hline ES-16 & 0.3 & 12 & $<0.5$ & $<0.25$ & 14.8 & $<0.5$ & 32 \\
\hline C-221 & $<0.25$ & 63 & $<0.5$ & $<0.25$ & $<0.5$ & $<0.5$ & 13.4 \\
\hline
\end{tabular}

Table 3.3 Trace element results via inductively-coupled argon plasma/atomic emission spectrometry (1991)

\begin{tabular}{|c|c|c|c|c|c|c|c|c|c|c|c|}
\hline $\begin{array}{c}\text { Well } \\
\text { No. }\end{array}$ & $\mathrm{Na}$ & $\mathrm{Mg}$ & $\mathrm{Ca}$ & $\mathrm{Si}$ & $\mathrm{Fe}$ & $\mathrm{B}$ & $\mathrm{Ba}$ & $\mathrm{Cu}$ & $\mathrm{Mn}$ & $\mathrm{Sr}$ \\
\cline { 2 - 11 } & \multicolumn{10}{|c|}{ Concentration $(\mu \mathrm{g} / \mathrm{mL})$} \\
\hline ES-16 & 28 & 1.8 & 4.7 & 4.2 & 0.06 & 0.1 & 0.08 & $<0.01$ & 0.08 & 0.03 \\
\hline C-221 & 17 & 6.4 & 18 & 6.7 & 14 & 0.2 & 0.14 & 0.03 & 0.22 & 0.16 \\
\hline
\end{tabular}

The results from this 1991 study also seem to suggest that particle-size fractionation may serve to effectively segregate individual species and allow further elucidation of their structure by other (e.g., spectroscopic) means. Figure 3.5 shows the relative proportions of ${ }^{60} \mathrm{Co}$ and ${ }^{106} \mathrm{Ru}$ retained by the separate prefilter membranes placed upstream of the ionexchange beds. A majority of the microparticulate and/or colloidal radionuclide species in the sampled groundwater resides in the smallest size fraction $(0.2$ $\mu \mathrm{m})$. This behavior is somewhat intuitive in that these smallest particles would exhibit the largest specific surface areas and, consequently, higher radionuclide-retention capabilities per unit mass. Indeed, a great deal of recent and projected research has targeted a variety of organic (e.g., humic and fulvic macromolecules) and inorganic microparticulate/ colloidal materials that are suspected of acting as vehicles for the facilitated transport of radionuclides and other contaminants of interest (Wobber 1991; Williams et al. 1991; Warwick et al.; 1991, Lieser et al. 1990 and 1986; McCarthy and Zachara 1989; McCarthy 1988; Ramsay 1988; Choppin 1988; Jensen and Jensen 1988; and Boggs et al. 1985). If significant size and speciation diversity does exist in the smaller submicron range, then ultrafiltration would seem an appropriate means of 
Table 3.4 Charge speciation and particulate natures of selected radionuclides (1991)

\begin{tabular}{|c|c|c|c|c|c|c|c|c|}
\hline \multirow{2}{*}{ Nuclide } & \multicolumn{4}{|c|}{ ES-16 Concentrations (pCi/L) } & \multicolumn{3}{c|}{ C-221 Concentrations (pCi/L) } \\
\cline { 2 - 9 } & Cationic & Anionic & Nonionic & Part. & Cationic & Anionic & Nonionic & Part. \\
\hline${ }^{60} \mathrm{Co}$ & 188.7 & 33860 & 430 & 3.0 & 0.12 & 0.495 & 0.03 & $<0.02$ \\
\hline${ }^{106} \mathrm{Ru}$ & 235 & 28070 & 490 & 5.4 & $<1.5$ & $<1.7$ & $<0.28$ & $<0.23$ \\
\hline${ }^{125} \mathrm{Sb}$ & 8.13 & 251 & 21.3 & 0.05 & $<0.75$ & $<0.87$ & $<0.14$ & - \\
\hline${ }^{239,240} \mathrm{Pu}$ & $<0.05$ & 7.89 & - & - & $<0.001$ & $<0.004$ & - & - \\
\hline${ }^{55} \mathrm{Fe}$ & 10.53 & 351.32 & - & - & 403.74 & 14.67 & - & - \\
\hline
\end{tabular}

separating individual migration species into "purer" fractions, thereby facilitating further detailed radionuclide speciation studies (see Sections 3.4 and 3.5).

The results of the sampling effort in 1993 to segregate the migrating radionuclides as a function of charge speciation are summarized in Table 3.5. As in 1991, anionic species of $\mathrm{Co}, \mathrm{Ru}$, and $\mathrm{Sb}$ are seen to dominate in the Chemical Pit (with the exception of ${ }^{125} \mathrm{Sb}$ at $\mathrm{CP}$ 4, which appears to be a neutral species; see Figures 3.6-3.9). Gamma-emitting radionuclide concentrations in Area $\mathrm{C}$ groundwater were extremely low, but showed traces of anionic ${ }^{60} \mathrm{Co}$ and ${ }^{106} \mathrm{Ru}$. In the Chemical Pit groundwater, nonionic forms of these radionuclides are generally intermediate in abundance, and cationic forms have the lowest concentrations. At Area $\mathrm{C}$, however, cationic forms of ${ }^{60} \mathrm{Co}$ exceed the concentrations of uncharged species for this isotope. Cobalt content exceeds that of $\mathrm{Ru} 10 \mathrm{~m}$ downgradient of the Chemical Pit at well CP-4, but the condition is reversed in the mid and far fields ( $22 \mathrm{~m}$ and $40 \mathrm{~m}$ from the point of dispersal, respectively).

Few claims can be made with regard to charge speciation as a function of migration distance or time because of dispersal due to non-steady-state discharge practices and variable redox conditions along the plume axis. It is useful, however, to note the differences between charged- and uncharged-species concentrations in this dimension. Figures 3.10-3.12 summarize the 1993 results for ${ }^{60} \mathrm{Co}$, ${ }^{106} \mathrm{Ru}$, and ${ }^{125} \mathrm{Sb}$ from this perspective. In each case, the highest concentrations exist in the near field at well $\mathrm{CP}-4$ (regardless of the charge form), with somewhat lower radionuclide contents in the far field at ES-16 and much lower specific activities at the intermediate distance (ES-39B). This bimodal behavior ${ }^{6}$ may be a manifestation of two distinct radionuclide plumes, one present near the point of dispersal (CP-4) and the other resulting from the holdup of radionuclides in the far-field wetland area (ES16). This phenomenon is most apparent for the cationic and uncharged species, but less so for the anionic component. Although the negatively charged species also have the highest abundances at CP-4 and ES-16, the less-pronounced near-midfar-field disparity may imply that these species are less susceptible to varying redox conditions and/or are more consistently (although weakly) retarded by the aquifer matrix along the plume axis.

Figures 3.13-3.15 provide additional information with respect to possible inter-species disequilibria during migration from the Chemical Pit. In the case of ${ }^{60} \mathrm{Co}$ (Figure 3.13), anionic species become slightly more prevalent between $\mathrm{CP}-4$ and ES-39B (despite the fact that the total anionic concentration actually decreases), seemingly at the expense of both cationic and nonionic forms. Between ES-39B and ES-16, the proportion of anionic Co remains roughly constant (while the total concentration increases) and nonionic species are apparently converted to cations. Figure 3.14 suggests that anionic $\mathrm{Ru}$ is produced midfield from nonionic species, while the opposite occurs in transit to the far field. Antimony-125 (Figure 3.15) appears to originate in an uncharged form, convert to anionic species midfield, and revert to nonionic forms further downgradient.

The above hypotheses are based on the assumption that steadystate conditions existed in the Chemical Pit discharge zone in terms of the total volumes of waste discharged, the concentrations of the discharged radionuclides, and the redox environment along the plume axis. As this assumption is overly simplistic, the above claims should be taken only at face value. Figure 3.16 provides additional evidence of the changing

\footnotetext{
"Based on the assumption that waters sampled from each well are representative
of "equivalent" regions of the contaminant plume.

"Based on the assumption that waters sampled from each well are representative
of "equivalent" regions of the contaminant plume.
} 
Results

Figure 3.5 Relative proportions of ${ }^{60} \mathrm{Co}$ and ${ }^{106} \mathrm{Ru}$ at ES-16 with respect to particle size (1991)

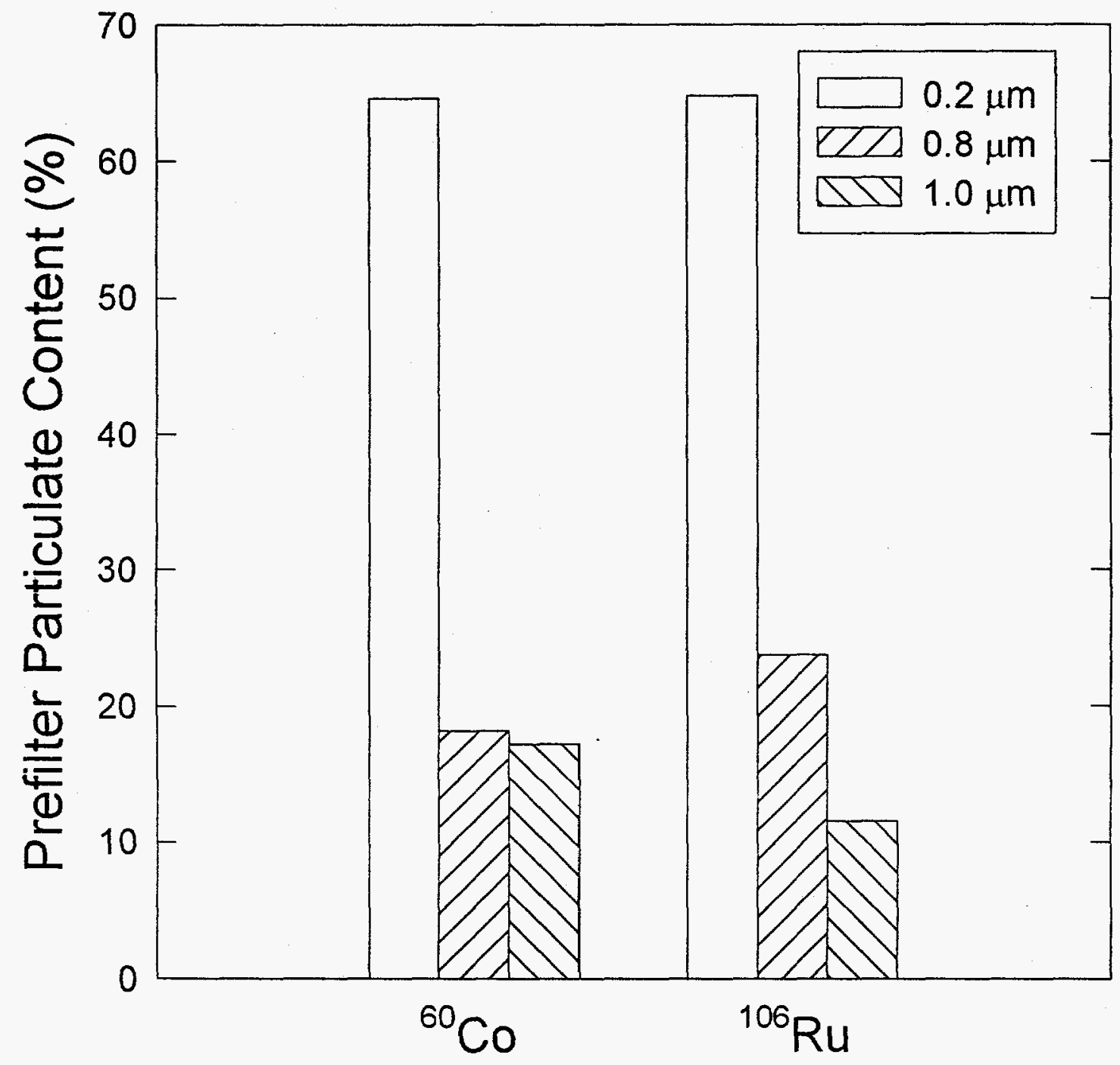


Figure 3.6 Charge speciation results for well CP-4 (1993)

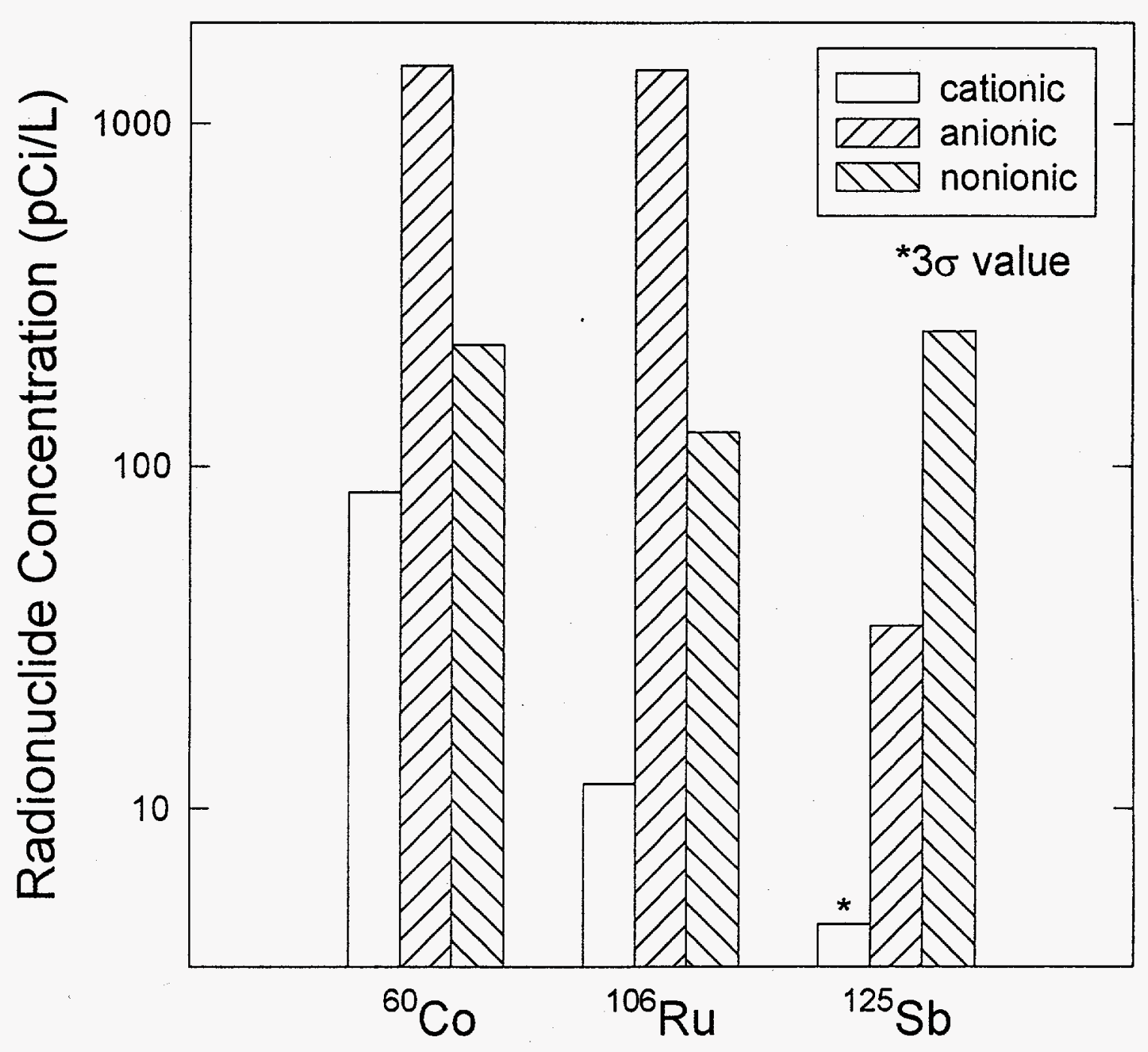


Results

Figure 3.7 Charge speciation results for well ES-39B (1993)

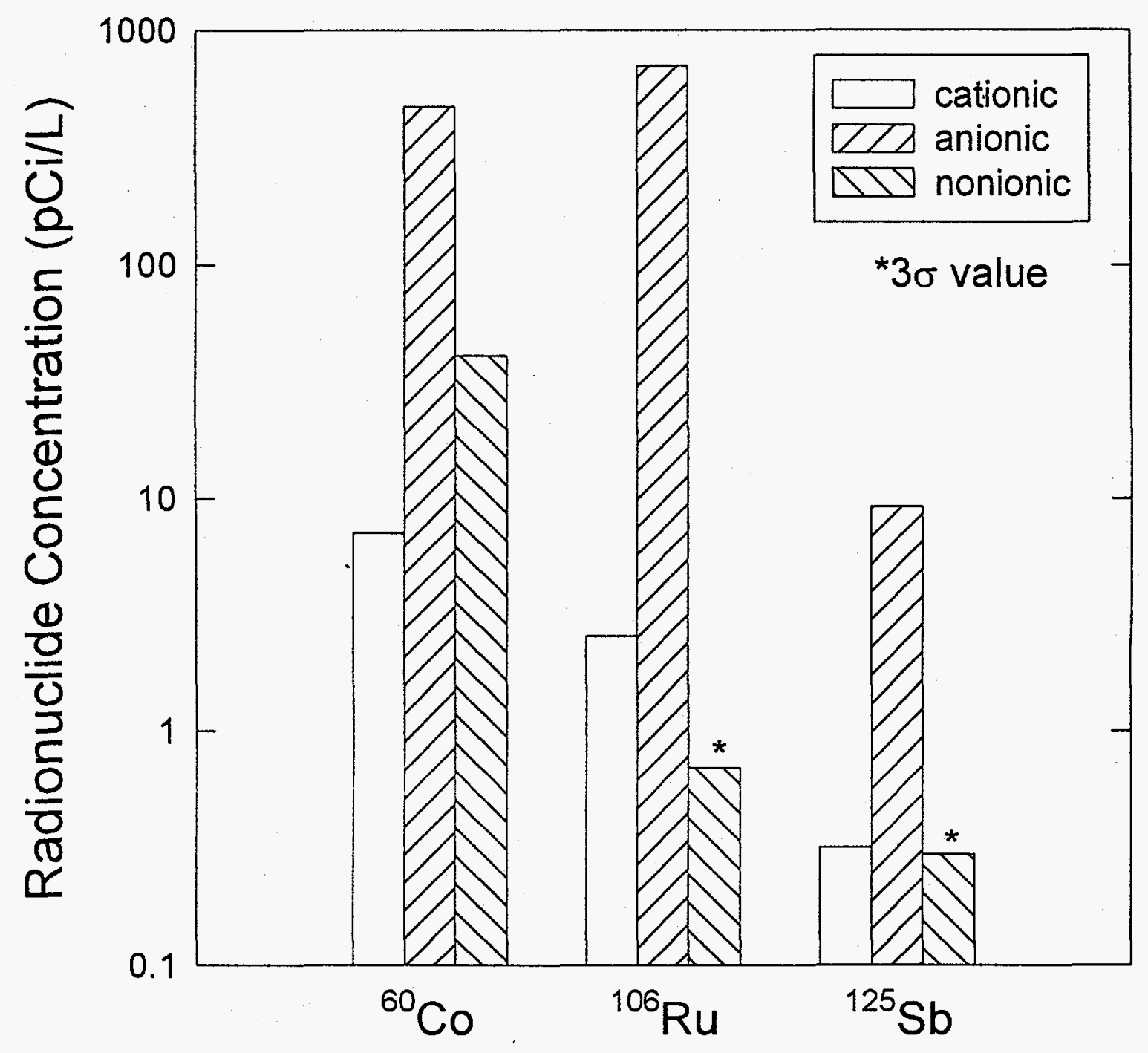


Radionuclide Concentration $(\mathrm{pCi} / \mathrm{L}$ )

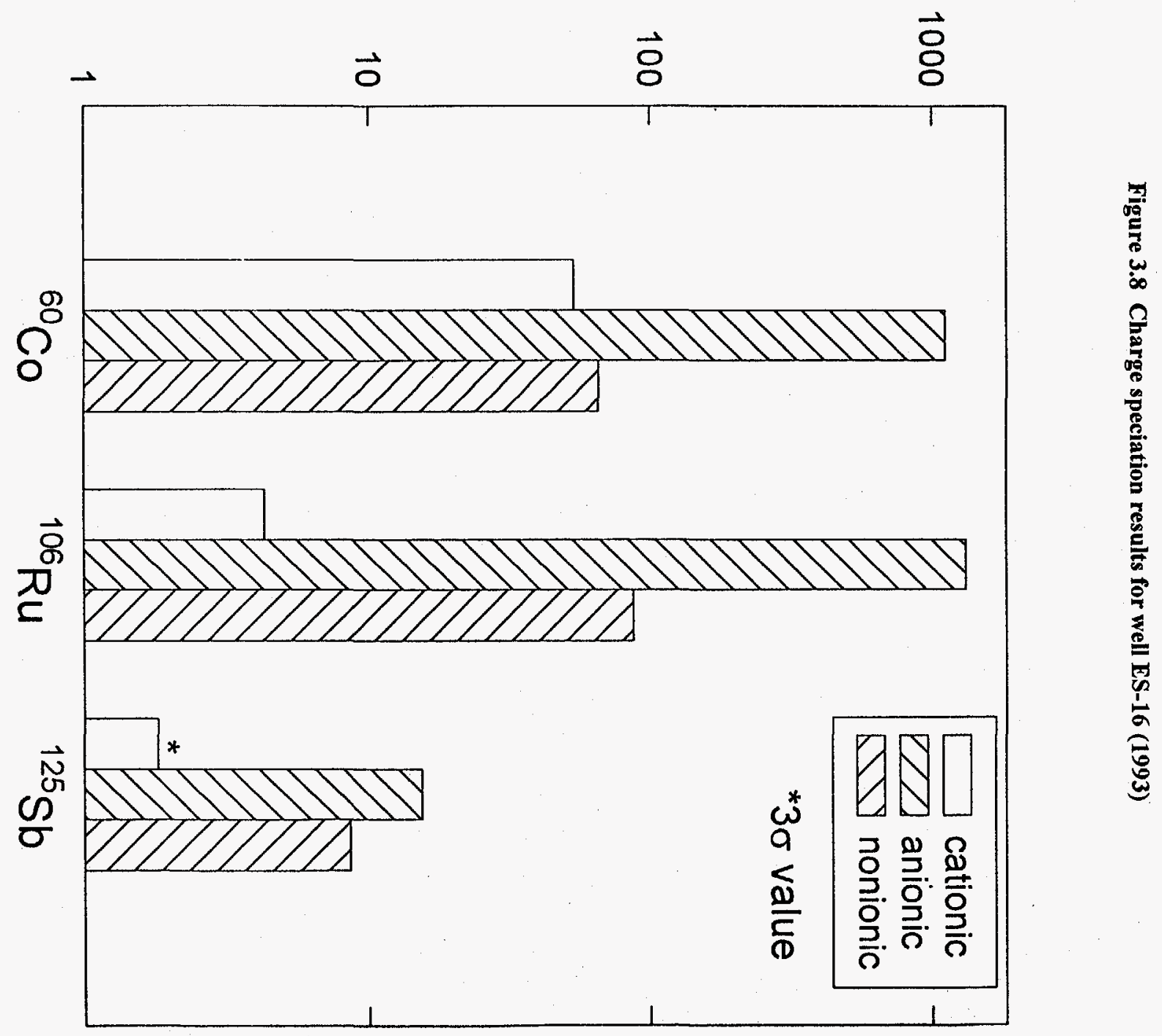


Results

Figure 3.9 Charge speciation results for A rea C wells (1993)

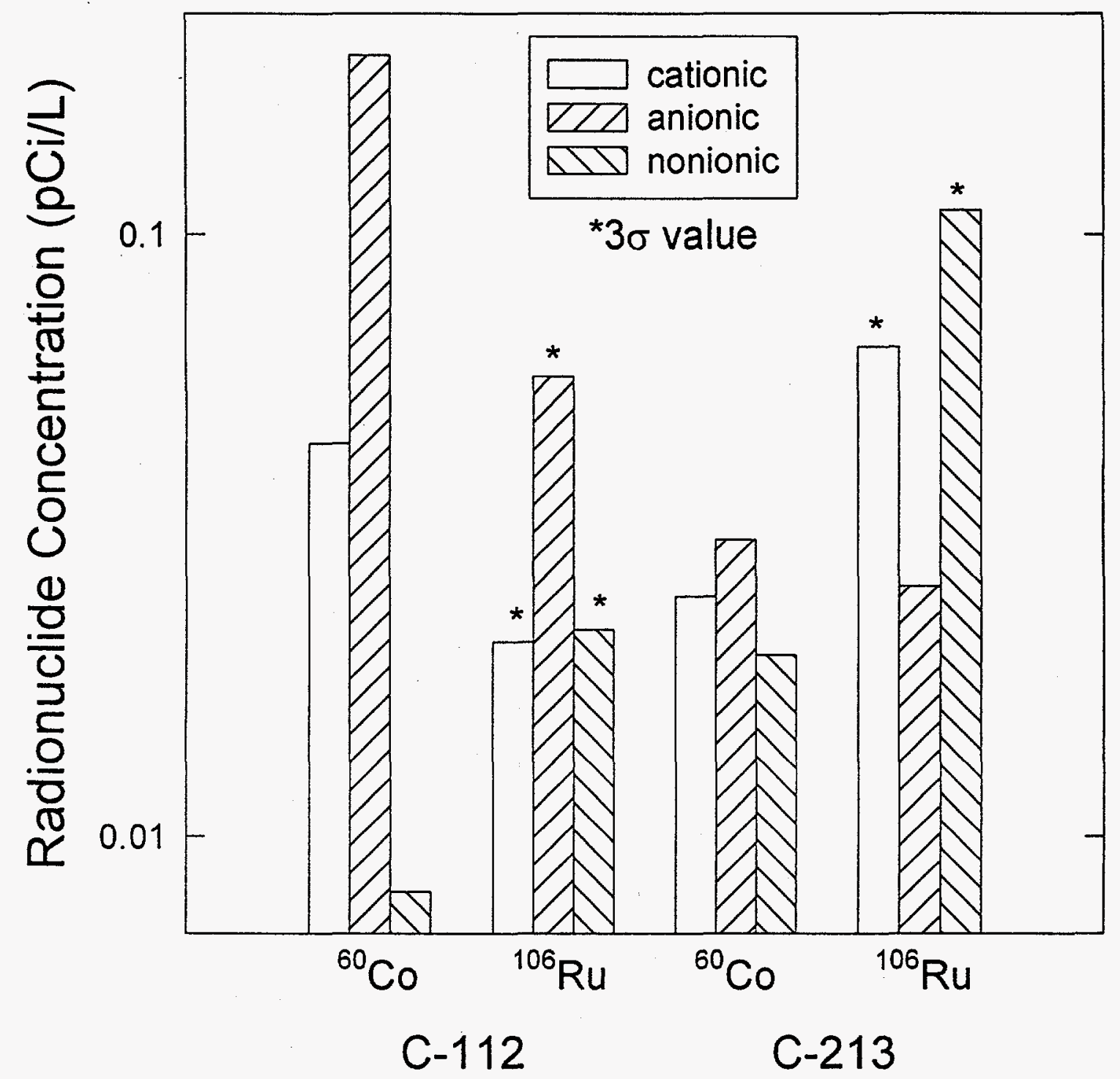


Figure 3.10 Cobalt-60 charge speciation as a function of distance from the Chemical Pit (1993)

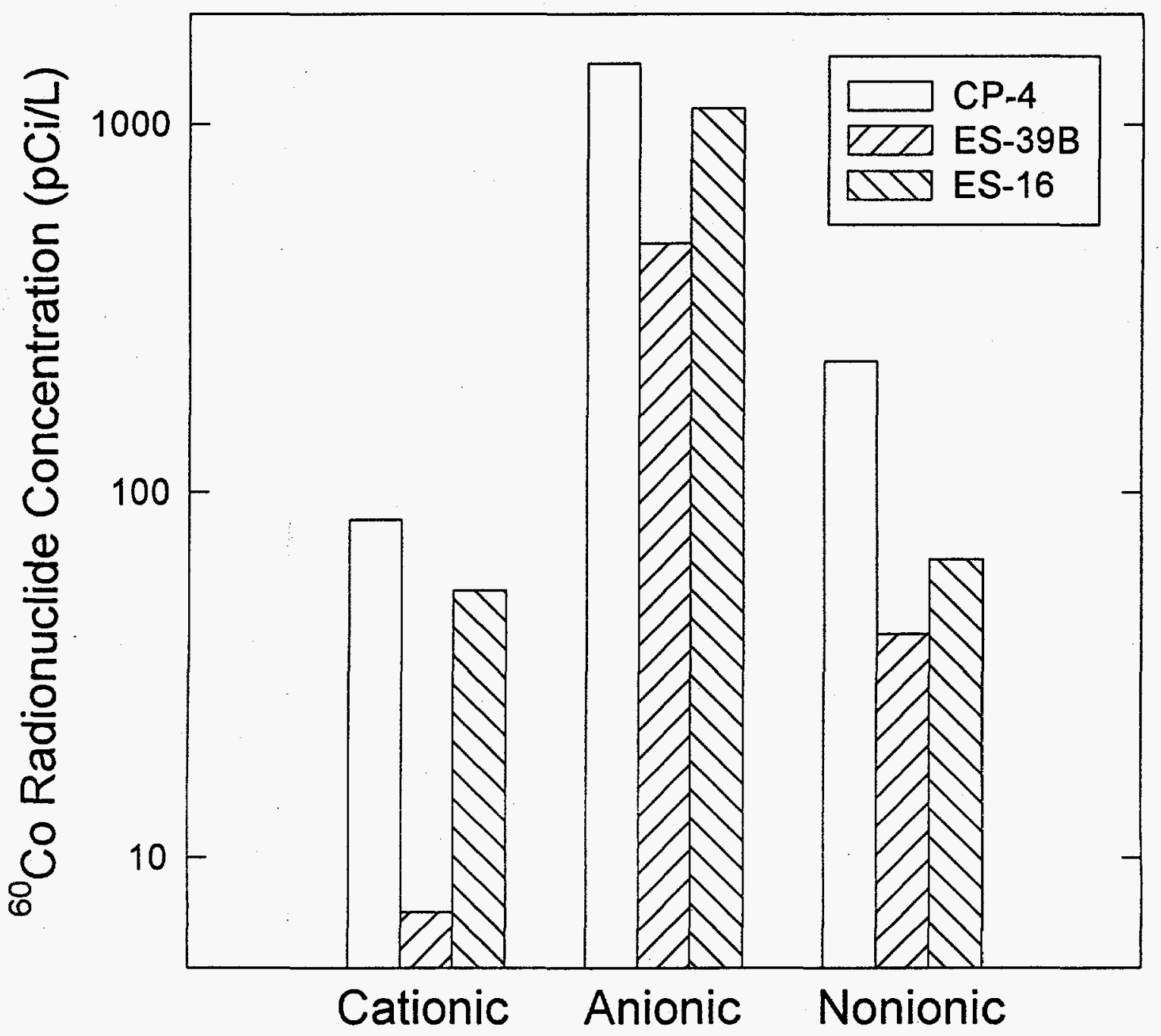


${ }^{106} \mathrm{Ru}$ Radionuclide Concentration (pCi/L)

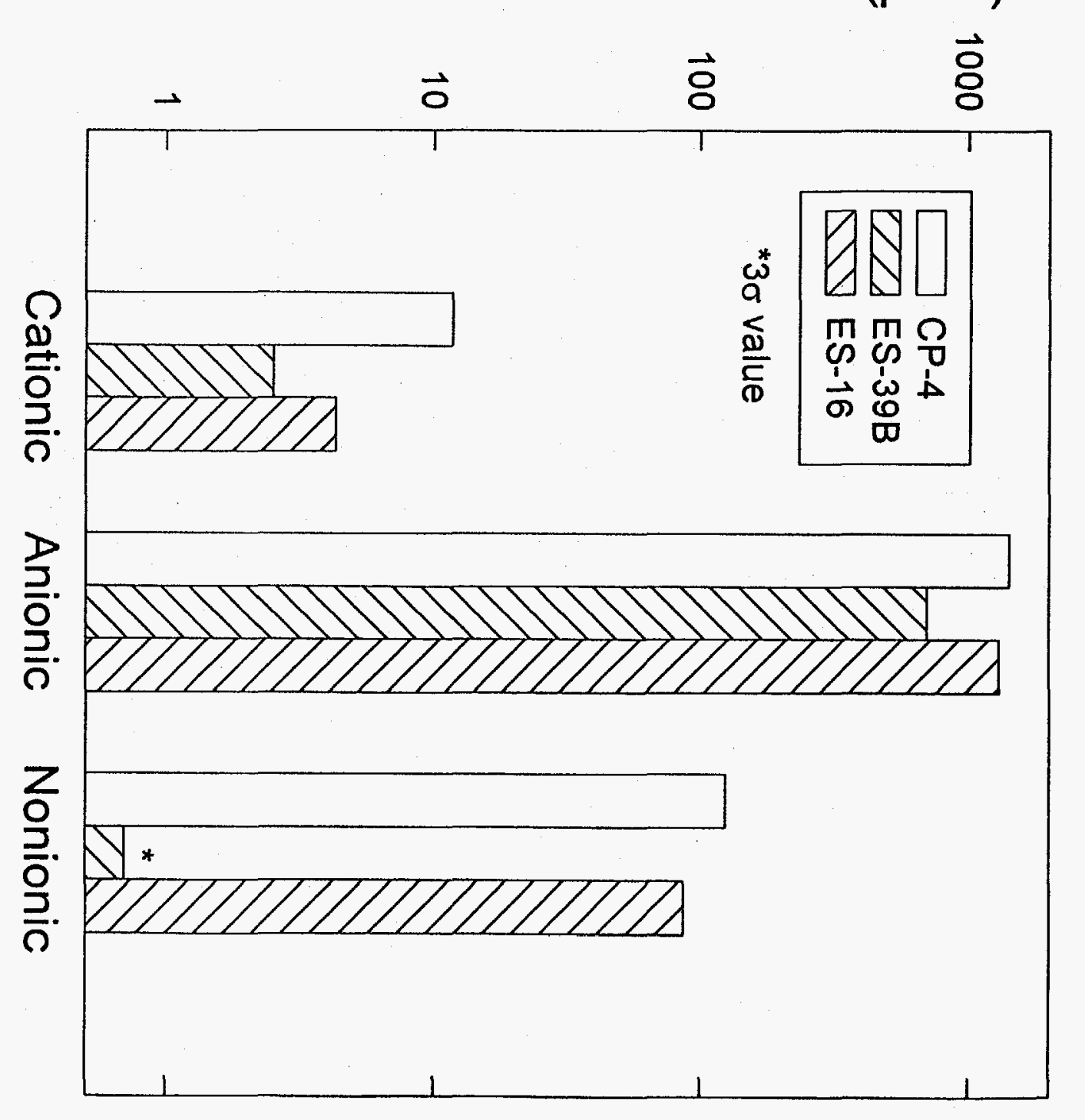


Figure 3.12 Antimony-125 charge speciation as a function of distance from the Chemical Pit (1993)

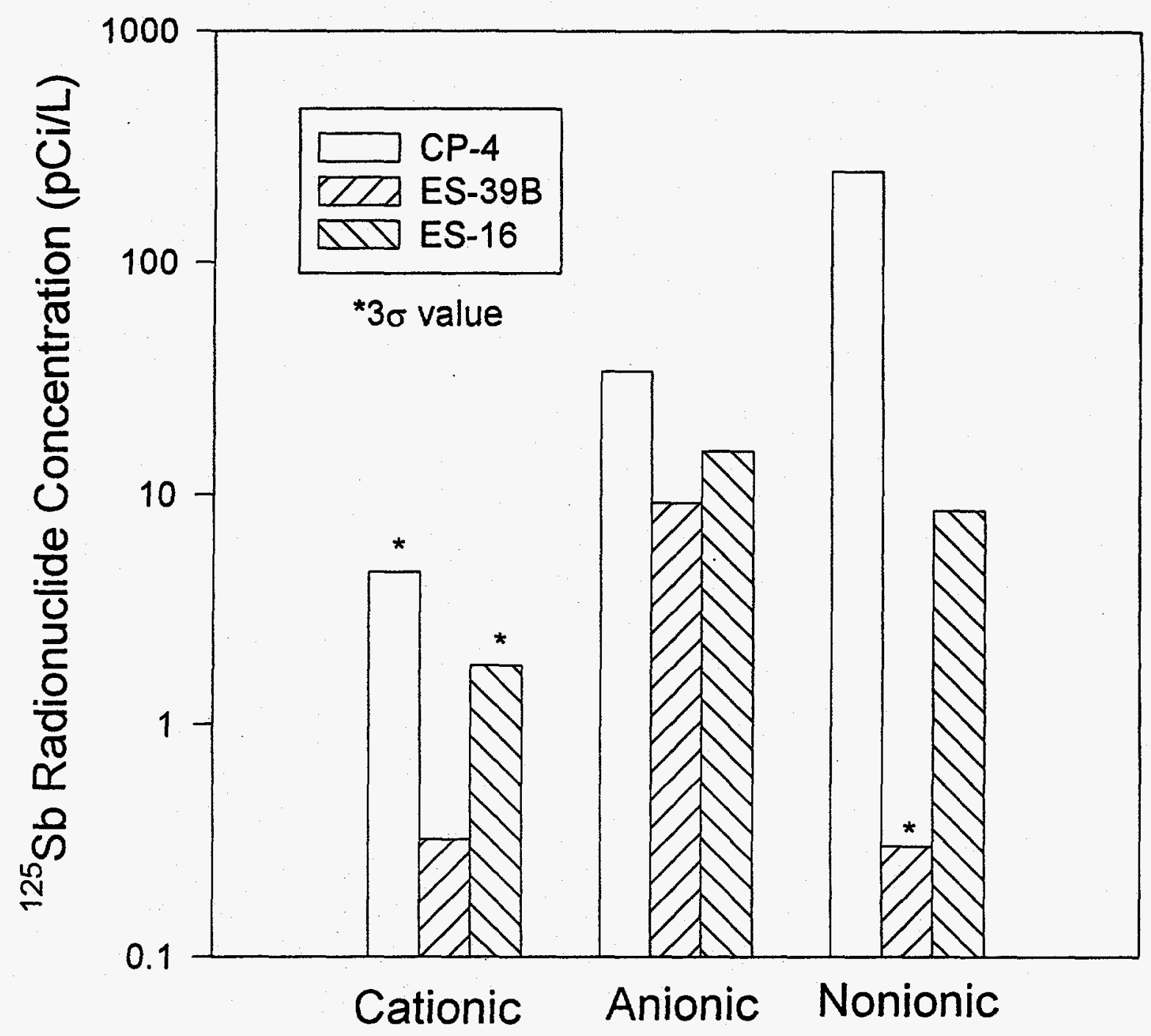


Results

Figure 3.13 Relative proportions of ${ }^{60} \mathrm{Co}$ charged species at the Chemical Pit (1993)

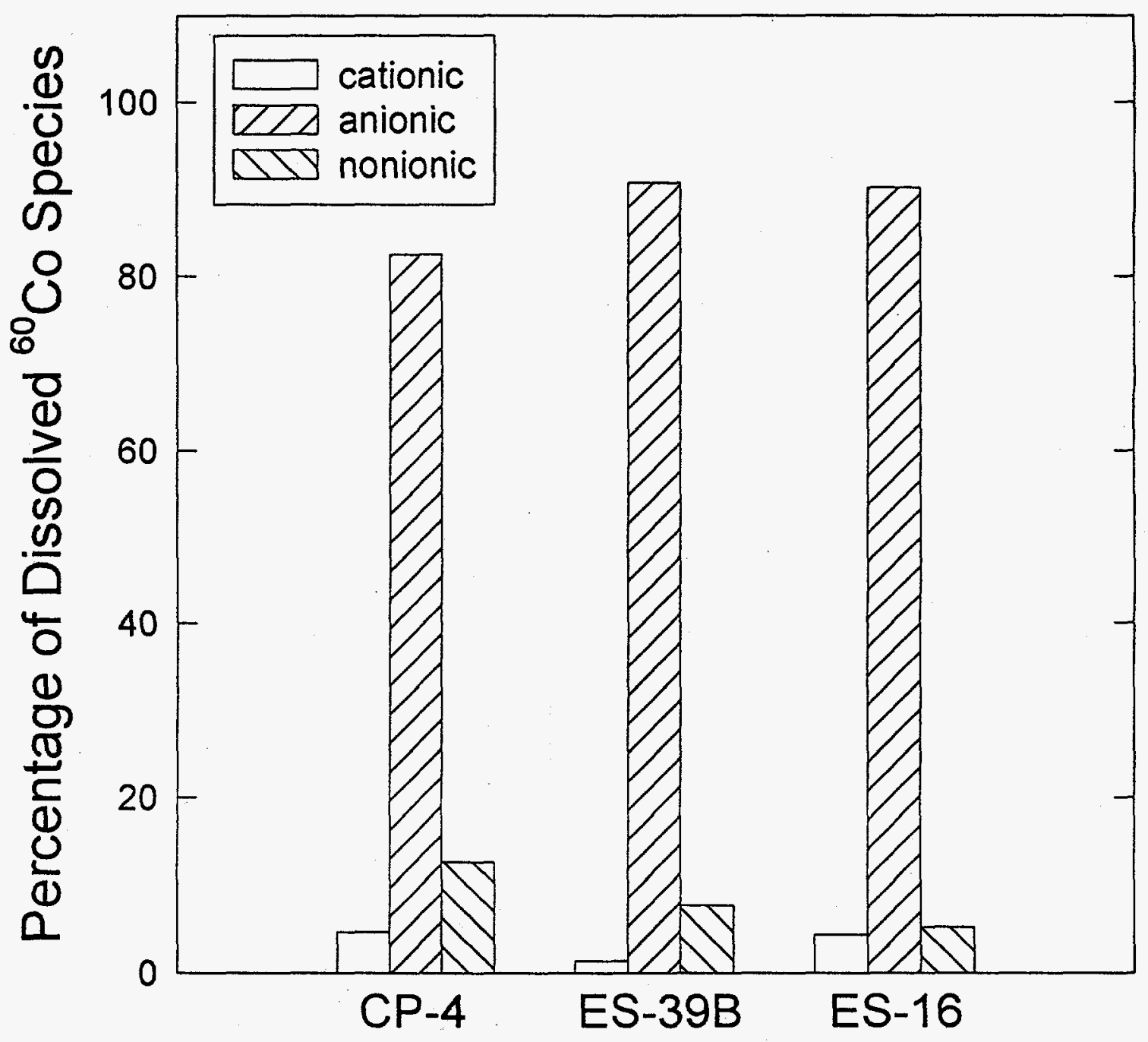


Figure 3.14 Relative proportions of ${ }^{106} \mathrm{Ru}$ charged species at the Chemical Pit (1993)

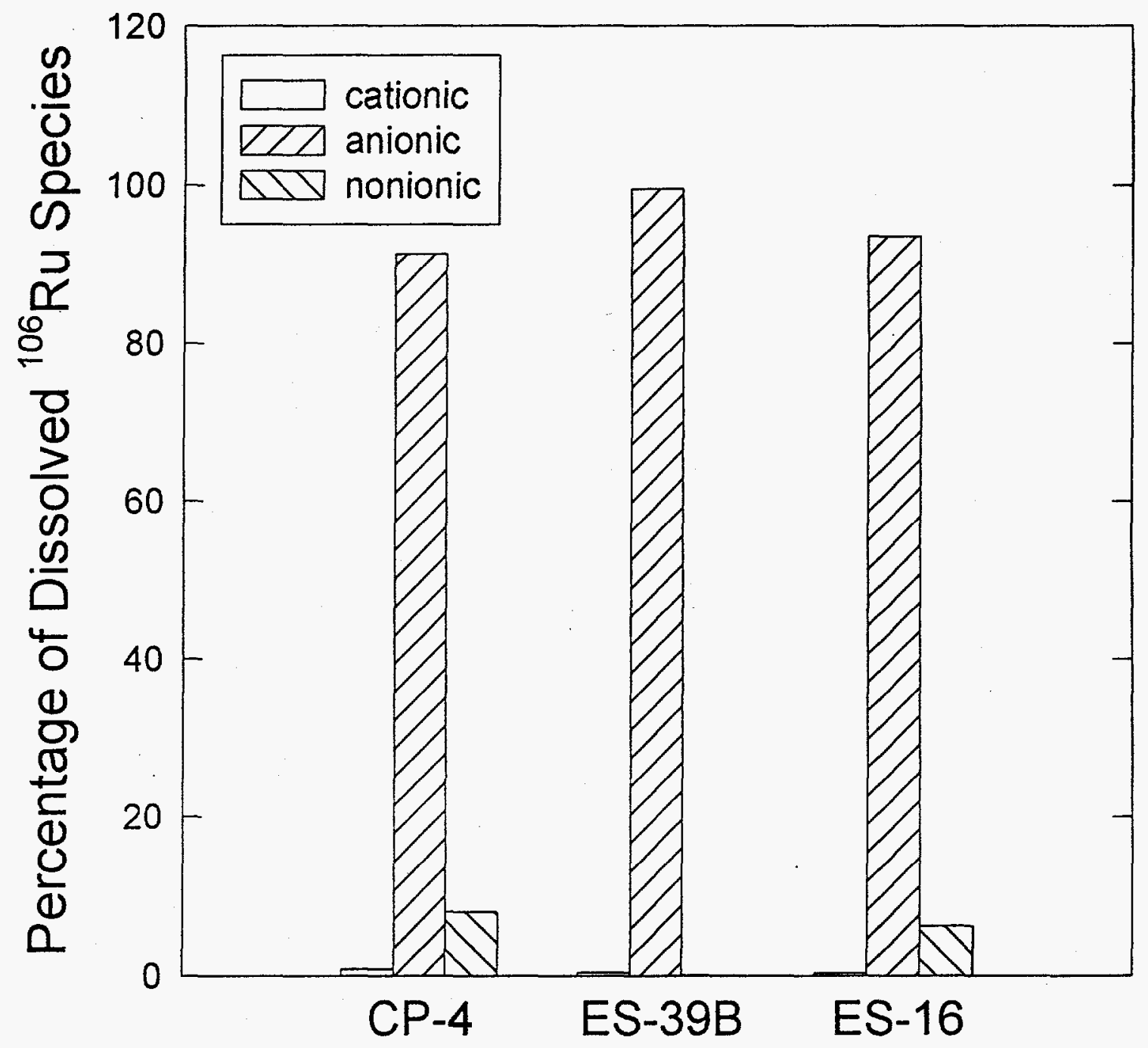


Results

Figure 3.15 Relative proportions of ${ }^{125}$ Sb charged species at the Chemical Pit (1993)

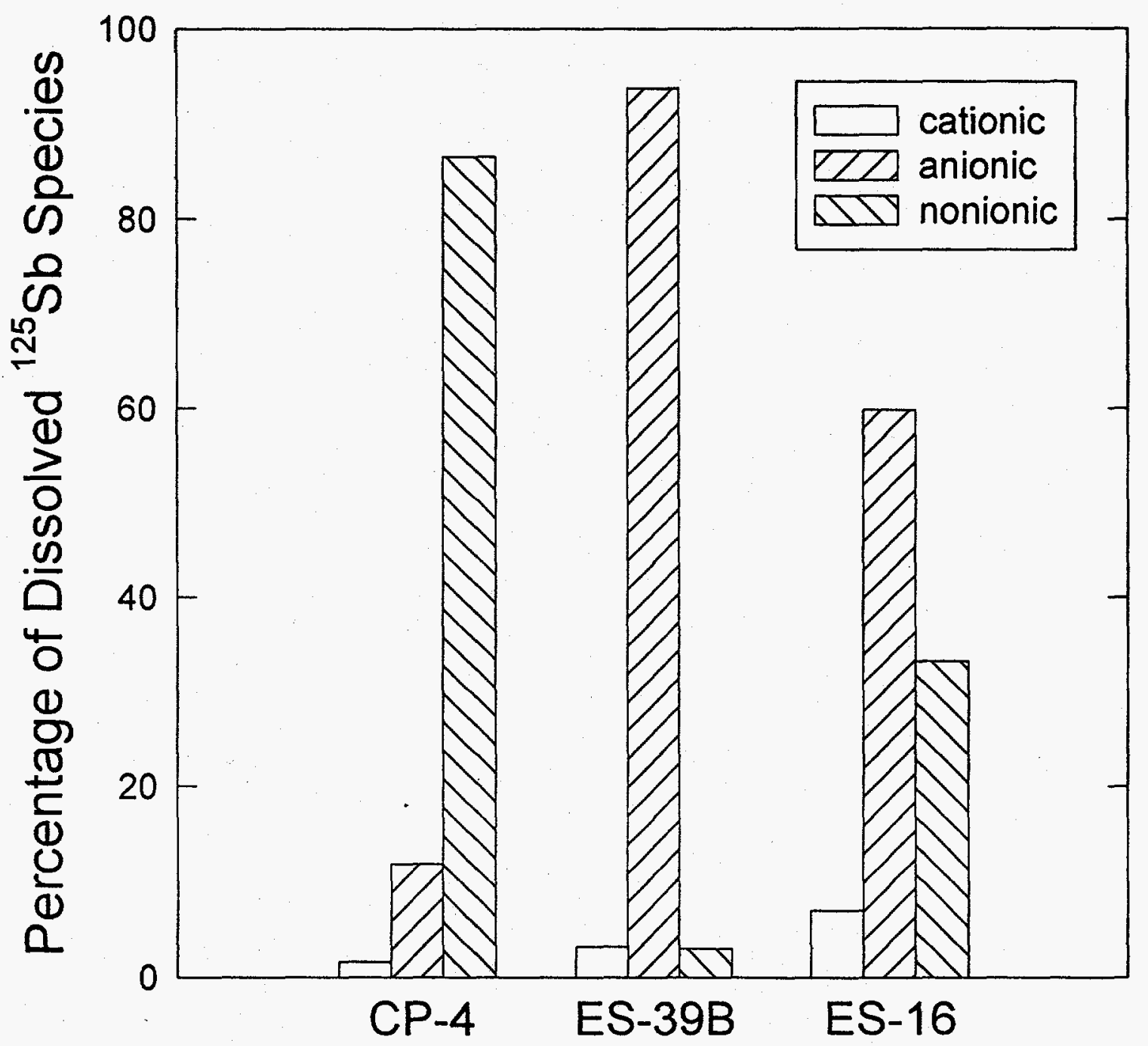


Figure 3.16 Changes in speciation at well ES-16 between 1991 and 1993

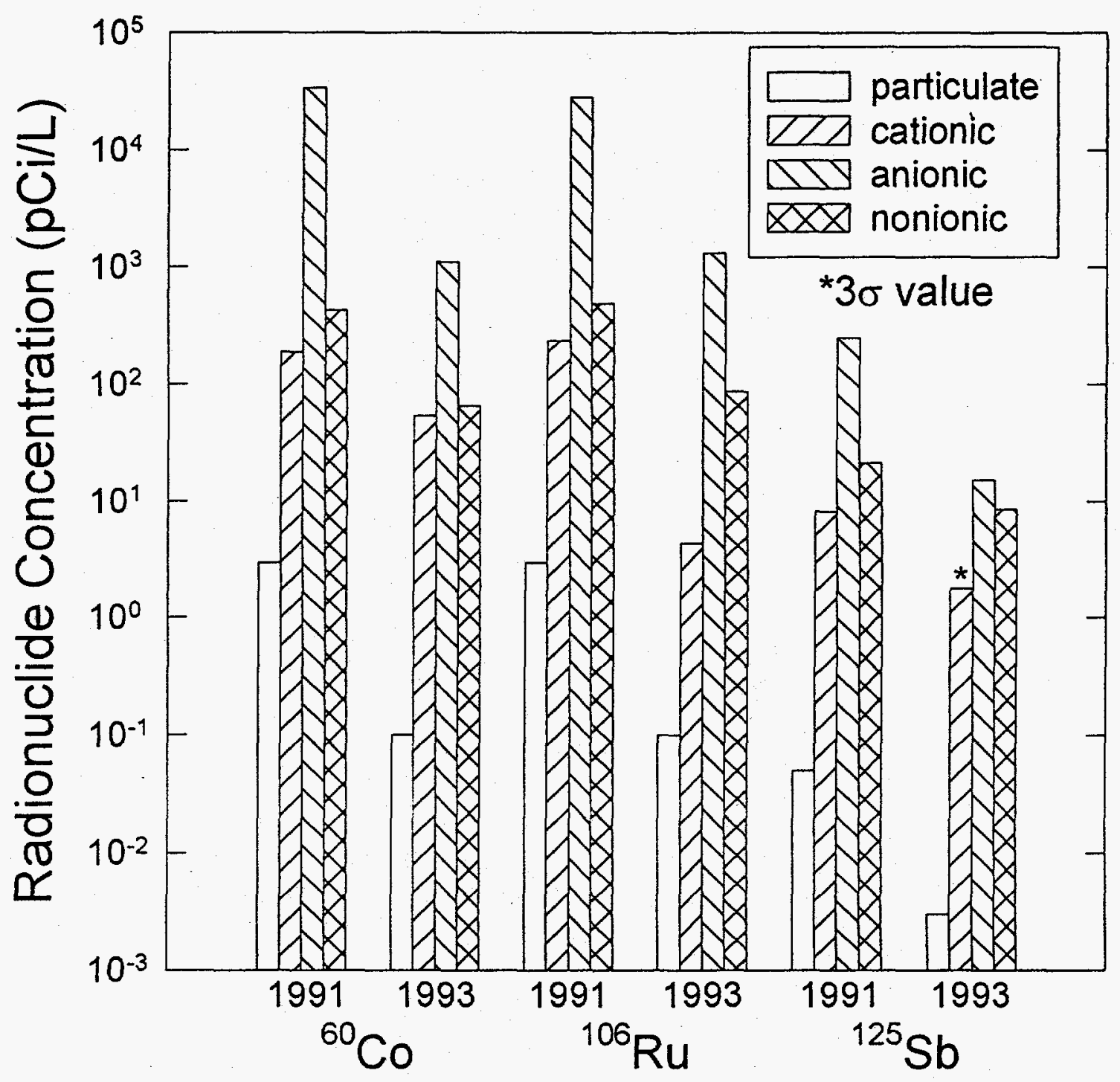


Table 3.5 Charge speciation results for selected radionuclides (1993)

\begin{tabular}{|c|c|c|c|c|c|c|}
\hline \multicolumn{2}{|c|}{ Nuclide/Charge } & $\mathrm{CP}-4$ & ES-39B & ES-16 & $\mathrm{C}-112$ & $C-213$ \\
\hline & & \multicolumn{5}{|c|}{ Concentration $(\mathrm{pCi} / \mathrm{L})$} \\
\hline \multirow[t]{3}{*}{${ }^{60} \mathrm{Co}$} & Cationic & 84.1 & 7.11 & 53.7 & 0.045 & 0.025 \\
\hline & Anionic & 1470 & 474 & 1110 & 0.199 & 0.031 \\
\hline & Nonionic & 226 & 40.9 & 65.7 & 0.008 & 0.020 \\
\hline \multirow[t]{3}{*}{${ }^{106} \mathrm{Ru}$} & Cationic & 11.8 & 2.52 & 4.31 & $<0.021$ & $<0.065$ \\
\hline & Anionic & 1430 & 704 & 1310 & $<0.058$ & 0.026 \\
\hline & Nonionic & 125 & $<0.7$ & 87.0 & $<0.022$ & $<0.11$ \\
\hline \multirow[t]{3}{*}{${ }^{125} \mathrm{Sb}$} & Cationic & $<4.6$ & 0.32 & $<1.8$ & - & - \\
\hline & Anionic & 34.1 & 9.25 & 15.4 & - & - \\
\hline & Nonionic & 247 & $<0.3$ & 8.54 & - & - \\
\hline
\end{tabular}

concentrations and charged-species proportions at ES16 between 1991 and 1993. Cobalt-60, ${ }^{106} \mathrm{Ru}$, and ${ }^{125} \mathrm{Sb}$ concentrations at this location are seen to decrease over a 2-year period ${ }^{7}$, and inter-species proportions are somewhat variable despite the fact that the qualitative relationships between these individual species remain constant.

The concentrations of the most abundant dissolved radionuclides along the Chemical Pit flowpath (as of 1993) are presented in Table 3.6. These results indicate that ${ }^{60} \mathrm{Co}$ and ${ }^{90} \mathrm{Sr}$ concentrations decrease with distance from the dispersal area (as expected for any partially retarded species), whereas ${ }^{106} \mathrm{Ru}$ activity actually increases along this dimension. Again, this apparent discrepancy may simply be a function of the variable discharge history at the Chemical Pit. The increasing $\mathrm{Ru}$ concentrations could be analogous to the trailing edge of an analyte in a chromatographic column (e.g., the aquifer medium) through which the bulk of the analyte has already passed.

One of the most notable observations is the continued presence of ${ }^{3} \mathrm{H}$ (as HTO), even though no transfers of contaminated water to the Chemical Pit had been reported during the previous year. Because the HTO moves at the same velocity as the transporting groundwater, all tritiated water was anticipated to have been completely flushed from this flow system.

\footnotetext{
'There had been no discharges to the Chemical Pit for at least one year prior to the 1993 sampling effort.
}

Earlier estimates of groundwater flow velocity suggested that the residence time between the Chemical Pit and well ES-16 is on the order of $\sim 170$ days. Since appreciable quantities of ${ }^{3} \mathrm{H}$ were still observable in CP-4A $\sim 10 \mathrm{~m}$ downgradient of the nearest infiltration pit boundary), either the groundwater flow velocity estimates are in error by at least a factor of 10 , or there was still a supply of ${ }^{3} \mathrm{H}$ to the local aquifer.

Two possible sources exist for the presence of this tritiated water. The first scenario involves the drainage and flushing of residual wastewater from the Chemical Pit. During the drilling of boreholes CHPT-1 and CHPT-2, which are situated within the infiltration pits, water cascaded down the hollow-stem augers after the base of the pits had been penetrated. This observation confirmed the presence of perched water in the pits. This checking of the downward flow of discharged water and the creation of a local perched-water reservoir has been attributed to the "clogging" of vadose sands by particulate materials transferred to the Chemical Pit. Whether this phenomenon is sufficient to maintain wastewater and previously released ${ }^{3} \mathrm{H}$ in the pit for a protracted period is uncertain.

Another plausible source of ${ }^{3} \mathrm{H}$ in the Chemical Pit plume exists. A pipeline used for transferring water to Reactor Pit \#2 runs roughly parallel to the northwest (upgradient) fence surrounding the Chemical Pit (refer to Figure 1.2) and passes through a valve house located beside this compound. Any leakage from this section of the Reactor Pit pipeline would infiltrate the aquifer, flow downgradient, and mingle with contamination discharged directly to the Chemical Pit. Support for this leaky-pipeline hypothesis is afforded by the detection of ${ }^{103} \mathrm{Ru}$ in groundwater from well ES-16 by one of the authors (E.L. Cooper) in 1993. 
Table 3.6 Dissolved radionuclide concentrations downgradient from the Chemical Pit (1993)

\begin{tabular}{|c|c|c|c|c|c|}
\hline \multirow{2}{*}{$\begin{array}{c}\text { Well } \\
\text { No. }\end{array}$} & ${ }^{3} \mathrm{H}$ & ${ }^{106} \mathrm{Ru}$ & ${ }^{60} \mathrm{Co}$ & ${ }^{137} \mathrm{Cs}$ & ${ }^{90} \mathrm{Sr}$ \\
\cline { 2 - 6 } & \multicolumn{5}{|c|}{ Concentration (nCi/L) } \\
\hline CP-4A & 1091 & 11 & 16 & - & 44 \\
\hline ES-39B & 1905 & 14 & 15 & - & 42 \\
\hline ES-16W & 270 (est.) & 20 & 9 & $<1.4$ & 27 \\
\hline
\end{tabular}

\subsection{Radiological Analyses of Soils from Boreholes}

The results of gamma-ray analyses of soils collected from beneath the Chemical Pit (borehole CHPT-2) are given in Table 3.7, along with data from the analyses of composite samples from wells CP-4A, ES-39A, and ES-16A. Table 3.8 provides results from ${ }^{60} \mathrm{CO}$ and ${ }^{90} \mathrm{Sr}$ analyses of individual soil samples from the latter three boreholes. Neither ${ }^{60} \mathrm{Co}$ nor ${ }^{106} \mathrm{Ru}$ appears to exhibit any readily definable trend in concentration versus distance from the source, apart from the fact that ${ }^{60} \mathrm{Co}$ concentrations are significantly higher immediately beneath the infiltration pit than at points farther downgradient. This lack of a largescale trend might be interpreted as evidence that the sampling locations are not along a single flowline. Assuming a uniform infiltration through the base of the trapezoidal portion of the Chemical Pit, however, one might propose that the source area is large enough that deviations in sample locations from a single flowline would not be significant. The similarity in dissolved ${ }^{60} \mathrm{Co},{ }^{106} \mathrm{Ru}$, and ${ }^{90} \mathrm{Sr}$ concentrations (Table 3.6) might be interpreted as support for such an inference. The fact that no significant correlation exists between ${ }^{60} \mathrm{Co}$ and ${ }^{90} \mathrm{Sr}$ in soil samples from individual boreholes, however, implies that input functions and/or system chemistry may have resulted in appreciable differences in contaminant behavior even over short distances.

Although Table 3.6 indicates that the relative concentrations of ${ }^{106} \mathrm{Ru}$ and ${ }^{60} \mathrm{Co}$ are within the same order of magnitude in the pore waters of borehole soils in the study area, the radioactivity distribution ratios for the two gamma emitters are apparently quite different. Based on the composite soil data in Table 3.7, calculated $\mathrm{K}_{\mathrm{d}}$ values for ${ }^{106} \mathrm{Ru}$ are seen to range from $0.8 \mathrm{~mL} / \mathrm{g}$ to $1.3 \mathrm{~mL} / \mathrm{g}$. Up to $\sim 20 \%$ of the ${ }^{106} \mathrm{Ru}$ measured in the soil samples, however, is residual from adsorbed pore waters contained in the soil samples before drying; hence the true $K_{d} s$ are somewhat lower than the calculated values. These low ratios emphasize the relatively non-reactive nature of ${ }^{106} \mathrm{Ru}$ in the aquifer medium. Since $\mathrm{RuO}_{4}{ }^{2-}$ is the thermodynamically favored species in this flow system, the observed retention is not unreasonable. Radioactivity distribution ratios for ${ }^{60} \mathrm{Co}$ are significantly higher, with values of $7.8 \mathrm{~mL} / \mathrm{g}, 5.7 \mathrm{~mL} / \mathrm{g}$, and $11.9 \mathrm{~mL} / \mathrm{g}$ for CP-4, ES39 , and ES-16, respectively. Using the average values of the ${ }^{90} \mathrm{Sr}$ concentrations from Table 3.8 , radioactivity distribution ratios of $38 \mathrm{~mL} / \mathrm{g}, 32 \mathrm{~mL} / \mathrm{g}$, and $19 \mathrm{~mL} / \mathrm{g}$ were obtained.

Apart from the calculated ${ }^{106} \mathrm{Ru} \mathrm{K} \mathrm{K}_{d} \mathrm{~s}$, perhaps these ratios are rather poor representations of actual radionuclide mobility. For example, if the calculated radioactivity distribution ratios for ${ }^{90} \mathrm{Sr}$ were assumed to be valid, these data would suggest that the leading edge of the ${ }^{90} \mathrm{Sr}$ plume should have only recently arrived in the East Swamp, which is not the case. It should also be noted that the ${ }^{90} \mathrm{Sr}$ radioactivity distribution ratios are substantially higher than the shortterm $\mathrm{K}_{\mathrm{d}} \mathrm{s}(5 \mathrm{~mL} / \mathrm{g}$ to $15 \mathrm{~mL} / \mathrm{g})$ measured in laboratory and field studies using soils from nearby locations and in the same aquifer system (Patterson and Spoel 1981; Pickens et al. 1981).

The calculated radioactivity distribution ratios for ${ }^{60} \mathrm{Co}$, on the other hand, are substantially lower than the values commonly reported in the literature. A comparison between the results of this study and data obtained in 1980 on sorbed ${ }^{60} \mathrm{Co}$ concentrations at boreholes $\mathrm{CP}-4$ and ES-16 (Killey and Munch 1984) suggests that ${ }^{6} \mathrm{Co}$ concentrations in soil have decreased by a factor of 3 to 5 . Such a decrease may be attributed solely to radioactive decay, although releases to groundwater remain a viable mechanism for some of the ${ }^{60} \mathrm{Co}$ loss. Current soil inventories of both ${ }^{60} \mathrm{Co}$ and ${ }^{90} \mathrm{Sr}$ account for more than $95 \%$ of the total contamination in the aquifer; hence even substantial releases to the groundwater from the soil would not be particularly evident in the soil inventory. This supports the hypothesis that radioactive decay is the primary contributor to the decrease in ${ }^{60} \mathrm{Co}$ content within the aquifer sands, and suggests that the plume may have originated from a mobilization event that occurred prior to 1980 (e.g., during the 1960s; see Figure 1.6). 
Table 3.7 Gamma-ray spectrometry results from Chemical Pit soils (1993)

\begin{tabular}{|c|c|c|c|c|c|c|}
\hline \multirow[t]{2}{*}{ Well No. } & \multicolumn{2}{|c|}{ Depth $(\mathrm{m})$} & ${ }^{60} \mathrm{Co}$ & ${ }^{106} \mathrm{Ru}$ & ${ }^{125} \mathrm{Sb}$ & ${ }^{137} \mathrm{Cs}$ \\
\hline & From & To & \multicolumn{4}{|c|}{ Concentration (nCi/g) } \\
\hline \multirow[t]{14}{*}{ CHPT-2 } & 5.06 & 5.33 & 4.7 & 0.1 & 0.1 & 45.6 \\
\hline & 5.33 & 5.64 & 4.5 & 0.2 & 0.1 & 43.0 \\
\hline & 6.10 & 6.40 & 1.6 & 0.0 & 0.0 & 11.5 \\
\hline & 6.40 & 6.71 & 1.3 & 0.0 & 0.0 & 0.8 \\
\hline & 6.71 & 7.01 & 4.6 & 0.1 & 0.0 & 0.4 \\
\hline & 7.62 & 7.99 & 0.3 & 0.1 & 0.0 & 0.1 \\
\hline & 7.99 & 8.35 & 0.3 & 0.0 & 0.0 & 0.1 \\
\hline & 8.35 & 8.53 & 0.4 & 0.0 & 0.0 & 0.0 \\
\hline & 8.53 & 8.84 & 0.1 & 0.0 & 0.0 & 0.0 \\
\hline & 8.84 & 9.02 & 0.1 & 0.0 & 0.0 & 0.0 \\
\hline & 9.14 & 9.45 & 0.1 & 0.0 & 0.0 & 0.1 \\
\hline & 9.45 & 9.75 & 0.1 & 0.0 & 0.0 & 0.0 \\
\hline & 9.75 & 10.06 & 0.1 & 0.0 & 0.0 & 0.0 \\
\hline & 10.76 & 10.79 & 0.0 & 0.0 & 0.0 & 0.1 \\
\hline $\mathrm{CP}-4 \mathrm{~A}$ & 6.55 & 10.24 & 0.1 & 0.0 & 0.0 & 0.0 \\
\hline ES-39A & 5.33 & 9.48 & 0.1 & 0.0 & 0.0 & 0.0 \\
\hline ES-16A & 0.31 & 3.35 & 0.1 & 0.0 & 0.0 & 0.0 \\
\hline
\end{tabular}

\subsection{Hollow-Fiber Ultrafiltration}

Results from the 1993 field ultrafiltration efforts are summarized in Tables 3.9 (ES-16) and 3.10 (CP-4), respectively. At well ES-16, the highest concentrations of ${ }^{60} \mathrm{Co}$ and ${ }^{106} \mathrm{Ru}$ are found in the smallest size fraction $(<3,000 \mathrm{MW})$. The general trend of these radionuclides with regard to particle size (Figure 3.17a) indicates that their concentrations decrease as the size of the dissolved species increases (with a slight enhancement of the 10,000-MW-to$30,000-\mathrm{MW}$ fraction). This phenomenon may be the result of the natural fragmentation and/or size filtration of radionuclide-complexed humic and fulvic acid macromolecules as they migrate through the aquifer medium. A direct contribution from low-molecularweight anthropogenic species in the smallest fraction, however, cannot be discounted.

The results from the 1993 sampling of the near-field well (CP-4) are similar to those observed for ES-16 (Table 3.10; Figure 3.18a). The smallest size fraction $(<3,000 \mathrm{MW})$ dominates in terms of overall activity, and the concentrations of the four reported radionuclides decrease in a regular fashion with increasing particle size. The second highest concentrations are again found in the 10,000-MW-to-30,000-MW size range, which suggests that two individual particle-size populations may exist in this groundwater. As described above, the smallest particles $(<3,000 \mathrm{MW})$ may represent molecular fragments of humic and fulvic materials or low-molecular-weight anthropogenic chelators.

The 1994 sampling effort was conducted under an inert nitrogen gas blanket (as discussed in Section 2.4) to eliminate the possibility of oxidation reactions occurring during the sample acquisition and filtration phases, which could generate colloidal hydrous metal oxides and potentially disrupt the original sample speciation. The CP-4 groundwater was found to have an unusually large amount of amber-colored material present (possibly indicative of dissolved humic and fulvic acids), and 
Table 3.8 Strontium-90 and ${ }^{60}$ Co results from Chemical Pit soils (1993)

\begin{tabular}{|c|c|c|c|c|}
\hline \multirow{2}{*}{$\begin{array}{l}\text { Well } \\
\text { No. }\end{array}$} & \multicolumn{2}{|c|}{ Depth (m) } & ${ }^{60} \mathrm{Co}$ & ${ }^{90} \mathrm{Sr}$ \\
\hline & From & To & \multicolumn{2}{|c|}{ Concentration (pCi/g) } \\
\hline \multirow[t]{22}{*}{$\mathrm{CP}-4 \mathrm{~A}$} & 6.55 & 6.71 & 32.4 & 35.1 \\
\hline & 6.71 & 6.86 & 37.8 & 108.1 \\
\hline & 6.86 & 7.01 & 48.6 & 221.6 \\
\hline & 7.01 & 7.16 & 89.2 & 445.9 \\
\hline & 7.16 & 7.25 & 48.6 & 508.1 \\
\hline & 7.62 & 7.77 & 56.8 & 735.1 \\
\hline & 7.77 & 7.92 & 124.3 & 1040.5 \\
\hline & 7.92 & 8.08 & 151.4 & 1378.4 \\
\hline & 8.08 & 8.23 & 183.8 & 1745.9 \\
\hline & 8.23 & 8.38 & 186.5 & 2437.8 \\
\hline & 8.38 & 8.53 & 197.3 & 4408.1 \\
\hline & 8.53 & 8.69 & 183.8 & 5394.6 \\
\hline & 8.69 & 8.84 & 189.2 & 4678.4 \\
\hline & 8.84 & 8.99 & 194.6 & 3235.1 \\
\hline & 8.99 & 9.14 & 116.2 & 2397.3 \\
\hline & 9.14 & 9.30 & 59.5 & 1132.4 \\
\hline & 9.30 & 9.45 & 70.3 & 1386.5 \\
\hline & 9.45 & 9.60 & 91.9 & 1356.8 \\
\hline & 9.60 & 9.75 & 97.3 & 935.1 \\
\hline & 9.75 & 9.91 & 191.9 & 1381.1 \\
\hline & 9.91 & 10.06 & 208.1 & 962.1 \\
\hline & 10.06 & 10.24 & 1159.5 & 656.8 \\
\hline \multirow[t]{6}{*}{ ES-39A } & 5.33 & 5.94 & 24.3 & 281.1 \\
\hline & 6.10 & 6.71 & 94.6 & 835.1 \\
\hline & 6.71 & 7.44 & 118.9 & 1070.3 \\
\hline & 7.62 & 8.23 & 86.5 & 3237.8 \\
\hline & 8.23 & 8.90 & 91.9 & 1791.9 \\
\hline & 9.14 & 9.48 & 54.1 & 997.3 \\
\hline
\end{tabular}


Results

Table 3.8 (continued)

\begin{tabular}{|c|c|c|c|c|}
\hline \multirow{2}{*}{$\begin{array}{l}\text { Well } \\
\text { No. }\end{array}$} & \multicolumn{2}{|c|}{ Depth (m) } & ${ }^{60} \mathrm{Co}$ & ${ }^{90} \mathrm{Sr}$ \\
\hline & From & To & \multicolumn{2}{|c|}{ Concentration (pCi/g) } \\
\hline \multirow[t]{9}{*}{ ES-16 } & 0.05 & 0.30 & 113.5 & 643.2 \\
\hline & 0.31 & 0.72 & 59.5 & 327.0 \\
\hline & 0.72 & 1.12 & 78.4 & 202.7 \\
\hline & 1.12 & 1.37 & 275.7 & 340.5 \\
\hline & 1.37 & 1.71 & 194.6 & 294.6 \\
\hline & 1.71 & 2.05 & 108.1 & 1235.1 \\
\hline & 2.05 & 2.39 & 67.6 & 913.5 \\
\hline & 2.39 & 2.73 & 135.1 & 289.2 \\
\hline & 2.73 & 2.85 & 35.1 & 462.2 \\
\hline
\end{tabular}

Table 3.9 Hollow-fiber ultrafiltration results for well ES-16 (1993)

\begin{tabular}{|c|c|c|c|c|c|}
\hline \multirow{2}{*}{ Radionuclide } & $<3 \mathrm{~K} \mathrm{MW}$ & $<10 \mathrm{~K}>3 \mathrm{~K} \mathrm{MW}$ & $<30 \mathrm{~K}>10 \mathrm{~K} \mathrm{MW}$ & $<100 \mathrm{~K}>30 \mathrm{~K} \mathrm{MW}$ & $<0.2 \mu \mathrm{m}>100 \mathrm{~K} \mathrm{MW}$ \\
\cline { 2 - 6 } & \multicolumn{6}{|c|}{ Activity Concentration in Size Fraction $(\mathrm{pCi} / \mathrm{L})$} \\
\hline${ }^{{ }^{60} \mathrm{Co}}$ & 383 & 135 & 132 & 98.2 & 115 \\
\hline${ }^{106} \mathrm{Ru}$ & 270 & 116 & 136 & 87.9 & 89.3 \\
\hline${ }^{125} \mathrm{Sb}$ & - & - & - & 0.68 & 0.54 \\
\hline
\end{tabular}

Table 3.10 Hollow-fiber ultrafiltration results for well CP-4 (1993)

\begin{tabular}{|c|c|c|c|c|c|}
\hline \multirow{2}{*}{ Radionuclide } & $<3 \mathrm{~K} \mathrm{MW}$ & $<10 \mathrm{~K}>3 \mathrm{~K} \mathrm{MW}$ & $<30 \mathrm{~K}>10 \mathrm{~K} \mathrm{MW}$ & $<100 \mathrm{~K}>30 \mathrm{~K} \mathrm{MW}$ & $\begin{array}{c}<0.45 \mu \mathrm{m}>100 \mathrm{~K} \\
\mathrm{MW}\end{array}$ \\
\cline { 2 - 6 } & \multicolumn{5}{|c|}{ Activity Concentration in Size Fraction $(\mathrm{pCi} / \mathrm{L})$} \\
\hline${ }^{60} \mathrm{Co}$ & 16880 & 8940 & 10810 & 6256 & 6218 \\
\hline${ }^{106} \mathrm{Ru}$ & 14200 & 9364 & 12630 & 5186 & 5212 \\
\hline${ }^{125} \mathrm{Sb}$ & 893.8 & 354.2 & 489.7 & 294.8 & 284.5 \\
\hline${ }^{137} \mathrm{Cs}$ & 28.37 & 15.10 & 16.58 & 14.73 & 18.28 \\
\hline
\end{tabular}

this material was not substantially removed from solution by filtering the groundwater through a 0.45 $\mu \mathrm{m}$ prefilter. These highly-colored compounds undoubtedly played an important role in the size distribution of radionuclide-bearing materials in the CP-4 groundwater, although the nature of this role is not entirely clear. As seen in Table 3.11 and Figure
$3.18 \mathrm{~b}$, the highest concentrations of the primary radionuclides in these size-fractionated samples are associated with the largest dissolved species $(<0.45 \mu \mathrm{m} ;>100,000 \mathrm{MW})$. Radionuclide concentrations generally decrease with decreasing particle size in this groundwater sample, yet a significant fraction of the ${ }^{60} \mathrm{Co}$ and ${ }^{106} \mathrm{Ru}$ activities are found to reside in the 10,000-MW-to$30,000-\mathrm{MW}$ fraction. This behavior is exactly opposite of that 
Figure 3.17 General size-fractionation trends for selected radionuclides at well ES-16 in 1993 (a) and 1994 (b)
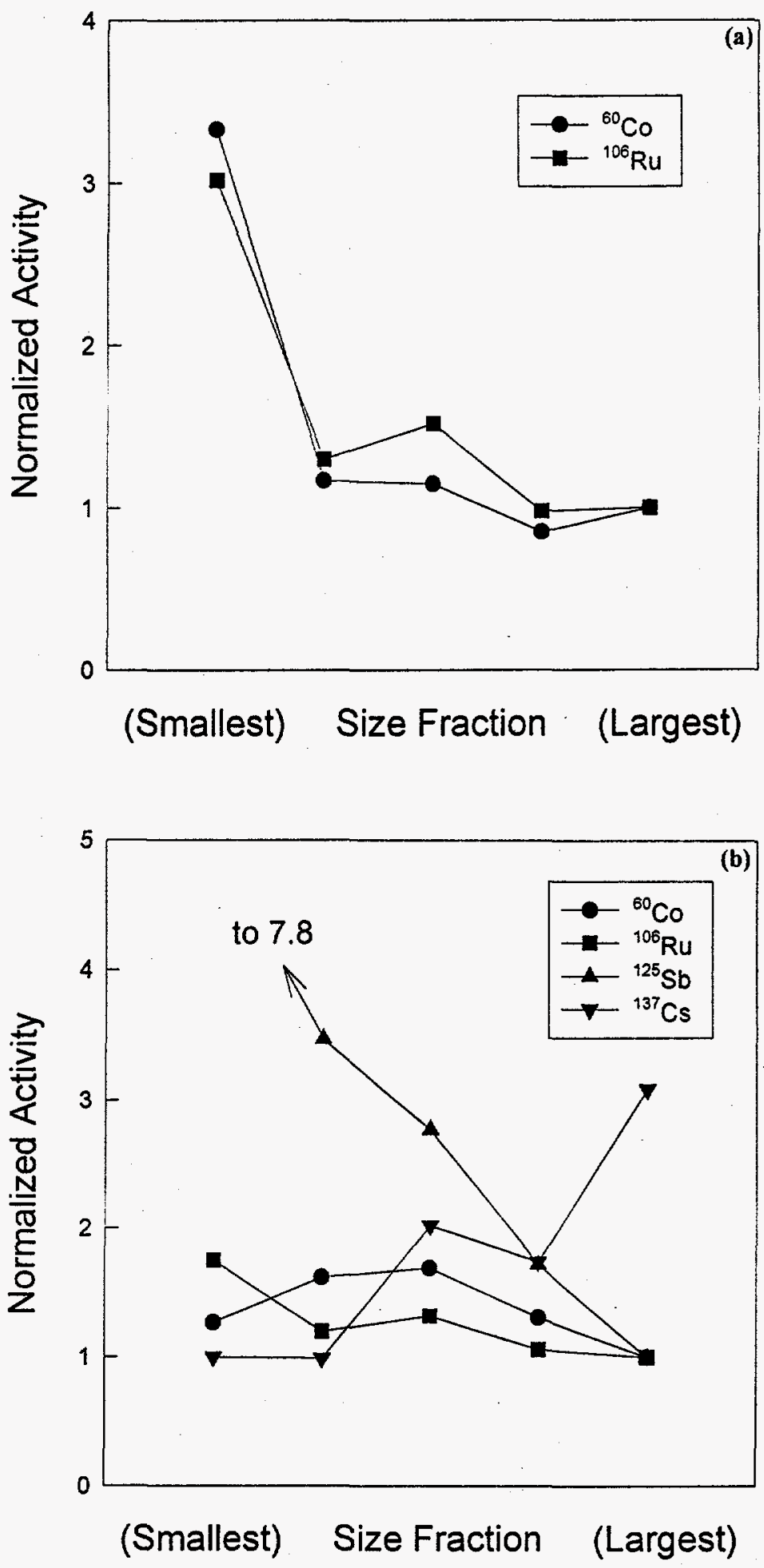
Results

Figure 3.18 General size-fractionation trends for selected radionuclides at well CP-4 in 1993 (a) and 1994 (b)
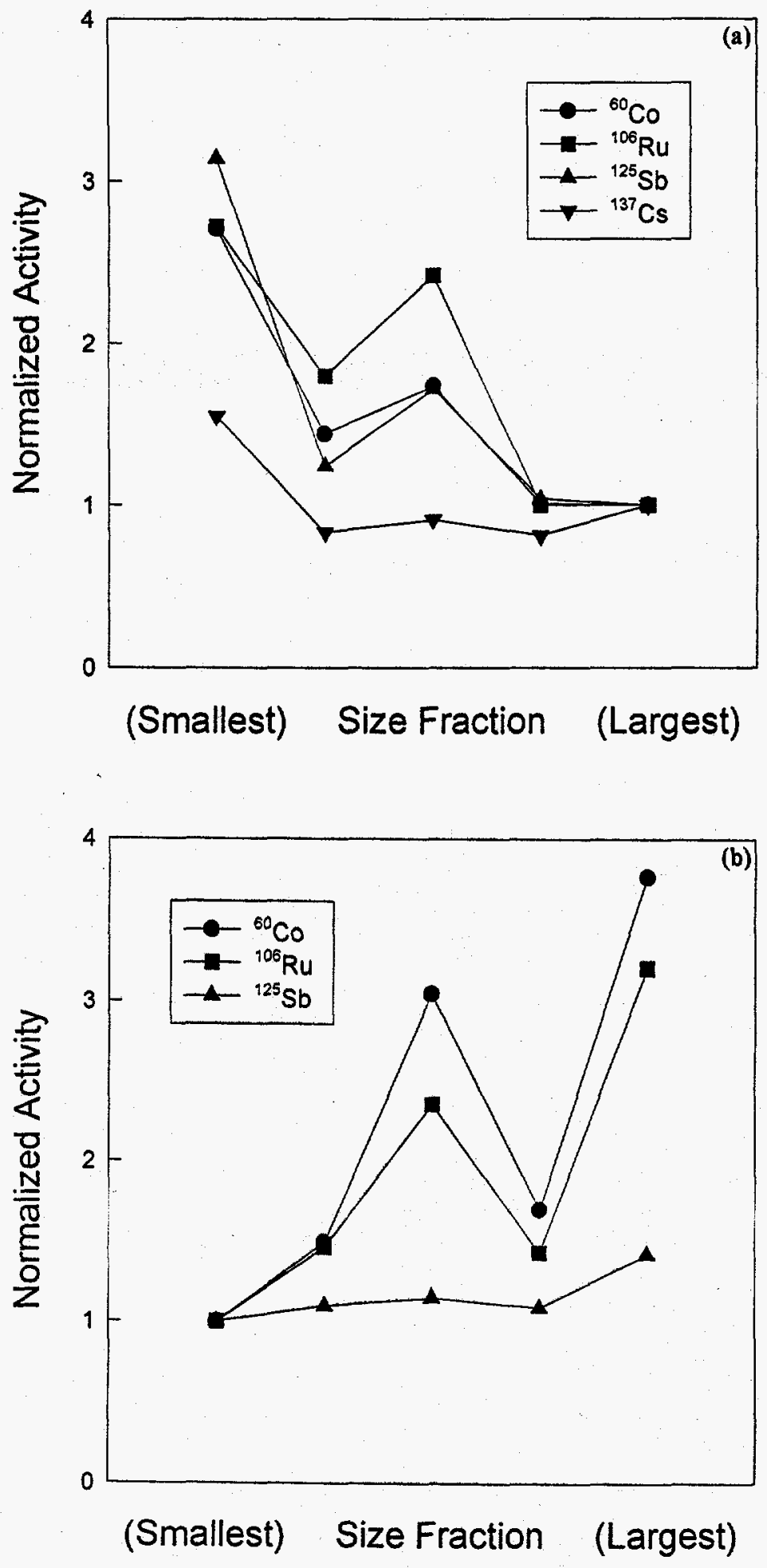
Table 3.11 Hollow-fiber ultrafiltration results for well CP-4 (1994)—nitrogen blanket utilized.

\begin{tabular}{|c|c|c|c|c|c|}
\hline \multirow[t]{2}{*}{ Radionuclide } & $<3 \mathrm{KMW}$ & $<10 \mathrm{~K}>3 \mathrm{~K} \mathrm{MW}$ & $<30 \mathrm{~K} / 10 \mathrm{~K}$ MW & $<100 \mathrm{~K}>30 \mathrm{~K} \mathrm{MW}$ & $\begin{array}{c}<0.45 \mu \mathrm{m}>100 \mathrm{~K} \\
\mathrm{MW}\end{array}$ \\
\hline & \multicolumn{5}{|c|}{ Activity Concentration in Size Fraction (pCi/L) } \\
\hline${ }^{60} \mathrm{Co}$ & 62290 & 93100 & 190000 & 106200 & 235000 \\
\hline${ }^{106} \mathrm{Ru}$ & 14300 & 20900 & 33700 & 20400 & 45900 \\
\hline${ }^{125} \mathrm{Sb}$ & 6950 & 7630 & 8020 & 7550 & 9870 \\
\hline${ }^{137} \mathrm{Cs}$ & $<37$ & $<44$ & 433 & 699 & 160100 \\
\hline
\end{tabular}

observed in the previous year with regard to the general trend of radioactivity versus particle size, although the second highest accumulation of radionuclides (in the middle size range) is consistent for groundwater obtained in both 1993 and 1994. These diametrically opposed results may simply reflect the two extremes of a natural groundwater particle-size spectrum, in which the 1993 data indicate the presence of smaller fragments of (or filtration residue from) humic and fulvic acid macromolecules created by the relatively slow passage of such material through the aquifer medium, and the 1994 data indicate the presence of larger, nonfragmented species that have become resuspended due to the enhanced groundwater flow rate associated with the recent high-volume discharges at the Chemical Pit (Section 2.4). The existence of the recurring radionuclide population in the 10,000-MW-to-30,000-MW fraction is intriguing, and may represent a distinctly different, persistent species or relatively stable fragments of natural macromolecules in the 3-nm-to-5-nm size range.

The 1994 results from well ES-16 (Table 3.12; Figure $3.17 \mathrm{~b}$ ) are only partially consistent with those observed in the previous year. The ${ }^{125} \mathrm{Sb}$ activity is seen to increase strongly with decreasing particle size, as did ${ }^{60} \mathrm{Co}$ and ${ }^{106} \mathrm{Ru}$ in 1993. Cobalt-60, ${ }^{106} \mathrm{Ru}$, and ${ }^{137} \mathrm{Cs}$ (which was not detected at ES-16 in 1993), on the other hand, behave quite differently. In particular, the ${ }^{106} \mathrm{Ru}$ concentration increases only slightly with decreasing particle size, the ${ }^{137} \mathrm{Cs}$ activity actually decreases with decreasing particle size, and the ${ }^{60} \mathrm{Co}$ data indicates that highest concentration resides in the 10,000-MW-to-30,000-MW fraction (all of the observed radionuclides, in fact, appear to have relatively elevated concentrations in the middle size range) with activities decreasing toward the smaller and larger size fractions. These disparate trends may be indicative of a dynamic transition between an earlier condition (dominated by the smallest material) and a later one (dominated by the largest material). These results, therefore, may be interpreted as a far-field snapshot of overlapping phenomena that have already stabilized in the near field (CP-4). If so, this would imply that ${ }^{137} \mathrm{Cs}$ migrated faster than the other radionuclides and ${ }^{125} \mathrm{Sb}$ was the most efficiently retarded.

\subsection{Membrane Ultrafiltration}

The results of the particle-size analysis (Section 2.5) carried out with ultrafiltration membranes are summarized in Table 3.13. Except for the elevated concentration of suspended particles $(>0.45 \mu \mathrm{m})$ in $\mathrm{CP}-4$, colloid and suspended-particle concentrations are low in this groundwater. The lowest suspended-particle concentrations were found in the most developed borehole (ES-16) and were highest in the most recently emplaced well (CP-4), although the latter may be the result of insufficient flushing of the well and the presence of colloidal material created by the installation process. Since the original particle concentrations in these waters were too low to scatter sufficient light, the Ultrafine Particle-Size Analyzer (UPA) required highly concentrated samples to produce meaningful results. Size analyses with the UPA indicate that CP-4 contained particles ranging from $20 \mathrm{~nm}$ to $2,500 \mathrm{~nm}$ in size with a high concentration of particles at $\sim 50 \mathrm{~nm}$. Colloidal particles in ES-39 were dominated by materials ranging in size from $6 \mathrm{~nm}$ to $15 \mathrm{~nm}$. The UPA could only detect particles smaller than $400 \mathrm{~nm}$ in ES-16.

By analyzing the filtrate and retentate fractions produced during an ultrafiltration process, it is possible to calculate the groundwater concentrations of a given radionuclide associated with dissolved species, colloids ranging from 1-10 nm and 10$450 \mathrm{~nm}$, and suspended particles larger than $0.45 \mu \mathrm{m}$. The concentration of dissolved radionuclides is given by

$$
\text { dissolved concentration }=F_{2}
$$

where $F_{2}$ represents the concentration in the $F_{2}$ filtrate. The groundwater concentration of radionuclides associated with 
Results

Table 3.12 Hollow-fiber ultrafiltration results for well ES-16 (1994)-nitrogen blanket utilized

\begin{tabular}{|c|c|c|c|c|c|}
\hline \multirow{2}{*}{ Radionuclide } & $<3 \mathrm{KMW}$ & $<10 \mathrm{~K}>3 \mathrm{~K} \mathrm{MW}$ & \multicolumn{2}{|c|}{$<30 \mathrm{~K}>10 \mathrm{~K} \mathrm{MW}$} & \multicolumn{2}{|c|}{$<100 \mathrm{~K}>30 \mathrm{~K} \mathrm{MW}$} & $<0.2 \mu \mathrm{m}>100 \mathrm{~K} \mathrm{MW}$ \\
\cline { 2 - 7 } & & \multicolumn{2}{|c|}{ Activity Concentration in Size Fraction (pCi/L) } \\
\hline${ }^{60} \mathrm{Co}$ & 6820 & 8710 & 9087 & 7020 & 5370 \\
\hline${ }^{106} \mathrm{Ru}$ & 5440 & 3720 & 4096 & 3300 & 3100 \\
\hline${ }^{125} \mathrm{Sb}$ & 313.0 & 139.0 & 111.1 & 68.8 & 40.1 \\
\hline${ }^{1.37} \mathrm{Cs}$ & 54.3 & 53.5 & 109.9 & 94.4 & 168.0 \\
\hline
\end{tabular}

Table 3.13 Results from gravimetric particle-size analyses at the Chemical Pit (1993)

\begin{tabular}{|c|r|r|r|r|r|}
\hline \multicolumn{2}{|c|}{ CP-4 } & \multicolumn{2}{c|}{ ES-39 } & \multicolumn{2}{c|}{ ES-16 } \\
\hline Size $(\mathrm{nm})$ & Conc. $(\mathrm{mg} / \mathrm{L})$ & Size $(\mathrm{nm})$ & Conc. $(\mathrm{mg} / \mathrm{L})$ & Size $(\mathrm{nm})$ & $\begin{array}{c}\text { Conc. } \\
(\mathrm{mg} / \mathrm{L})\end{array}$ \\
\hline 10000 & 0.097 & 10000 & 0.064 & 10000 & 0.053 \\
\hline 5000 & 0.710 & 5000 & 0.058 & 5000 & 0.050 \\
\hline 1000 & 0.691 & 1000 & 0.316 & 1000 & 0.046 \\
\hline 400 & 0.026 & 400 & 0.070 & 400 & 0.064 \\
\hline 100 & 0.048 & 100 & 0.073 & 100 & 0.051 \\
\hline 50 & 0.072 & 50 & 0.097 & 50 & 0.058 \\
\hline 15 & 0.084 & 15 & 0.134 & 15 & 0.064 \\
\hline total $>450$ & 1.523 & total $>450$ & 0.509 & total $>450$ & 0.214 \\
\hline total $10-450$ & 0.2 & total $10-450$ & 0.304 & total $10-450$ & 0.173 \\
\hline
\end{tabular}

colloids between $1 \mathrm{~nm}$ and $10 \mathrm{~nm}$ in size is given by

$$
\text { colloids }(1-10 \mathrm{~nm})=\left(\mathrm{R}_{2}-\mathrm{F}_{2}\right) / \mathrm{C}_{2}
$$

where $R_{2}$ represents the radionuclide concentration in retentate $R_{2}$ and $C_{2}$ is the colloid concentration factor ${ }^{8}$ resulting from filtration with the $10,000-\mathrm{MW}$ membrane. The concentration of the radionuclides associated with colloids between $10 \mathrm{~nm}$ and $0.45 \mu \mathrm{m}$ can be calculated from equations 3.3 or 3.4. Indeed, the reported value for this concentration is the average of equations 3.3 and 3.4 .

\footnotetext{
The concentration factor is calculated by dividing the sample volume (before filtration) by the retentate volume.
}

$$
\begin{aligned}
& \text { colloids }(10-450 \mathrm{~nm})=\left(F_{3}-F_{1}\right) / C_{1} \\
& \text { colloids }(10-450 \mathrm{~nm})=\left(R_{1}-F_{1}\right) / C_{1}- \\
& \text { particles }(>450 \mathrm{~nm})
\end{aligned}
$$

In the above equations, $F_{3}$ represents the radionuclide concentration filtered through the 450-nm filter, $F_{1}$ is the filtrate from the $100,000-\mathrm{MW}$ membrane, $R_{1}$ is the retentate from the $100,000-\mathrm{MW}$ filtration, and $\mathrm{C}_{1}$ is the colloid concentration factor for the 100,000-MW filtration. The concentration of the radionuclides associated with suspended particles is given by the average of equations 3.5 and 3.6.

$$
\begin{aligned}
& \text { particles }(>450 \mathrm{~nm})=\left(R_{3}-F_{3}\right) / C_{3} / C_{1} \\
& \text { particles }(>450 \mathrm{~nm})=\left(R_{1}-F_{3}\right) / C_{1}
\end{aligned}
$$


Since the amount of dissolved salts concentrated along with the colloidal fraction can be as high as $4 \%$, it is necessary to account for salt retention when calculating colloid compositions from particle concentrates. The concentration of a given radionuclide in the particle concentrate is calculated first as a percentage of the total radionuclide concentration in solution. The measured percent salt retention, determined by conductivity, is then subtracted from this value. The concentration of the radionuclide associated with the colloidal fraction is calculated from this corrected value.
Radiochemical analyses performed at CRL on the filtrate and retentate samples were used to calculate radionuclide activities for dissolved and colloidal species. The results of these calculations are presented in Table 3.14. It is evident from the data that the smallest species dominate in each case for the measured radionuclides, thereby supporting the 1993 hollowfiber ultrafiltration results.

Table 3.14 Size-fractionation results for radionuclides at the Chemical Pit (1993)

\begin{tabular}{|c|c|r|r|r|r|}
\hline \multirow{2}{*}{$\begin{array}{c}\text { Well } \\
\text { No. }\end{array}$} & \multirow{2}{*}{ Radionuclide } & \multicolumn{4}{|c|}{ Radionuclide Concentration (pCi/kg) } \\
\cline { 2 - 6 } & & Dissolved Species & Colloids (1-10 nm) & Colloids (10-450 nm) & Particles (>450 nm) \\
\hline \multirow{2}{*}{ CP-4 } & ${ }^{60} \mathrm{Co}$ & 13216 & 286 & 140 & 8 \\
\cline { 2 - 6 } & ${ }^{106} \mathrm{Ru}$ & 8622 & 508 & 0 & 9 \\
\cline { 2 - 6 } & ${ }^{125} \mathrm{Sb}$ & 1073 & 0 & 3 & 1 \\
\hline \multirow{2}{*}{ ES-39 } & ${ }^{60} \mathrm{Co}$ & 9270 & 122 & 237 & 0 \\
\cline { 2 - 6 } & ${ }^{106} \mathrm{Ru}$ & 9027 & 714 & 622 & 93 \\
\cline { 2 - 6 } & ${ }^{125} \mathrm{Sb}$ & 351 & 16 & 5 & 0 \\
\hline \multirow{2}{*}{ ES-16 } & ${ }^{60} \mathrm{Co}$ & 7513 & 178 & 102 & 9 \\
\cline { 2 - 6 } & ${ }^{106} \mathrm{Ru}$ & 14270 & 722 & 303 & 1 \\
\cline { 2 - 6 } & ${ }^{125} \mathrm{Sb}$ & 210 & 15 & 9 & 9 \\
\hline
\end{tabular}

\subsection{Laboratory Chromatography: Anion Exchange and Gel Exclusion}

Before incorporating the rotary valve (Section 2.6), changes to $0.5-\underline{\mathrm{M} \mathrm{KCl}}$ and $0.1-\underline{\mathrm{M}} \mathrm{HCl}$ solutions were made by adding new eluent to the mixing chamber of the gradient mixer. This procedure, combined with difficulties associated with starting the gradient mixer, led to some variability in the observed retention times for the individual analytes. Nonetheless, a number of peaks were identified in the resulting chromatograms, and a good degree of consistency was evident in consecutive runs.

Initial ES-16 chromatograms for ${ }^{60} \mathrm{Co}$ and ${ }^{106} \mathrm{Ru}$ are shown in Figures $3.19 \mathrm{a}$ and $3.20 \mathrm{a}$, respectively. In each case, the vertical scale represents the count rate normalized to the total volume of groundwater originally loaded onto the column. The elution with $\mathrm{pH}-4.5 \mathrm{HCl}$ continued through fraction 5 . The gradient was initiated at fraction 6; however, the mixer failed to start, and distilled water was pumped for 5 fractions before the fault was discovered: The gradient was then restarted and continued to fraction 83. The eluent was then changed to $0.5-\mathrm{M} \mathrm{KCl}$ and pumped to fraction 101, when the eluent was switched to $0.1-\underline{\mathrm{M}} \mathrm{HCl}$. The chromatogram for ${ }^{60} \mathrm{Co}$ exhibits a number of prominent peaks (labeled 1 through 4) in addition to a minor peak in the $\mathrm{pH}-4.5 \mathrm{HCl}$ region. All peaks are readily discernable, except that the third, which is rather broad, begins near the end of the gradient step and continues into the final $\mathrm{KCl}$ phase. Peak 2 gradually disappeared from subsequent runs over a period of $\sim 2$ weeks. This would seem to indicate that the separated species is decomposing or being converted to another species. The chromatogram for ${ }^{106} \mathrm{Ru}$ exhibited poorer counting statistics, yet four 
Results

Figure 3.19 Cobalt-60 chromatograms for well ES-16, prior to (a) and following (b) installation of rotary valve (3/5/93 and $4 / 2 / 93$, respectively). Scintillation results for $0.318-\mathrm{MeV}$ beta particle (c).
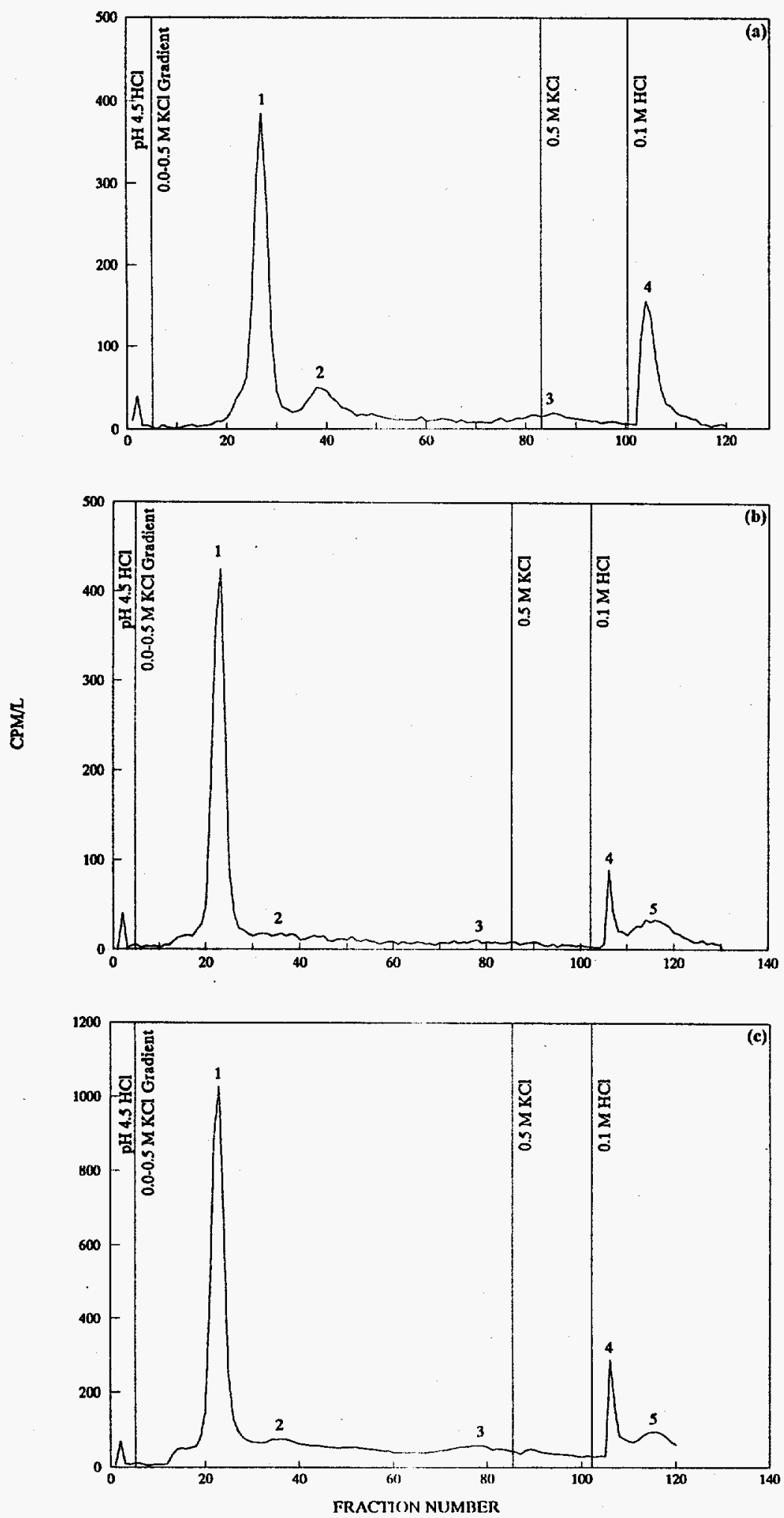
Figure 3.20 Ruthenium-106 chromatograms for well ES-16 ES-16, prior to (a) and following (b) installation of rotary valve (3/5/93 and 4/2/93, respectively). Scintillation results for 3.54-MeV beta particle from daughter, ${ }^{106} \mathrm{Rh}$ (c).
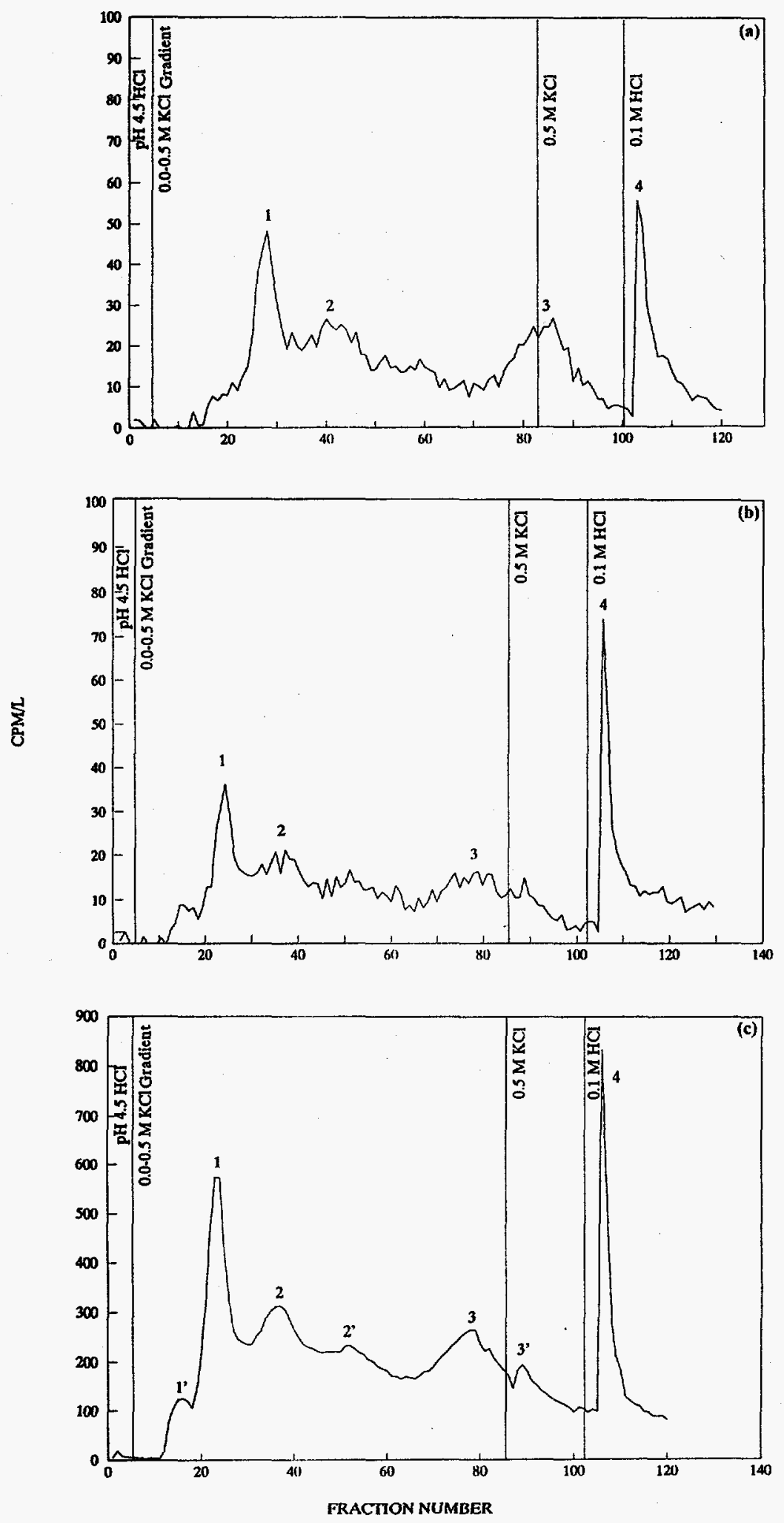
separate peaks were identified at roughly the same eluent fractions associated with elevated ${ }^{60} \mathrm{Co}$ activity.

Following installation of the rotary valve, much sharper changes were observed in the resulting chromatograms (Figures $3.19 \mathrm{~b}$ and $3.20 \mathrm{~b}$ for ${ }^{60} \mathrm{Co}$ and ${ }^{106} \mathrm{Ru}$, respectively); however, peaks 2 and 3 for ${ }^{60} \mathrm{Co}$ are no longer apparent in this 11-day-old sample. The sharper transition to the 0.1- $\underline{\mathrm{M}}$ $\mathrm{HCl}$ phase apparently resolved the tail in peak 4 into a separate ${ }^{60} \mathrm{Co}$ species (identified as peak 5 in Figure 3.19b). Qualitatively, the sequential ${ }^{106} \mathrm{Ru}$ chromatograms (Figure 3.20) are quite similar. The fractions from the second run were also analyzed on a low-background liquid scintillation counter, and the resulting alpha and beta chromatograms are shown in Figures 3.19c, 3.20c, and 3.21. Figure 3.19c summarizes the results from the ${ }^{60} \mathrm{Co}$ evaluation (beta particle energy $=0.318 \mathrm{MeV}$ ). This plot is analogous to Figure $3.19 \mathrm{~b}$, therefore, although the counting statistics are much improved. Peaks 2 and 3 appear in this chromatogram, but their presence is likely due to the contribution from higher-energy beta particles originating from the decay of ${ }^{106} \mathrm{Ru}$. Figure $3.20 \mathrm{c}$ is the chromatogram resulting from the observation of $3.54-\mathrm{MeV}$ betas from ${ }^{106} \mathrm{Rh}$, which is the short-lived daughter of ${ }^{106} \mathrm{Ru}$. This chromatogram is quite similar to Figure $3.20 \mathrm{~b}$, but the improved counting statistics led to the resolution of minor peaks associated with 1,2 , and 3 . The alpha-particle chromatogram is shown in Figure 3.21. Counting statistics are very poor in this case due to the low alpha activity, yet . three peaks are observed in the $\mathrm{KCl}$ gradient and $0.1-\underline{\mathrm{M}}$ $\mathrm{HCl}$ phase. Unfortunately, the resolution of the scintillometer is inadequate for identifying the specific isotopes. Aliquots were prepared from fractions 15 and 26 in peak 1 , and alpha spectrometry indicated the presence of ${ }^{241} \mathrm{Am}$ and ${ }^{244} \mathrm{Cm}$.

It was observed that the resin in the pre-column became discolored after repeated runs, thereby requiring the periodic replacement of resin. This phenomenon had also been observed in earlier work and was the primary reason for adding a separate pre-column in the present study. Both ${ }^{60} \mathrm{Co}$ and ${ }^{106} \mathrm{Ru}$ were detected on the discolored resin from the pre-columns, but their activity levels were not quantified.

An attempt was made to decrease the total elution time (by increasing the flow rate from $3 \mathrm{~mL} /$ minute to $6 \mathrm{~mL} /$ minute) and increase the amount of groundwater loaded. When this was attempted with 100-200 mesh AGMP1 resin, the chromatogram became distorted. A column was prepared using 200-400 mesh resin and was initially operated at 3 $\mathrm{mL} /$ minute for comparison with 100-200 mesh resin. Cobalt-60 and ${ }^{106} \mathrm{Ru}$ chromatograms obtained with the finer resin are shown in Figures 3.22a and 3.23a, whereas the results obtained from the 100-200 mesh run (for the same groundwater sample) are shown in Figures $3.22 \mathrm{~b}$ and $3.23 \mathrm{~b}$, respectively. It is apparent from this comparison that the finer resin leads to a superior separation of the individual species. Consequently, the finer-mesh resin was used in all subsequent analyses.

In July of 1993, an ES-16 groundwater sample was collected and analyzed four separate times under equivalent conditions over the following 5 days. A typical chromatogram for ${ }^{60} \mathrm{Co}$ is shown in Figure 3.24 in which five distinct peaks are evident. The total activities for the individual peaks in each run are summarized in Table 3.15. The total activity (i.e., the sum of all five peaks) is lowest in the first run, as is the activity associated with peak 1 . These differences may be due, in part, to sample aging. The results for the second and third runs are nearly identical. In the final run, the flow rate was increased to $6 \mathrm{~mL} /$ minute, and this appears to have shifted some of the species in peak 1 to peak 2 .

Improvement in the resolution of peaks 1 and 2 in Figure 3.24 was attempted by increasing the length of the analytical column from $17 \mathrm{~cm}$ to $25 \mathrm{~cm}$. A sample of ES16 groundwater was collected on $7 / 15 / 93$, and portions were chromatographed with both columns. An increased column length leads to a longer retention time; therefore, the $0.5-\underline{\mathrm{M} \mathrm{KCl}}$ volume was increased from $100 \mathrm{~mL}$ to 150 $\mathrm{mL}$. The resulting chromatograms for ${ }^{60} \mathrm{Co}$ are shown in Figures $3.25 \mathrm{a}$ and $3.25 \mathrm{~b}$ for the $17-\mathrm{cm}$ and $25-\mathrm{cm}$ columns, respectively. Corresponding results for ${ }^{106} \mathrm{Ru}$ are shown in Figure 3.26. The longer column had the desired effect in that peak resolution was somewhat enhanced, although additional improvement is still desirable, and the ${ }^{60} \mathrm{Co}$ and ${ }^{106} \mathrm{Ru}$ peaks near fraction 85 are no longer being eluted in the longer columns. The areas of the various peaks in the ${ }^{60} \mathrm{Co}$ chromatograms are presented in Table 3.16. The areas of peaks 4 and 5 increased with the longer column while that of peak 3 diminished, and this may be because the latter species were being eluted in $\mathrm{HCl}$ rather than in $\mathrm{KCl}$.

The ultraviolet absorbance at $254 \mathrm{~nm}$ of selected fractions from the 7/8/93 run in the above series was also measured, and the results are shown in Figure 3.27. Ultraviolet absorbance at this wavelength is often used as an indication of the presence of certain organic functional groups. These results, therefore, suggest that at least two organic fractions are present in well ES-16 groundwater and are distinguishable by this procedure. The early absorbance peak immediately follows peak 2 , and the latter absorbance peak coincides with peak 4 in the ${ }^{60} \mathrm{Co}$ chromatograms (e.g., Figure 3.19). The proximity of the ultraviolet absorbance peaks to those in the radionuclide chromatograms suggests that a significant fraction of the ${ }^{60} \mathrm{Co}$ species is likely 
Figure 3.21 Alpha particle liquid scintillation results from well ES-16

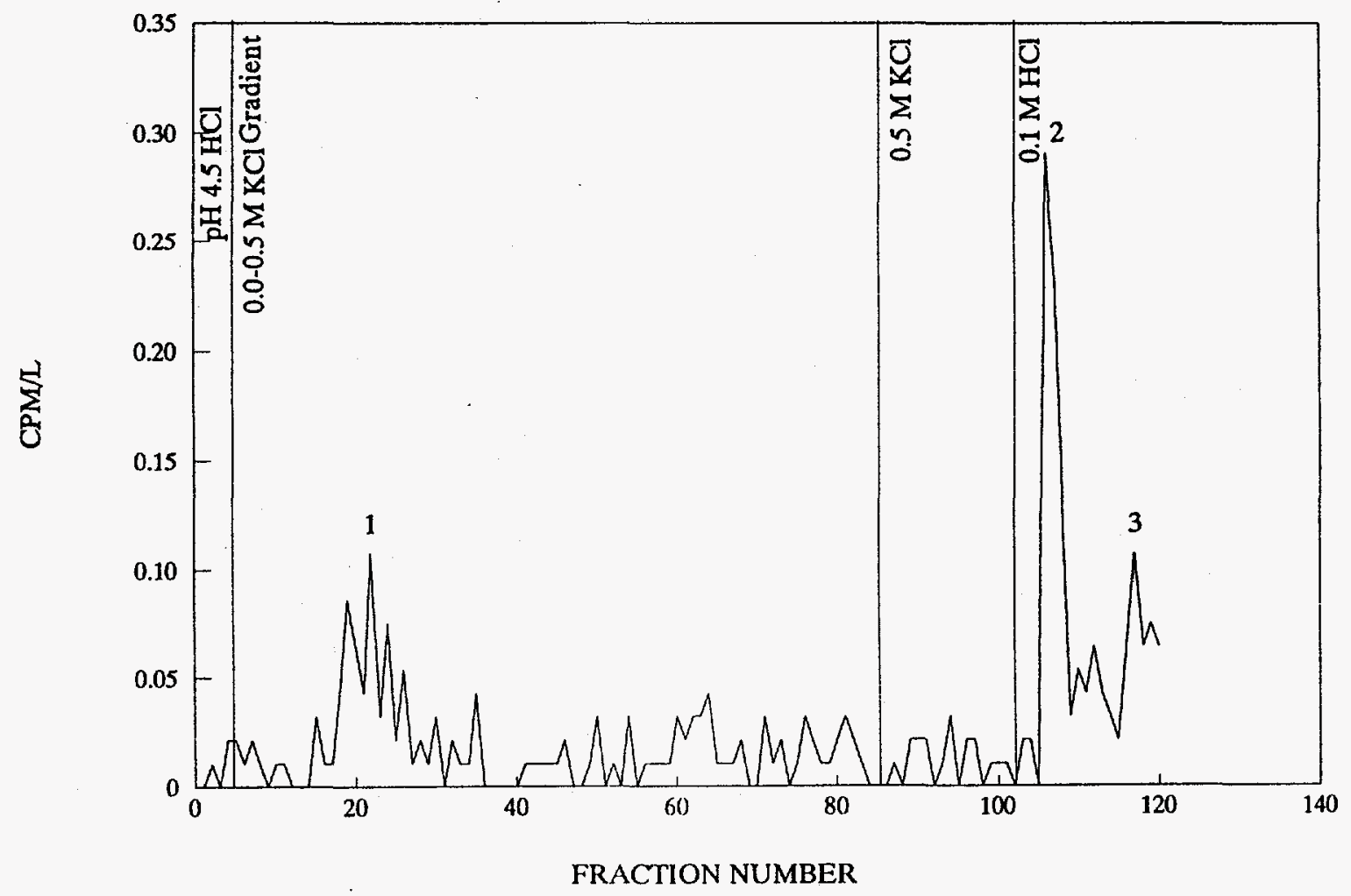


Results

Figure 3.22 Cobalt-60 chromatography using 200-400 (a) and 100-200 (b) mesh resins
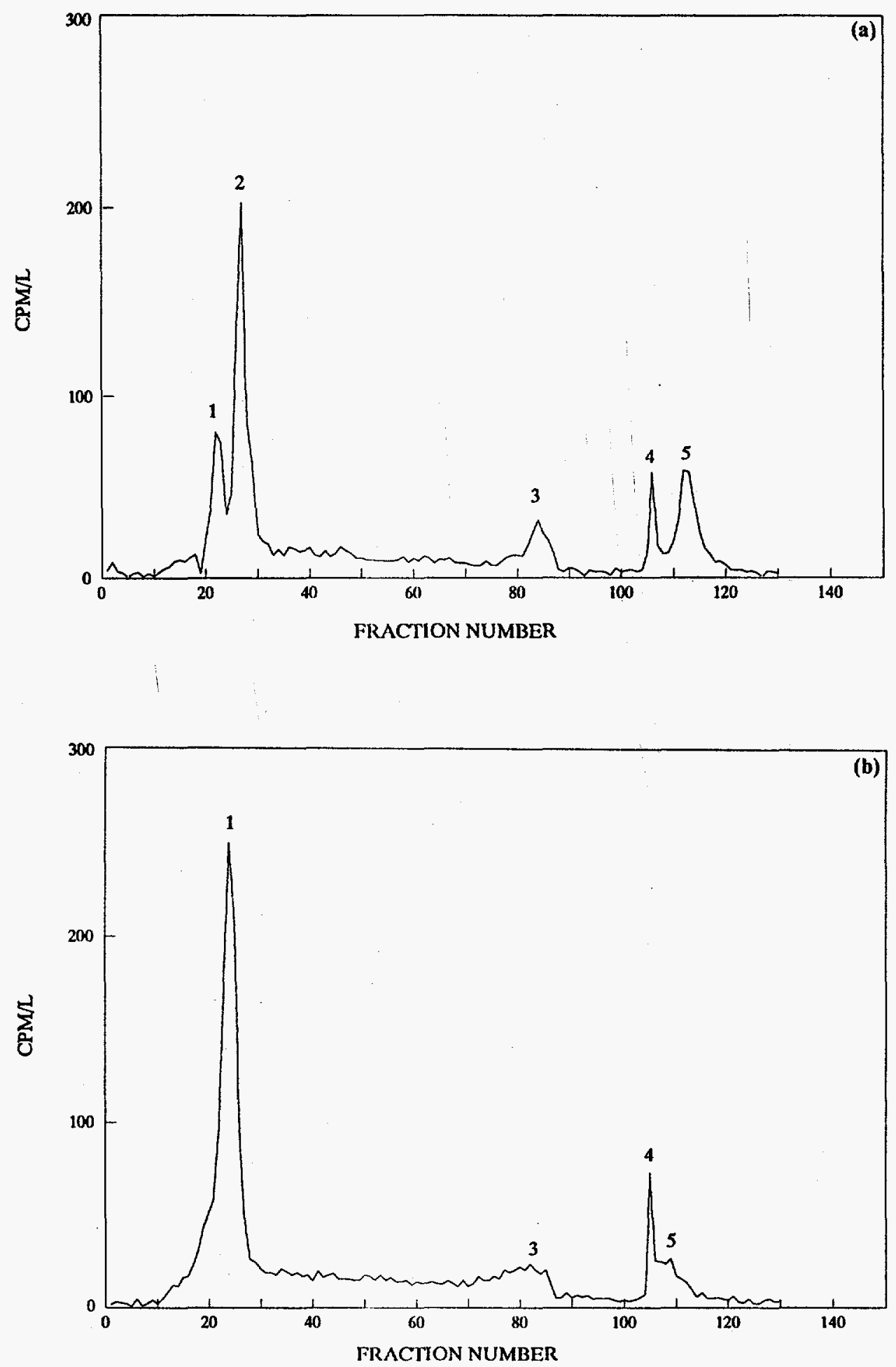
Figure 3.23 Ruthenium-106 chromatography using 200-400 (a) and 100-200 (b) mesh resins
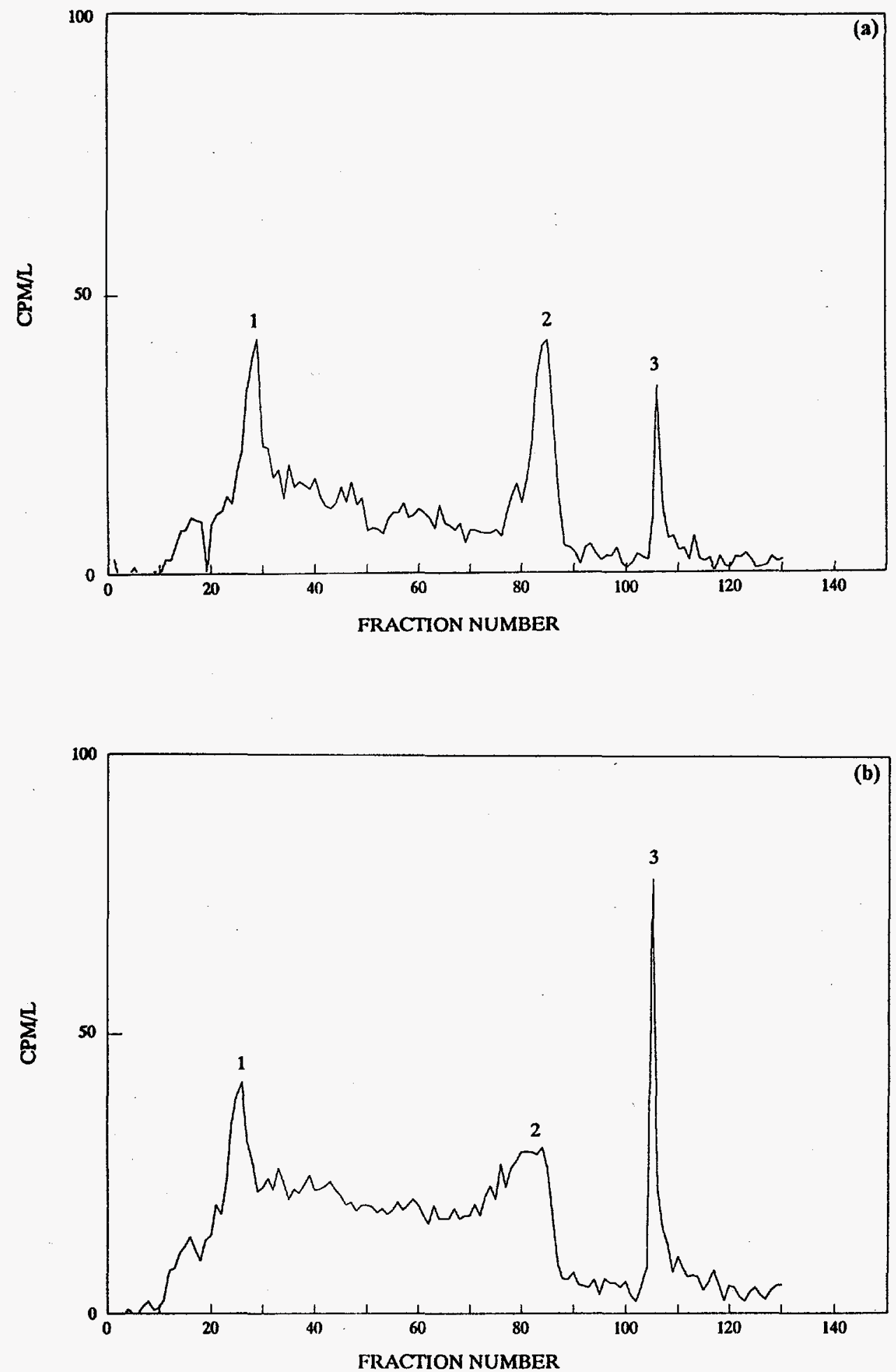
Results

Figure 3.24 Typical chromatogram for ${ }^{60} \mathrm{Co}$ at well ES-16 (1993)

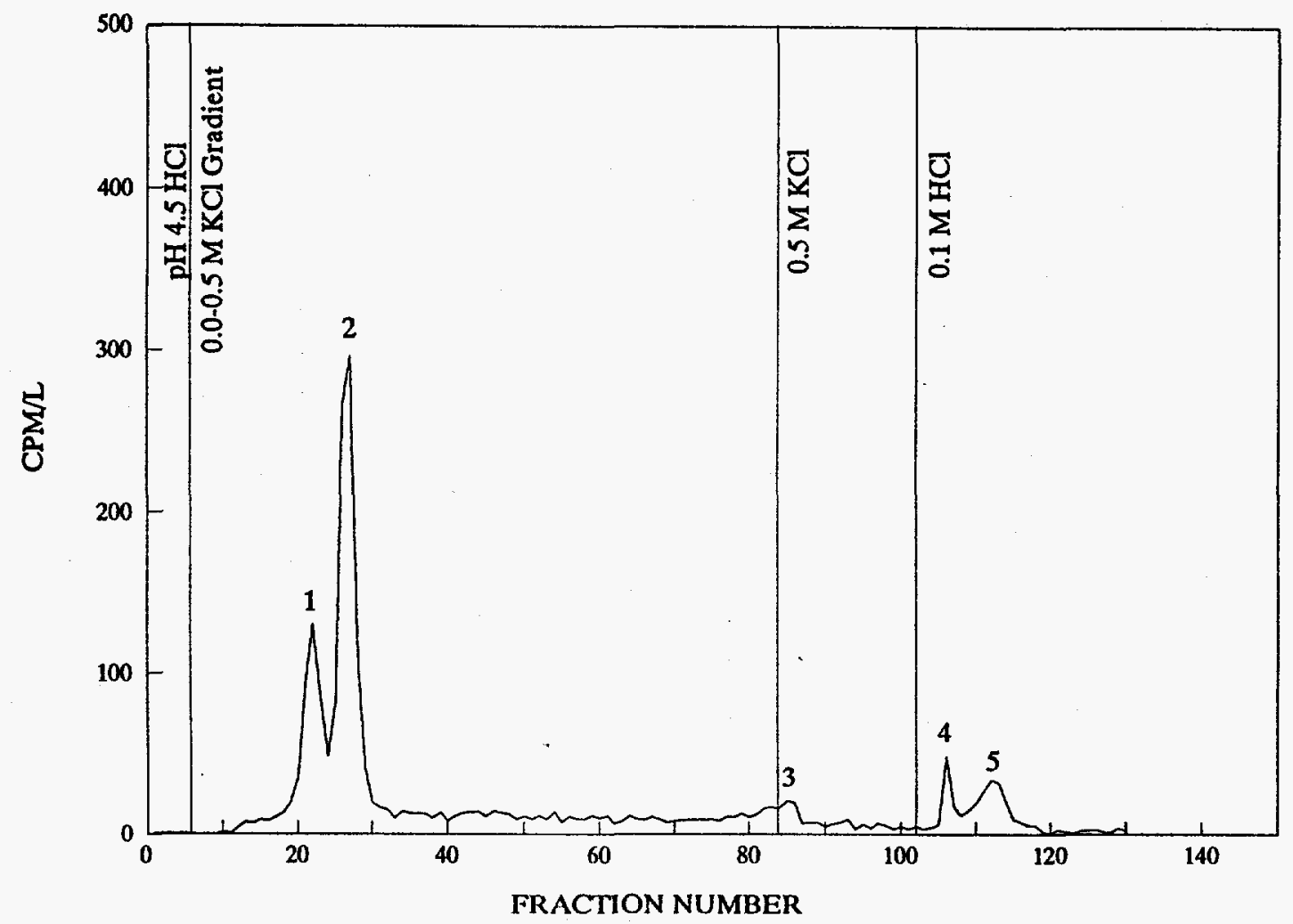



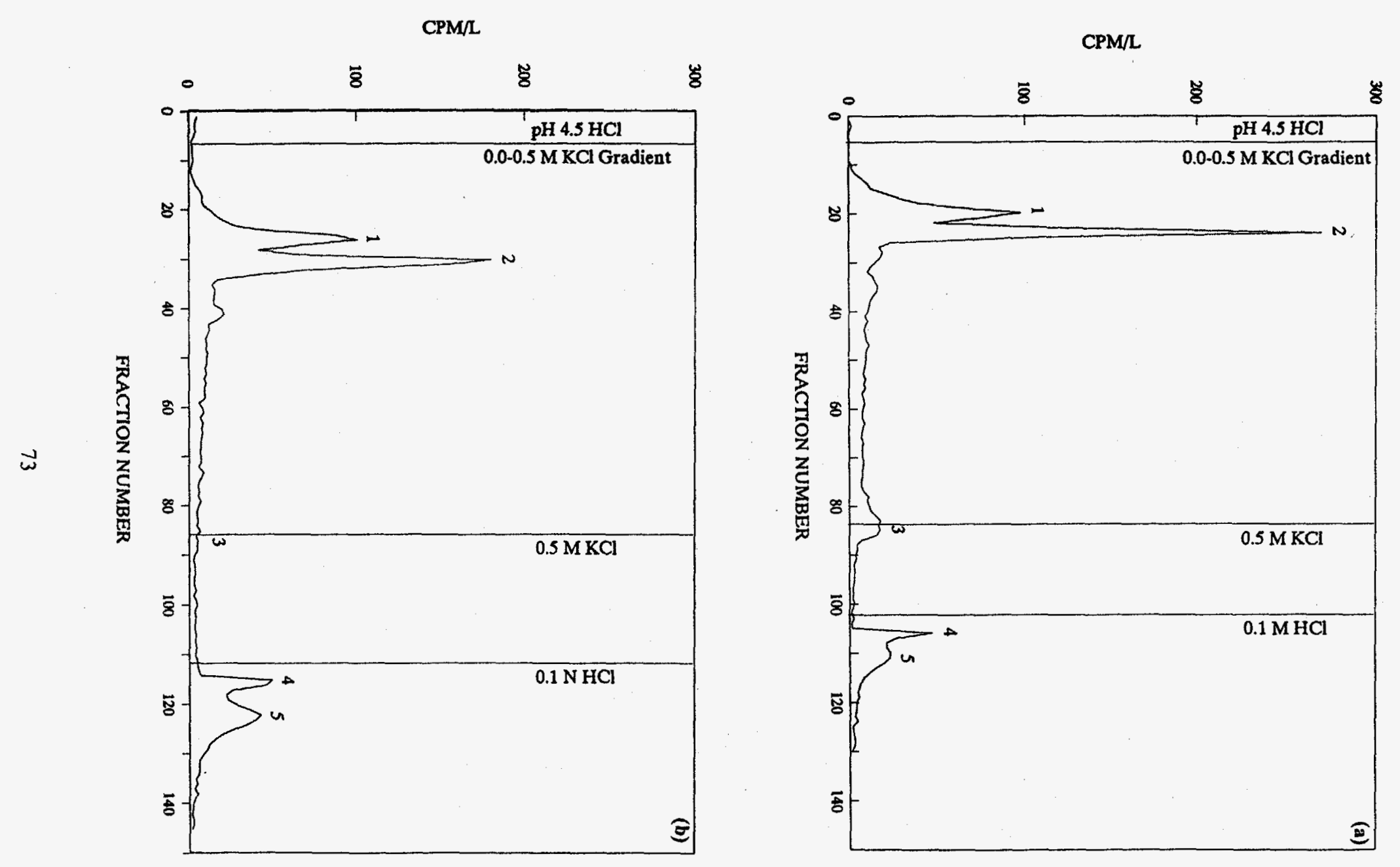

 
Results

Figure 3.26 Ruthenium-106 chromatograms for well ES-16 using 17-cm (a) and 25-cm (b) columns
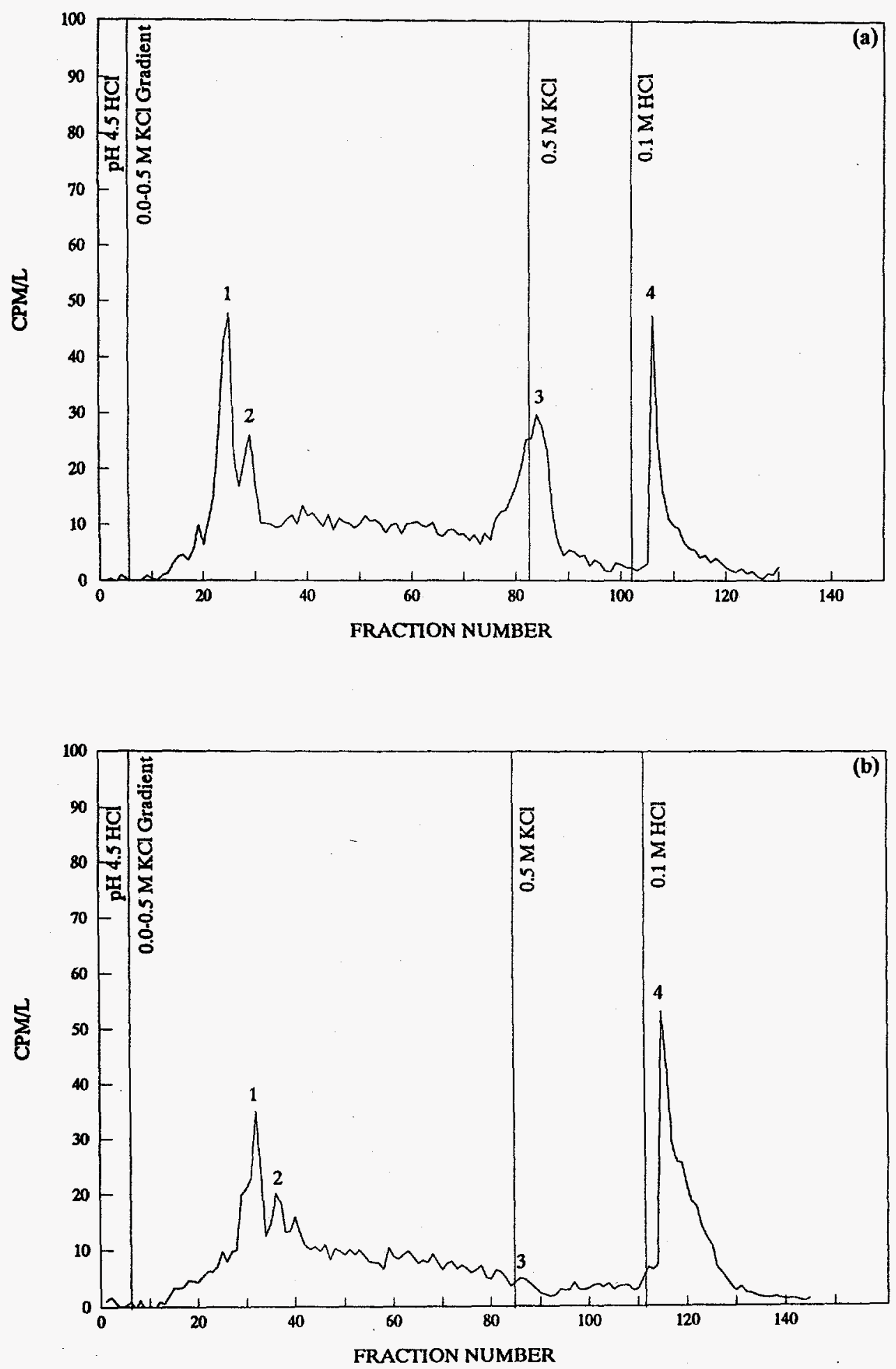
Figure 3.27 Ultraviolet absorbance at $254 \mathrm{~nm}$ for the $7 / 8 / 93$ run

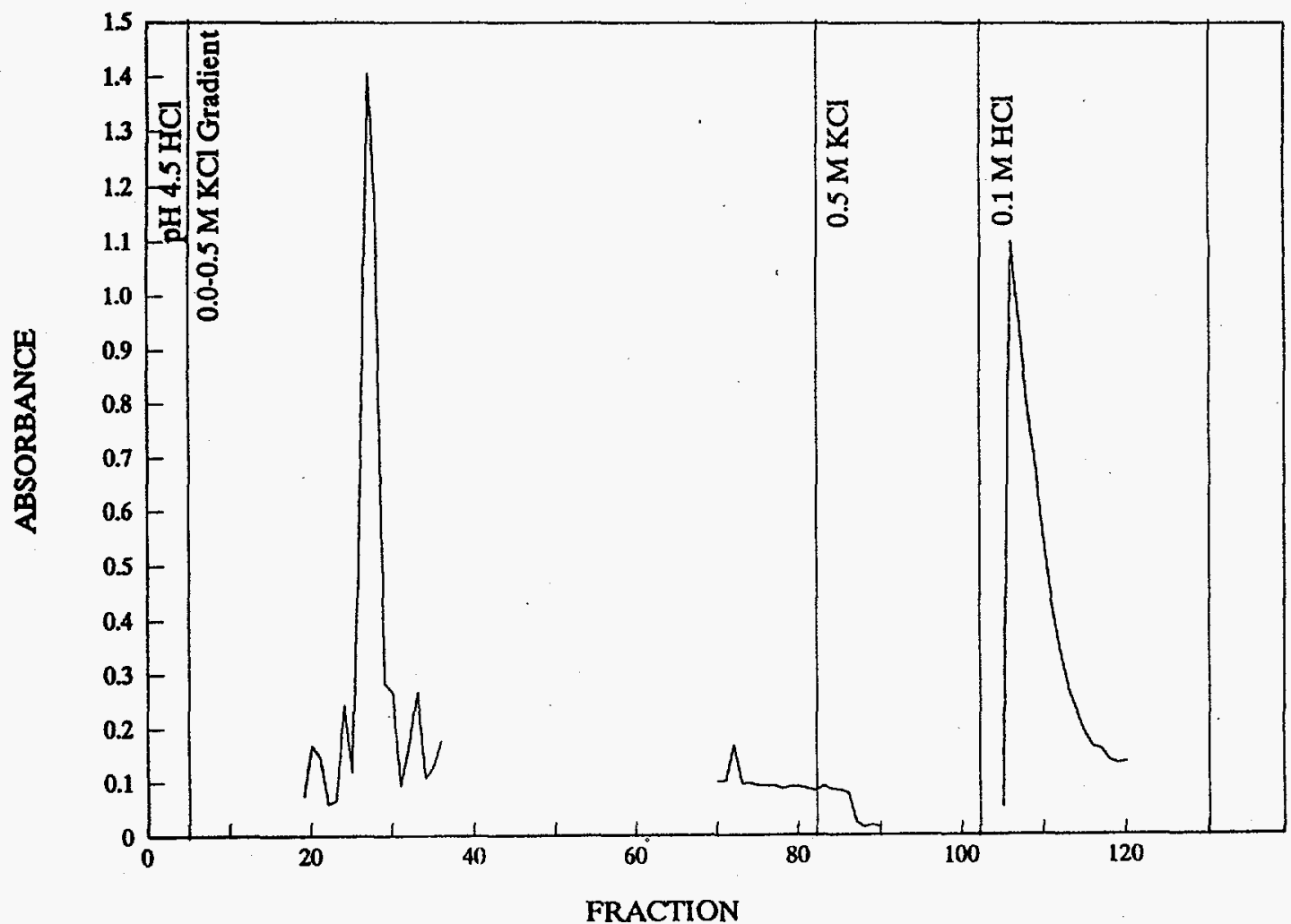


Results

Table 3.15 Anion chromatography results for ${ }^{60} \mathrm{Co}$ at well ES-16 (1993)

\begin{tabular}{|c|c|c|c|c|c|c|c|c|c|c|}
\hline \multirow{2}{*}{$\begin{array}{c}\text { Run } \\
\text { Date }\end{array}$} & \multirow{2}{*}{$\begin{array}{c}\text { Flow Rate } \\
(\mathrm{mL} / \mathrm{min})\end{array}$} & Peak 1 & Peak 2 & Peak 1\&2 & Peak 3 & Peak 4 & Peak 5 & Peak 4\&5 & Sum \\
\cline { 3 - 10 } & & \multicolumn{8}{|c|}{ Normalized Activity (cpm/L) } \\
\hline $7 / 6 / 93$ & 3 & 238 & 855 & 1093 & 152 & 104 & 234 & 337 & 1582 \\
\hline $7 / 7 / 93$ & 3 & 380 & 882 & 1263 & 153 & 84 & 164 & 247 & 1663 \\
\hline $7 / 8 / 93$ & 3 & 381 & 872 & 1253 & 171 & 103 & 188 & 291 & 1715 \\
\hline $7 / 9 / 93$ & 6 & 287 & 967 & 1254 & 183 & 101 & 213 & 314 & 1750 \\
\hline
\end{tabular}

Table 3.16 Anion chromatography results for ${ }^{60} \mathrm{Co}$ at well ES-16 (7/15/93)

\begin{tabular}{|c|c|c|c|c|c|c|c|c|c|}
\hline \multirow{2}{*}{$\begin{array}{l}\text { Run } \\
\text { Date }\end{array}$} & \multirow{2}{*}{$\begin{array}{l}\text { Column } \\
\text { Length }\end{array}$} & Peak 1 & Peak 2 & Peak 1\&2 & Peak 3 & Peak 4 & Peak 5 & Peak 4\&5 & Sum \\
\hline & & \multicolumn{8}{|c|}{ Normalized Activity (cpm/L) } \\
\hline $7 / 16 / 93$ & $17 \mathrm{~cm}$ & 326 & 616 & 942 & 142 & 93 & 124 & 218 & 1302 \\
\hline $7 / 22 / 93$ & $25 \mathrm{~cm}$ & 366 & 568 & 943 & 52 & 139 & 277 & 415 & 1410 \\
\hline
\end{tabular}

complexed with organic materials.

The radionuclide speciation in portions of the $<10,000-\mathrm{MW}$ Chemical Pit filtrates ( $\mathrm{F}_{2}$ from wells CP-4, ES-39, and ES16 [see Section 3.5]) was also investigated by anionexchange techniques. An additional sample of ES-16 groundwater was collected for comparison, and this sample was not ultrafiltered, but instead passed through a $0.45-\mu \mathrm{m}$ filter. These four samples were loaded and chromatographed with a $25-\mathrm{cm}$ analytical column at a flow rate of $\sim 6 \mathrm{~mL} /$ minute. Eight separate peaks were identified in the ${ }^{60} \mathrm{Co}$ chromatograms and are shown in Figures 3.28 (CP-4), 3.29 (ES-39), 3.30 (ES-16). An evolution in chemical speciation has apparently developed as the groundwater flows from the pit towards the wetland. The integrated counts in the individual peak regions are given in Table 3.17. Peak number 4 dominates each chromatogram and reaches a maximum at midfield well ES-39. Peak 3 decreases in intensity at ES-39, but increases again at ES16. It is possible that these two peaks were poorly resolved in the ES-39 chromatogram (Figure 3.29), and this might account for the observed differences in the corresponding peak intensities. Peaks 1,2, and 5 become less significant as the groundwater flows downgradient. Peak 6 does not seem to experience any significant changes, whereas peaks 7 and 8 in the ultra-filtered samples decrease in intensity as the water flows toward the wetland. The major difference between the ES-16 samples is in peaks 7 and 8, which have lower intensities in the ultrafiltered samples. This would seem to suggest that at least some of the associated species are larger than $\sim 10,000 \mathrm{MW}$. The bulk of these species, however, are less than 10,000 MW judging from the similarities in the remaining peaks.

A portion of the ES-16 sample from 8/16/93 was spiked with additional ${ }^{60} \mathrm{Co}$ to study the lability of the radionuclide species. The total cationic and anionic species of ${ }^{60} \mathrm{Co}$ were determined by passing the original groundwater through columns of AG1x8 and AG50Wx8 ion-exchange resins, respectively. These results indicated that the ${ }^{60} \mathrm{Co}$ species in this sample were $\sim 60 \%$ anionic and $\sim 37 \%$ cationic in nature. After spiking, the total ${ }^{60} \mathrm{Co}$ concentration was 27.5 $\mathrm{nCi} / \mathrm{L}$, or roughly three times higher than the total concentration in the original groundwater sample (9.1 $\mathrm{nCi} / \mathrm{L}$ ). However, the concentration of the cationic component of the spike was about seven times that of the original cationic content (thereby increasing the initial cationic concentration by a factor of eight). The spiked sample was allowed to stand in a coldroom for three days before $1.9 \mathrm{~L}$ were loaded and chromatographed. The volume of $0.5-\mathrm{M} \mathrm{KCl}$ was increased to $\sim 350 \mathrm{~mL}$ in this phase in an attempt to isolate the species that eluted near the end of the 17-cm-column $\mathrm{KCl}$ gradient (peak 3 in Figure 3.25a). The chromatograms for the spiked and unspiked samples are shown in Figure 3.31. A total of 14 peaks were identified in the chromatogram, and the resolution is better and the retention times are longer for the spiked sample (partly due to the lower sample volume). Peaks 13 and 14 eluted much later for the spiked sample due to the additional volume of $0.5-\mathrm{M} \mathrm{KCl}$ used; however, they were manifested in similar fractions in the two chromatograms with respect to the $0.1-\mathrm{N}-\mathrm{HCl}$ phase. Peaks 
Figure 3.28 Cobalt-60 chromatogram for ultrafiltered water from well CP-4 (8/13/93)

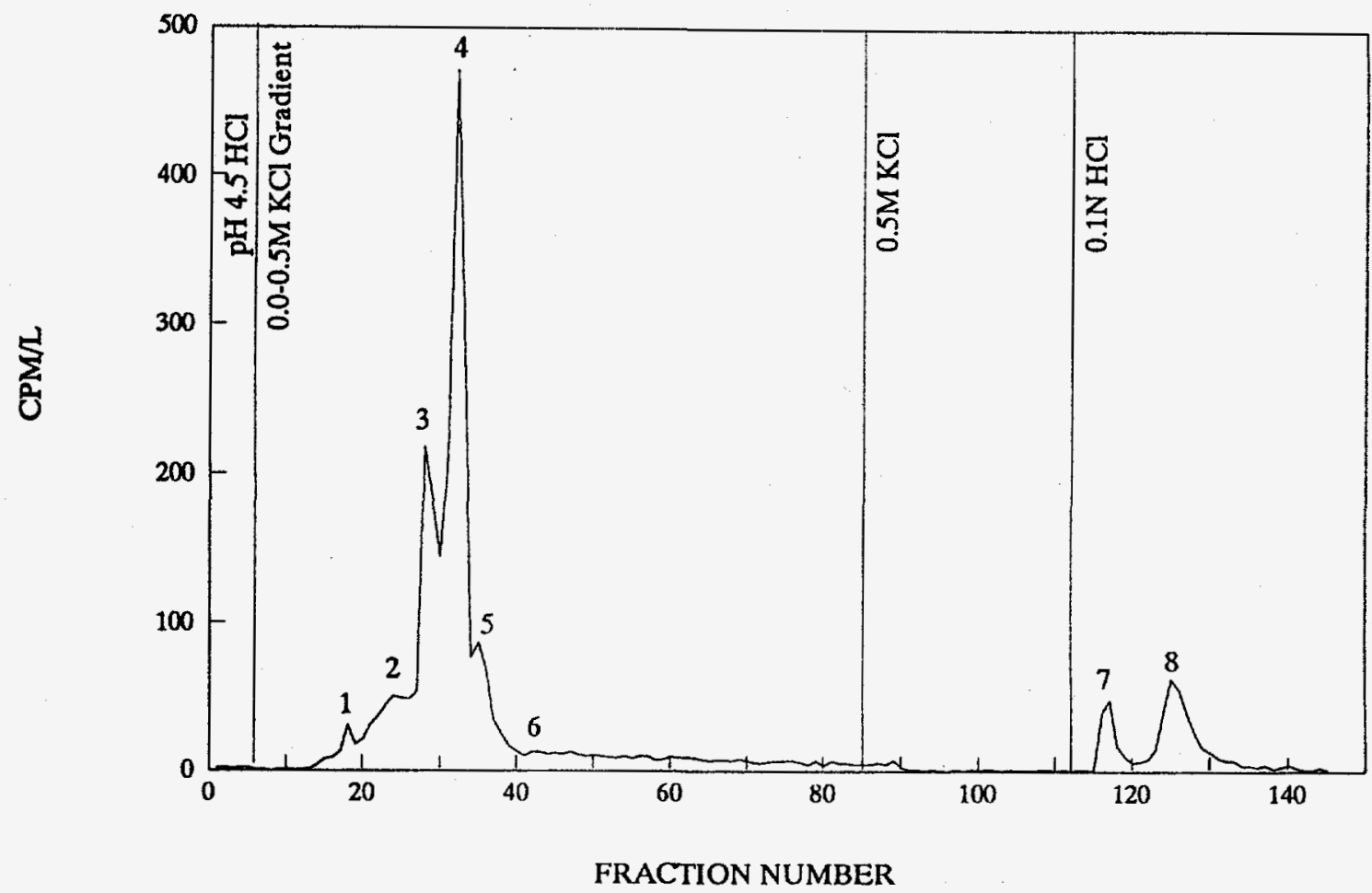


Results

Figure 3.29 Cobalt-60 chromatogram for ultrafiltered water from well ES-39 (8/11/93)

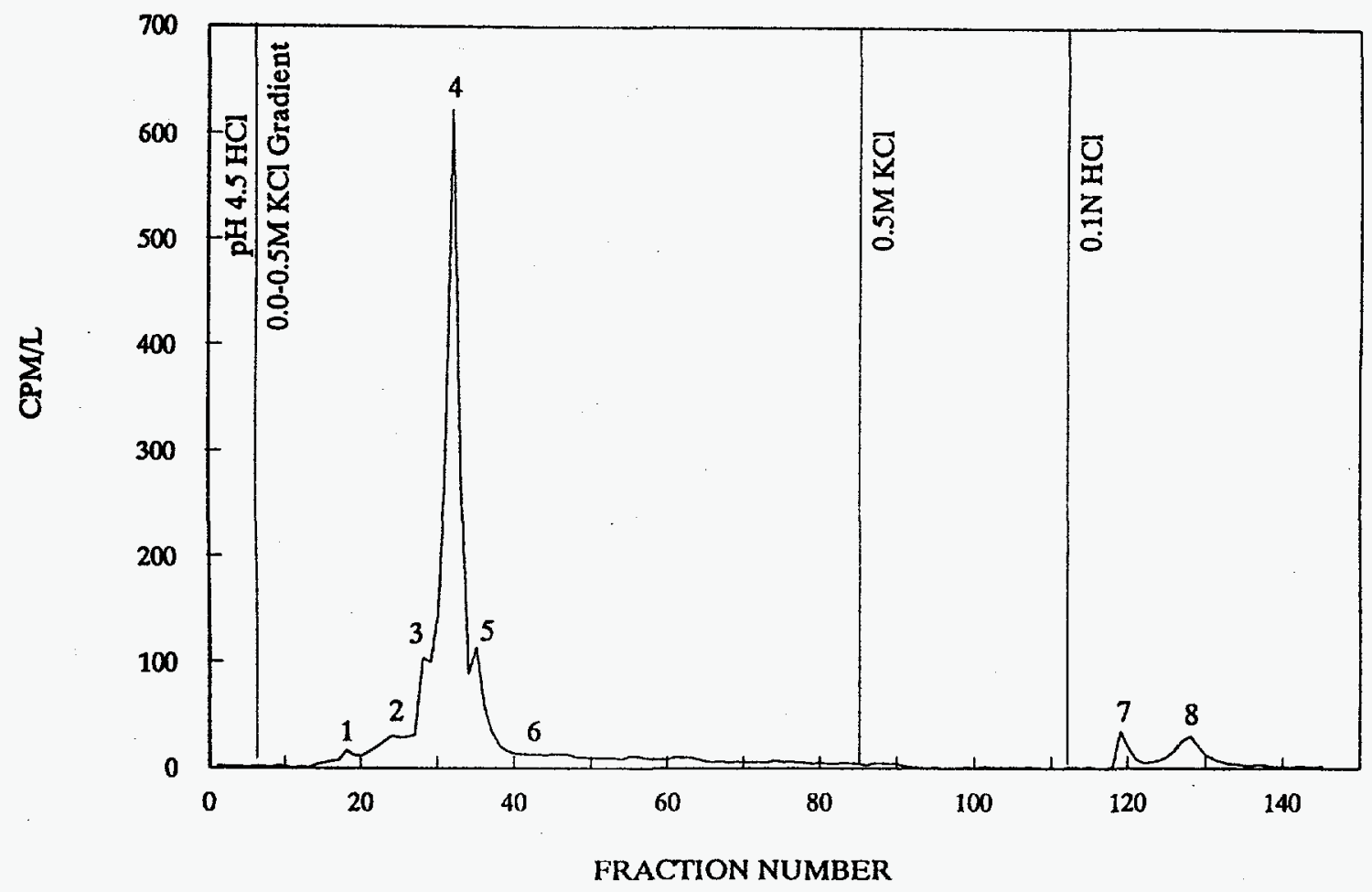


Figure 3.30 Cobalt-60 chromatograms for ultrafiltered (a) and 0.45- $\mu \mathrm{m}$-filtered (b) waters from well ES-16 (8/12/93 and $8 / 17 / 93$, respectively)
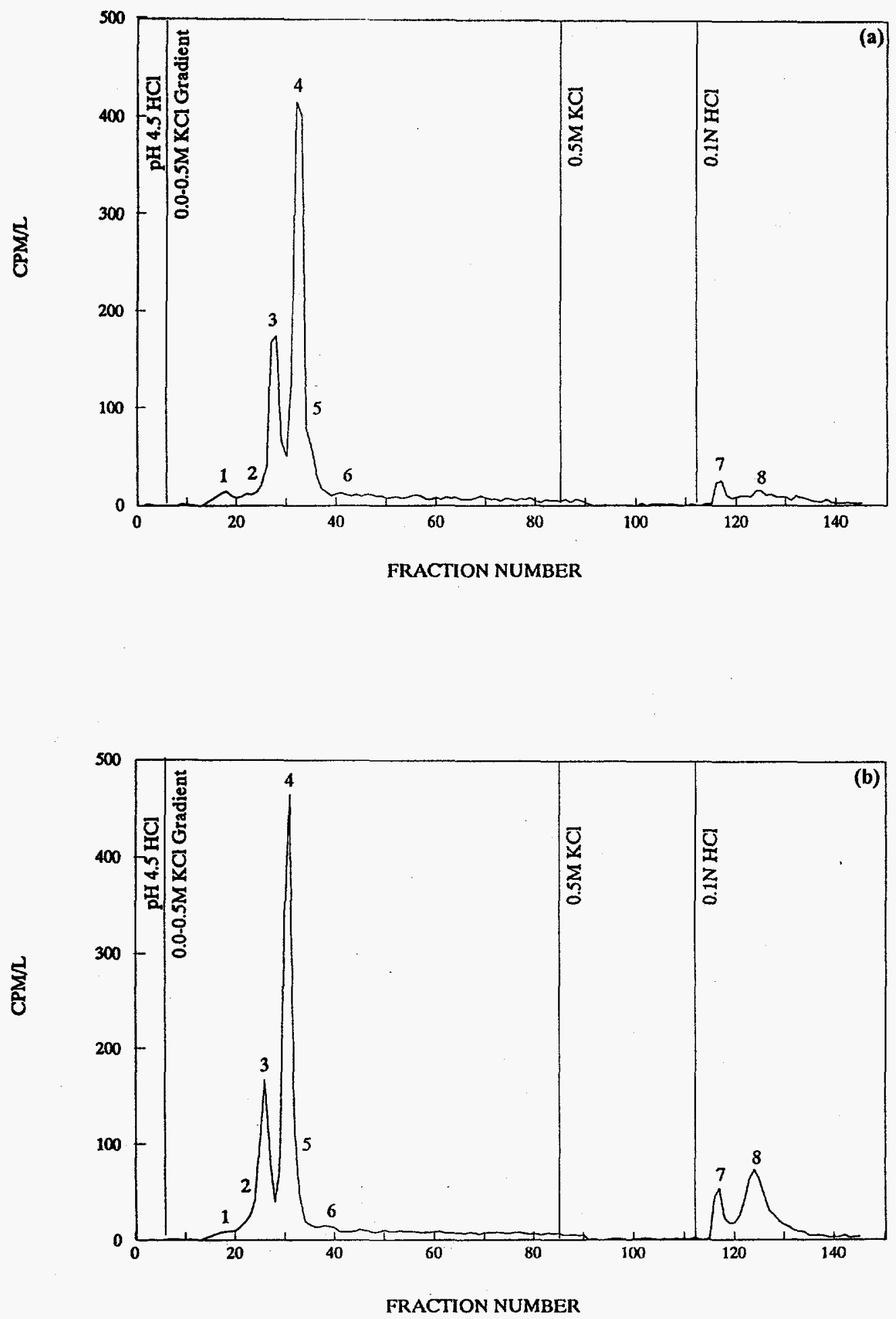
Results

Figure 3.31 Spiked (a) and unspiked (b) ${ }^{60} \mathrm{Co}$ chromatograms from well ES-16
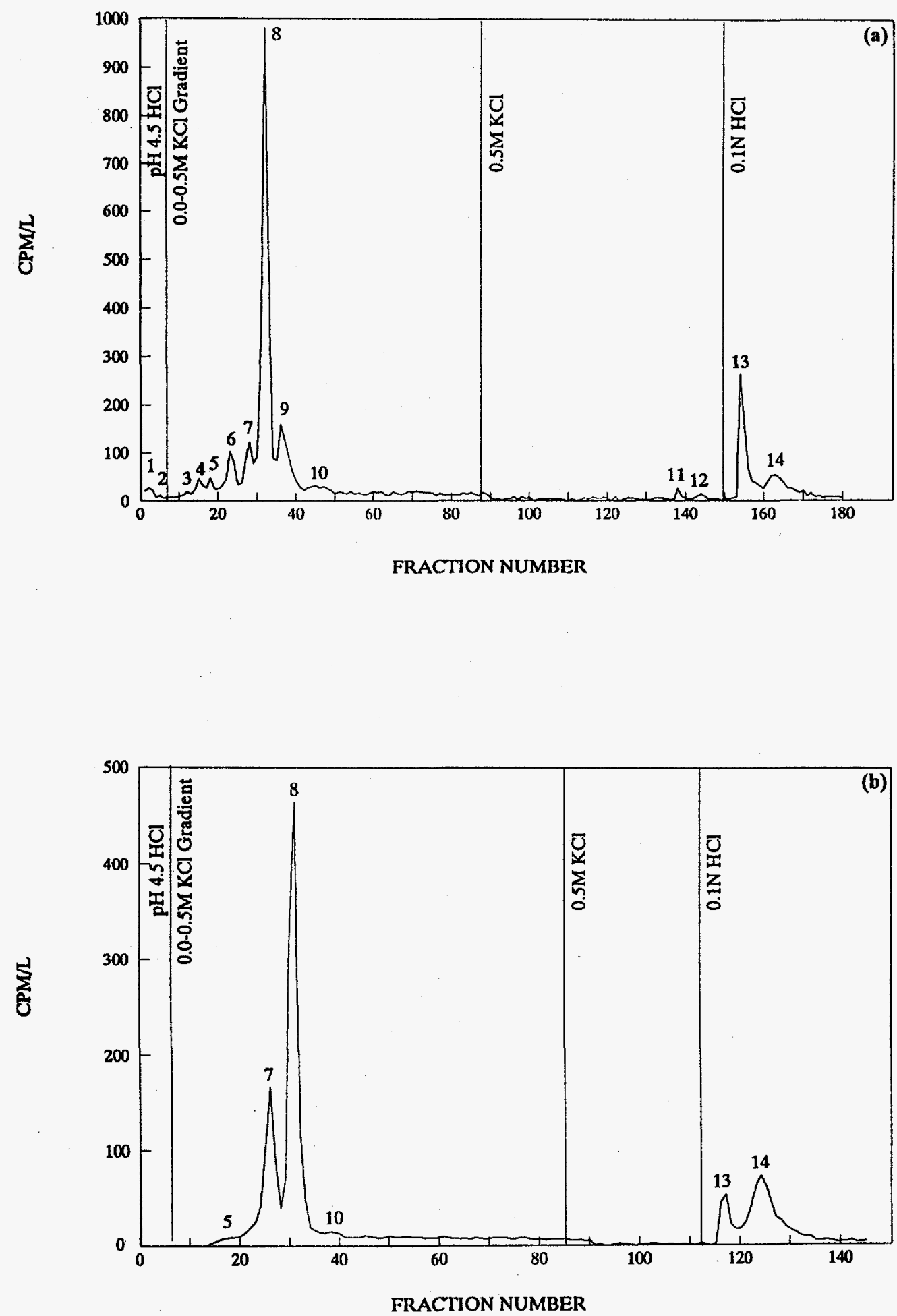
Table 3.17 Cobalt-60 activities in ultrafiltered Chemical Pit groundwater (1993)

\begin{tabular}{|c|c|r|r|r|}
\hline \multirow{2}{*}{$\begin{array}{c}\text { Peak } \\
\text { No. }\end{array}$} & CP-4 & ES-39 & ES-16 & ES-16(resample) \\
\cline { 2 - 5 } & & \multicolumn{2}{|c|}{ Activity Concentration (cpm/L) } \\
\hline 1 & 100 & 60 & 62 & 30 \\
\hline 2 & 216 & 191 & 68 & 78 \\
\hline 3 & 502 & 266 & 450 & 402 \\
\hline 4 & 1203 & 1419 & 1072 & 1022 \\
\hline 5 & 232 & 247 & 131 & 84 \\
\hline 6 & 106 & 113 & 101 & 140 \\
\hline 7 & 122 & 74 & 75 & 406 \\
\hline 8 & 283 & 125 & 115 & 108 \\
\hline
\end{tabular}

7 and 8 in the unspiked chromatogram have been resolved into four distinct peaks ( 6 through 9) in the chromatogram for the spiked sample.

The count rates associated with peaks in these chromatograms were integrated, and the results are shown in Table 3.18. Spiked/unspiked count-rate ratios were calculated for those peaks that could be defined in the unspiked chromatogram. If the dissolved ${ }^{60} \mathrm{Co}$ species are particularly non-labile, the resulting ratios would be expected to be near unity. However, if all of the species are equally labile and the ligand concentrations are not limiting, the same distribution between anionic and cationic species as in the original groundwater sample and a ratio of $\sim 1.8$ would be expected (i.e., $3 \times 0.6$ [ = anionic proportion]). If a mixture of labile and non-labile species is present, some ratios would approach unity while others could exceed 1.8. When the exchange between particular species is kinetically slow (compared to the 3-day equilibration period), the observed ratios may be less than 1.8 , whereas other species with faster exchange rates may exhibit ratios greater than 1.8. Some species might be transient in nature if they are thermodynamically weaker, yet kinetically faster, than other species. The ${ }^{60} \mathrm{Co}$ species. associated with peaks 14 and $6 \& 7$ have near-unit ratios, while the remainder exhibit ratios that are greater than 1.8. In earlier studies of interspecies exchange in these groundwaters using ${ }^{57} \mathrm{Co}$ spike solutions (Killey et al. 1984), very little exchange with anionic ${ }^{60} \mathrm{Co}$ species was observed. Conversely, the current study appears to suggest that considerable exchange is now taking place, and this may indicate a change in speciation has occurred in the Chemical Pit plume between these sampling periods.
Gel-exclusion chromatography.was used to obtain molecular-size information on the separated species from well ES-16 and to de-salt the individual fractions. These were selected from peaks I (fraction 23), 2 (fraction 32), 3 (fraction 80), and 4 (fraction 101) of the ${ }^{60} \mathrm{Co}$ chromatogram (Figure 3.19). Typical gel-exclusion chromatograms are shown in Figures 3.32a and 3.32b for ${ }^{60} \mathrm{Co}$ and ${ }^{106} \mathrm{Ru}$, respectively. The shapes of the chromatograms are affected by poor counting statistics, as well as a larger, $6-\mathrm{mL}$ fraction size. The void volume of the columns was $\sim 18 \mathrm{~mL}$, and the total volumes were $\sim 50 \mathrm{~mL}$. Since the fractionation range of the $\mathrm{P} 2 \mathrm{gel}$ is $100 \mathrm{MW}$ to $1,800 \mathrm{MW}$, species greater than $1,800 \mathrm{MW}$ will begin to elute near $18 \mathrm{~mL}$, those less than $100 \mathrm{MW}$ will elute after $50 \mathrm{~mL}$, and intermediate sizes will fall between the $18-\mathrm{mL}$ and $50-\mathrm{mL}$ fractions. It is evident from Figure 3.32 that a majority of the eluted radioactive species range from 100 MW to $1,800 \mathrm{MW}$ in size, although some smaller material is also present. A number of these species may have originated from the dissociation of larger, labile species during the elution process. This may be particularly true for those species that were eluted in the $0.1-\mathrm{M} \mathrm{HCl}$ phase, since the complexation of metal cations by organic functional groups becomes weak at low $\mathrm{pH}$ due to competition with $\mathrm{H}^{+}$ions in solution. Fractions 20-30, 85, 106, and 112 from the aforementioned series in July of 1993 (Figure 3.24) were also passed through gel-exclusion columns. Four of the resulting chromatograms for ${ }^{60} \mathrm{Co}$ are shown in Figure 3.33. Fractions 22, 26, and 27 (Figure $3.33 \mathrm{a}, \mathrm{b}$, and $\mathrm{c}$, respectively) show bimodal size distributions with larger- (at $\sim 24 \mathrm{~mL}$ ) and intermediatesized (at $\sim 42 \mathrm{~mL}$ ) species. With increasing fraction numbers, initially prevalent intermediate species become 
Results

Figure 3.32 Cobalt-60 (a) and ${ }^{106} \mathrm{Ru}$ (b) gel-exclusion chromatography for fraction 23
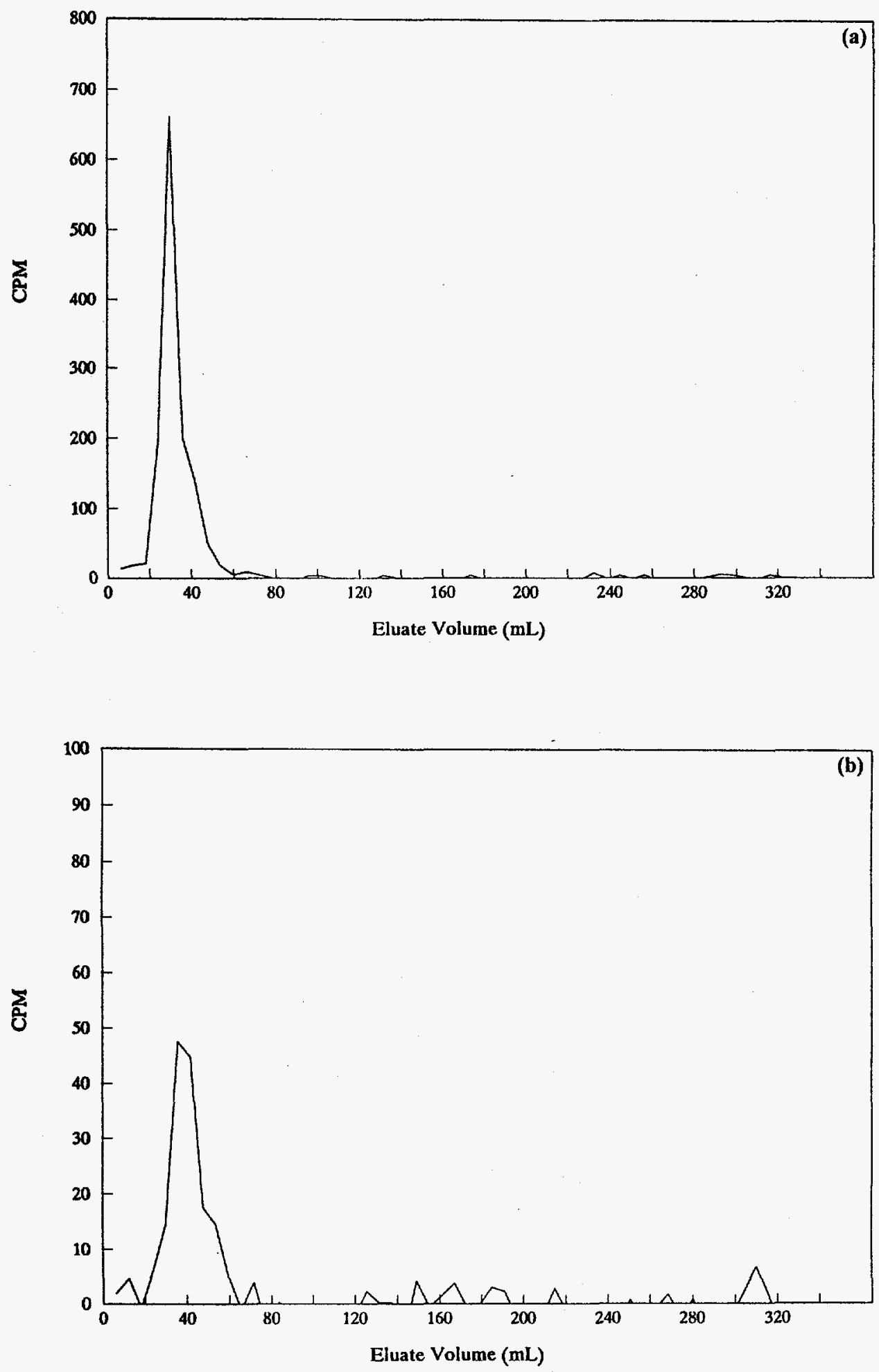
Table 3.18 Radiocobalt-spiked vs. -unspiked results from well ES-16 (1993)

\begin{tabular}{|c|c|c|c|c|c|}
\hline \multirow{2}{*}{$\begin{array}{l}\text { Peak } \\
\text { No. }\end{array}$} & \multicolumn{2}{|c|}{ Spiked Sample } & \multicolumn{2}{|c|}{ Unspiked Sample } & \multirow{2}{*}{$\begin{array}{c}\text { Spiked/ } \\
\text { Unspiked }\end{array}$} \\
\hline & Fractions & $\mathrm{cpm} / \mathrm{L}$ & Fractions & $\mathrm{cpm} / \mathrm{L}$ & \\
\hline 1 & $1-4$ & 72 & - & - & - \\
\hline 2 & $5-7$ & 23 & - & - & - \\
\hline 3 & $10-13$ & 52 & - & - & - \\
\hline 4 & $14-17$ & 121 & - & - & - \\
\hline 5 & $17-19$ & 95 & $17-19$ & 35 & 2.7 \\
\hline 6 & $21-25$ & 286 & - & - & - \\
\hline 7 & $26-29$ & 322 & - & - & - \\
\hline $6 \& 7$ & $21-29$ & 608 & $21-28$ & 501 & 1.2 \\
\hline 8 & $30-34$ & 1981 & - & - & - \\
\hline 9 & $35-40$ & 559 & - & -- & - \\
\hline $8 \& 9$ & $30-40$ & 2540 & $29-34$ & 1048 & 2.4 \\
\hline 10 & $42-50$ & 217 & $42-50$ & 81 & 2.7 \\
\hline 11 & $137-140$ & 40 & - & - & - \\
\hline 12 & $142-145$ & 35 & - & -- & - \\
\hline 13 & $154-159$ & 599 & $115-119$ & 140 & 4.3 \\
\hline 14 & $160-179$ & 433 & $120-145$ & 467 & 0.9 \\
\hline
\end{tabular}

replaced by larger materials. Smaller species dominate in fraction 112 (Figure 3.33d), yet it is uncertain whether these are original species or fragments resulting from the destruction of larger complexes due to the low $\mathrm{pH}$ (this fraction was eluted with $\mathrm{HCl}$ ).

The ${ }^{60} \mathrm{Co}$ gel chromatograms were examined for elevated count rates, which appeared in the following nominal retention-volume ranges: $18-24 \mathrm{~mL}, 30-36 \mathrm{~mL}$, and $42-48$ $\mathrm{mL}$. The results (Table 3.19), however, may only be considered semi-quantitative, as the fraction volumes were $\sim 6 \mathrm{~mL}$, and the pump flow rates varied from column to column. Consequently, it is difficult to clearly discriminate species of similar sizes, and significant overlap may exist between adjacent size fractions. In addition, recovery of the activity retained by the columns was not quantitative, and some cross-contamination may exist between samples eluted on the same gel columns. To improve this sizediscrimination capability, up to $100-\mathrm{cm}$-long gel columns would have to be employed, and these could be calibrated for molecular size by chromatographing synthetically labeled species of known sizes. The columns would have to be rinsed with several column volumes between runs to ensure that no residual activity is left to contaminate subsequent runs. Substantial count-rate peaks are indicated in Table 3.19, and these suggest that a variety of species are present in the individual peaks from the AGMP1 splits.

\subsection{Liquid Chromatography/Mass Spectrometry}

An aliquot of the concentrated water sample was analyzed using direct injection and a mobile phase of $0.001-\mathrm{M} \mathrm{HCl}$. The resulting total-ion chromatogram indicated the presence of a high-molecular-weight, polymeric material, such as humic or fulvic acid molecules. As no standard of 
Results
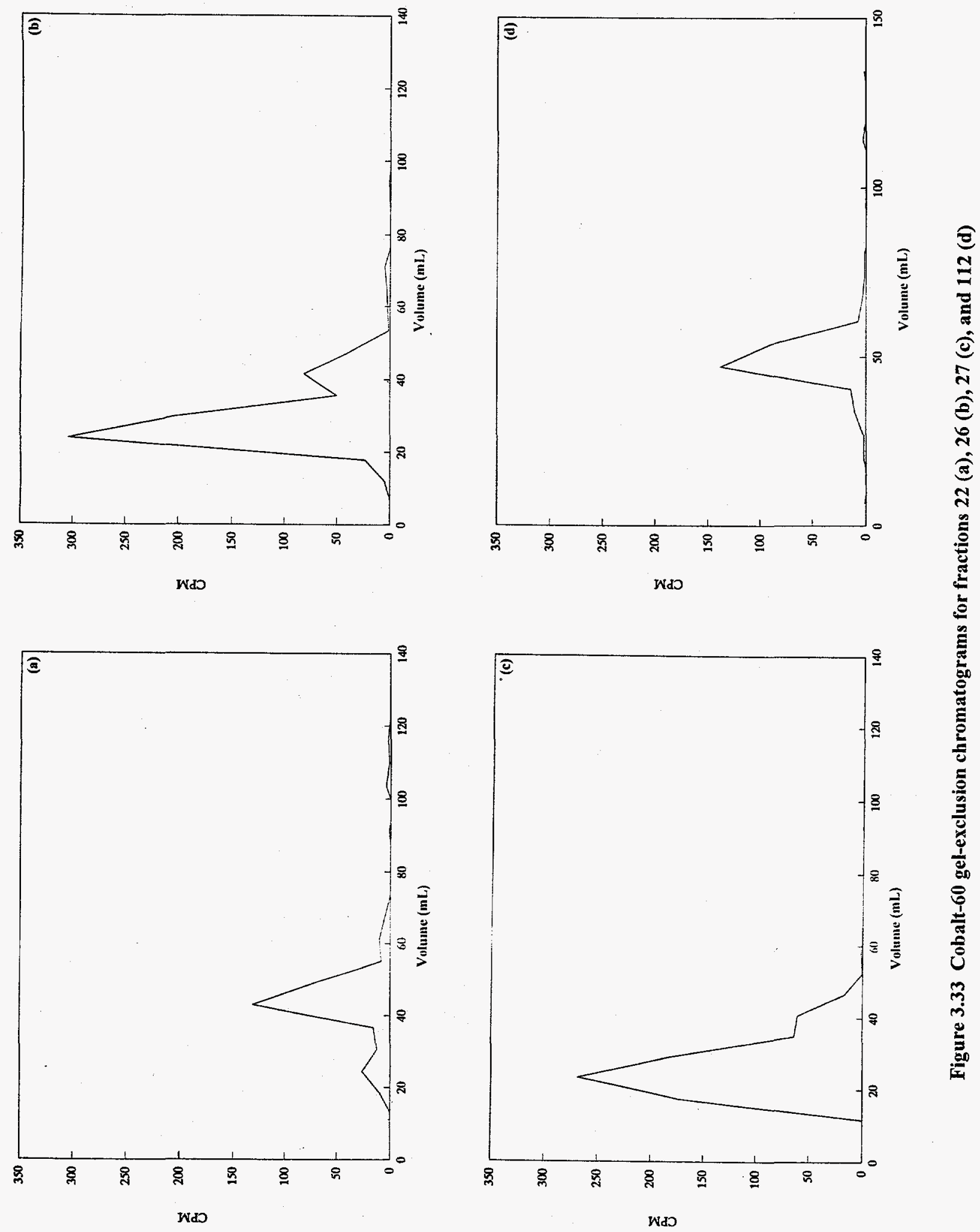
Table 3.19 Cobalt-60 activity levels in gel-exclusion fractions (7/7/93)

\begin{tabular}{|c|r|r|r|}
\hline \multirow{2}{*}{$\begin{array}{c}\text { AGMP1 } \\
\text { Fraction No. }\end{array}$} & \multicolumn{2}{|c|}{ Peak Count Rate (cpm) for Gel Retention Volumes } \\
\cline { 2 - 4 } & $18-24 \mathrm{~mL}$ & $30-36 \mathrm{~mL}$ & $42-48 \mathrm{~mL}$ \\
\hline 20 & 24.6 & 33.6 & 68.3 \\
\hline 21 & 4.6 & 162 & 65.6 \\
\hline 22 & 35.6 & 37.6 & 203 \\
\hline 23 & 7.6 & 26.6 & 59.6 \\
\hline 24 & 41.6 & 38.6 & 44.3 \\
\hline 25 & 17.6 & 46.6 & 69.6 \\
\hline 26 & 328 & 255 & 120 \\
\hline 27 & 444 & 248 & 78.6 \\
\hline 28 & 52.6 & 172 & 57.6 \\
\hline 29 & 40.6 & 61.6 & 18.6 \\
\hline 30 & 6.6 & 38.6 & 67.6 \\
\hline 85 & 11.6 & 35.6 & 20.6 \\
\hline 106 & -- & 19.6 & 42.6 \\
\hline 112 & 4.6 & 24.6 & 228 \\
\hline
\end{tabular}

this material was available for comparison, however, this claim could not be substantiated. Lowermolecular-weight organic acids have been analyzed with this technique and typically exhibit molecular weights less than $\sim 200$ daltons. The molecular weight range for the $\mathrm{CP}-4$ groundwater sample exceeds 500 daltons, thereby lending credence to the hypothesis that the dissolved species were naturally occurring organic macromolecules.

\subsection{Optical Spectroscopies}

The absorption spectra for the largest and smallest size fractions from wells CP-4 and ES-16 (Figure 3.34) are typical for solutions containing humic substances (Summers et al. 1987). Specifically, monotonic decrease in absorption occurs with decreasing excitation energy. The greatest absorption occurs in waters from well CP-4 (near field) and in the largest size fractions for each well. This would seem to suggest that the absorption intensity is due to the concentration and/or size of the dissolved colloidal material.

Little definition exists in the excitation-energy-dependent timeresolved emission spectra (Figure 3.35), although similar spectra have been reported for humic materials (Cabaniss and Shuman 1988; Ewald et al. 1983). A shift in a high-energy band to lower energies as a result of decreasing excitation energy was observed, however, and Levesque (1972) has indicated that this behavior is typical of the emission spectra of humic substances. This excitation-energy dependence is indicative of the presence of multiple fluorophores, which are known to be common to such materials.

Further evidence for the presence of multiple emissive species associated with the CRL groundwater samples was observed in the time-resolved luminescence spectra in which the delay and gate width of the photon counter were varied. These results (Figure 3.36) indicate that there is a short-lived $(<1 \mu \mathrm{s})$ band that underlies the broad band centered around $22,000 \mathrm{~cm}^{-1}$. A comparison of the aqueous and solid samples from CP-4's largest size fraction (Figure 3.37) shows that the broad peak centered at $\sim 22,000 \mathrm{~cm}^{-1}$ in the former is shifted to higher 
Results

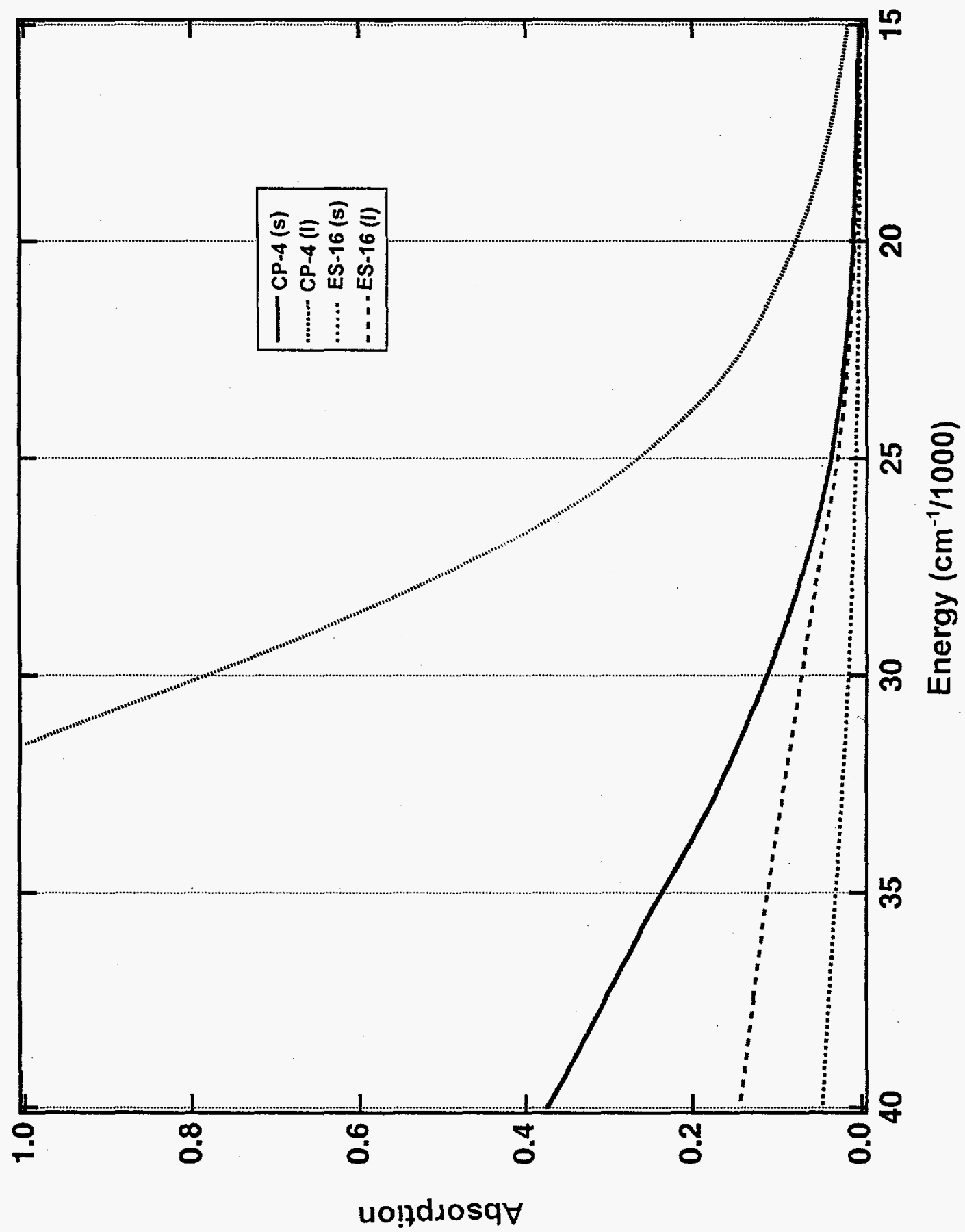

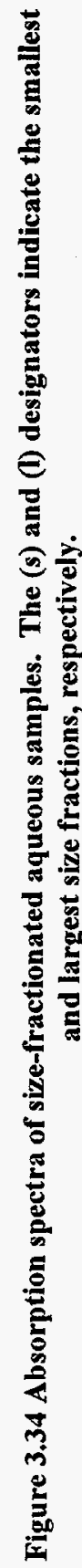


Figure 3.35 Emission spectra from well $\mathrm{CP}-4(<0.45 \mu \mathrm{m},>100,000 \mathrm{MW})$ as a function of excitation energy. Spectra were generated with a Xe flash lamp.

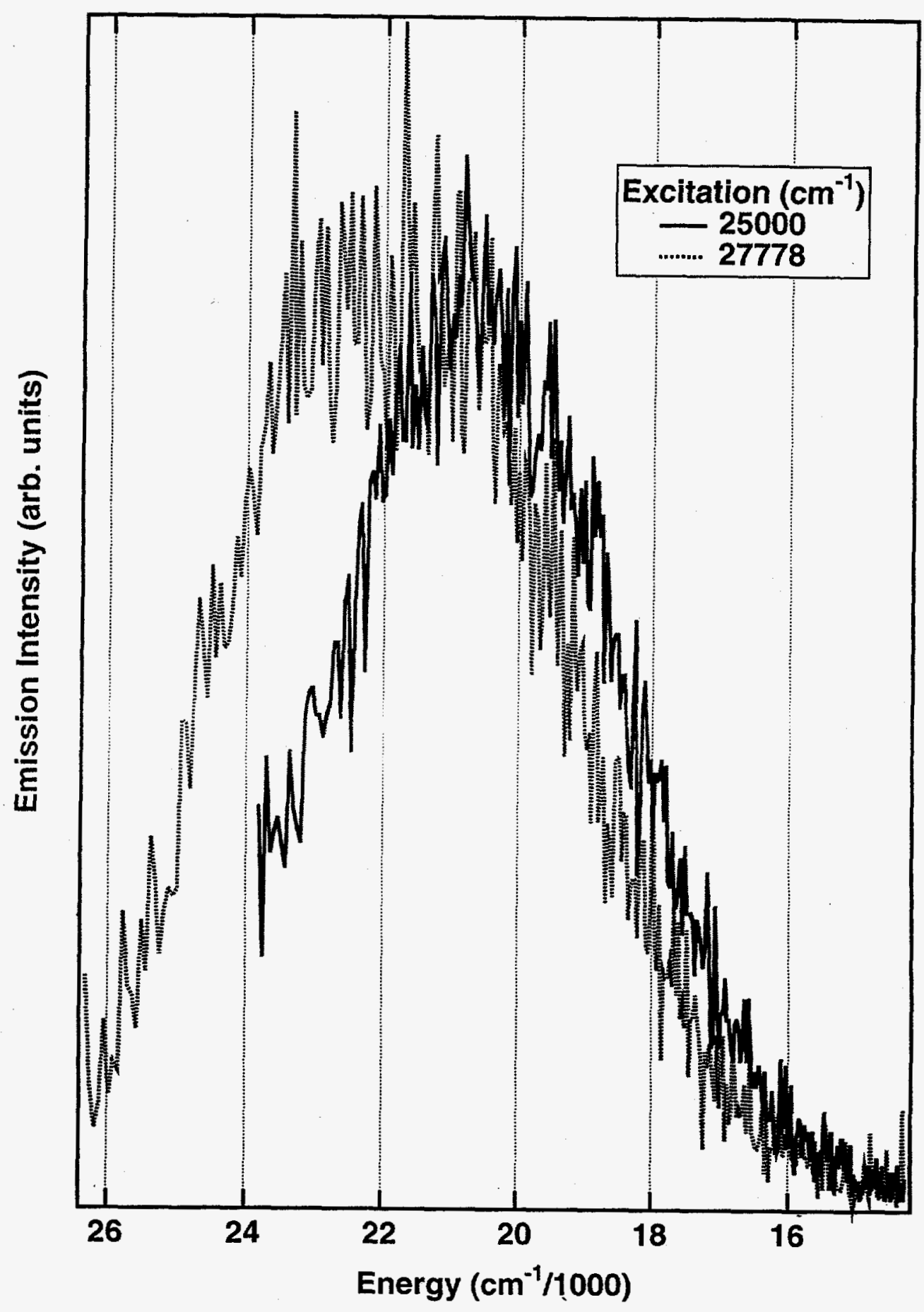


Table 3.20 Fitting results for the time-resolved luminescence lifetime measurements

\begin{tabular}{|c|c|c|c|c|c|c|c|}
\hline $\begin{array}{c}\text { Sample } \\
\text { Identification }\end{array}$ & $\begin{array}{c}\mathrm{CP}-4 \\
(<1 \mathrm{~nm})\end{array}$ & $\begin{array}{c}\mathrm{CP}-4 \\
(<1 \mathrm{~nm})\end{array}$ & $\begin{array}{c}\mathrm{CP}-4(<0.45 \\
\mu \mathrm{m}, 210 \mathrm{~nm})\end{array}$ & $\begin{array}{c}\mathrm{CP}-4(<0.45 \\
\mu \mathrm{m}, 210 \mathrm{~nm})\end{array}$ & $\begin{array}{c}\mathrm{CP}-4(\mathrm{solids} \\
\text { from left })\end{array}$ & $\begin{array}{c}\mathrm{ES}-16(<1 \\
\mathrm{nm})\end{array}$ & $\begin{array}{c}\mathrm{ES}-16(<0.2 \\
\mu \mathrm{m}, \geq 10 \mathrm{~nm})\end{array}$ \\
\hline Emission $\left(\mathrm{cm}^{-3}\right)$ & 21739 & 18315 & 21739 & 18315 & 18315 & 21739 & 21739 \\
\hline$\tau_{0}(\mu \mathrm{s})$ & 0.71 & 0.67 & 0.62 & 0.071 & 3.8 & 0.62 & 0.59 \\
\hline$\tau_{1}(\mu \mathrm{s})$ & 0.71 & 0.14 & 0.62 & 0.44 & 1.1 & 0.62 & 0.62 \\
\hline
\end{tabular}

energies $\left(-23,300 \mathrm{~cm}^{-1}\right)$ in the latter. Better-defined, smaller bands at $15,800 \mathrm{~cm}^{-1}$ and $18,600 \mathrm{~cm}^{-1}$ are observed in the solid sample spectrum, but do not appear to be shifted along with the broader peak. This differential shifting of the observed absorption bands is suggestive of the association of multiple emissive species in these samples. The greater definition of the subordinate bands in the solid spectrum are likely due to the higher concentration of the emissive species in the more concentrated sample. Time-resolved emission lifetime measurements were made at emission energies of $21,739 \mathrm{~cm}^{-1}$ and $18,315 \mathrm{~cm}^{-1}$ (chosen to reflect the approximate energies of the two bands identified in Figure 3.37), and the results are presented in Table 3.20. The largest and smallest size fractions from well $\mathrm{CP}-4$ were investigated at both emission energies. The two lifetimes observed for each sample were equivalent at $21,739 \mathrm{~cm}^{-1}$ and the longer lifetimes $(0.65$ $\pm 0.04 \mu \mathrm{s}$ ) were roughly the same at both emission energies. The shorter lifetimes, however, were significantly different at $18,135 \mathrm{~cm}^{-1}$ for the smaller and larger size fractions $(0.14 \mu \mathrm{s}$ and $0.44 \mu \mathrm{s}$, respectively), and this provides further evidence of the presence of multiple emissive species and/or emissive species in varied environments. The largest and smallest size fractions from well ES-16 exhibited lifetimes at $21,739 \mathrm{~cm}^{-1}$ that were similar to those observed in the $\mathrm{CP}-4$ samples $(0.65 \pm 0.04 \mu \mathrm{s})$.

The solids extracted from CP-4's largest size fraction had two lifetimes $(3.8 \mu \mathrm{s}$ and $1.1 \mu \mathrm{s})$ that were longer and significantly different in magnitude than those associated with the aqueous complement. These data probably result from the fact that the probed species in the solid sample exist in a more restrictive environment. The emissive species in the solid fraction are not as free to move as their counterparts in the aqueous fraction and, consequently, cannot as effectively transfer their energy to the surrounding water molecules. Conversely, the aqueous sample allows more extensive interactions between the species in solution and the surrounding water molecules, thereby resulting in more efficient dissipation of the vibrational energy of the emitting species. This hypothesis assumes that the same set of species are being probed in the aqueous and solid samples. The possibility also exists that some of the emitting species are adsorbed to the colloid surface, and their emission intensity is enhanced as a result of the concentrating effect of the centrifugation. The emission spectra tend to support the first hypothesis, however, since a number of the observed band energies (e.g., $15,800 \mathrm{~cm}^{-1}$ and $18,600 \mathrm{~cm}^{-1}$ ) are the same for both the solid and aqueous samples.

The results from the Raman investigation indicate that this methodology is not sensitive enough to determine the Ramanactive vibrational modes associated with the colloidal material and any adsorbed species. Nothing can be concluded, therefore, with respect to the stoichiometry of the complexed substances. 
Figure 3.36 Emission spectra from well CP-4 $(<0.45 \mu \mathrm{m},>100,000 \mathrm{MW})$ as a function of the photon counter gate and delay. Spectra were generated with $28,169-\mathrm{cm}^{-1} \mathrm{Nd}$ : YAG pulsed laser excitation.

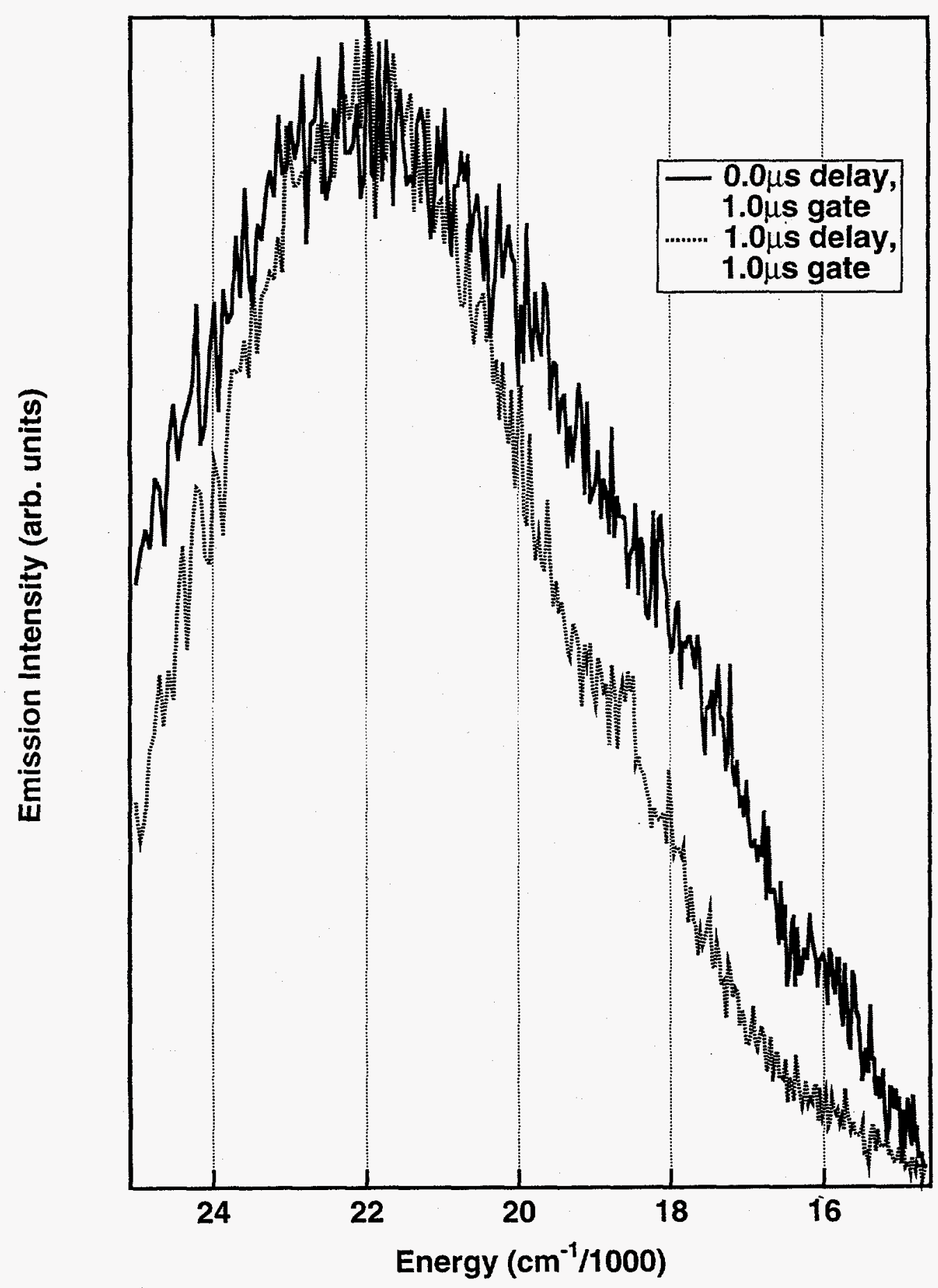


Results

Figure 3.37 Emission spectra from well CP-4, aqueous $(<0.45 \mu \mathrm{m},>100,000 \mathrm{MW})$ and solid material, as a function of the photon counter gate and delay. Spectra were generated with $28,169-\mathrm{cm}^{-1} \mathrm{Nd}$ : YAG pulsed laser excitation.

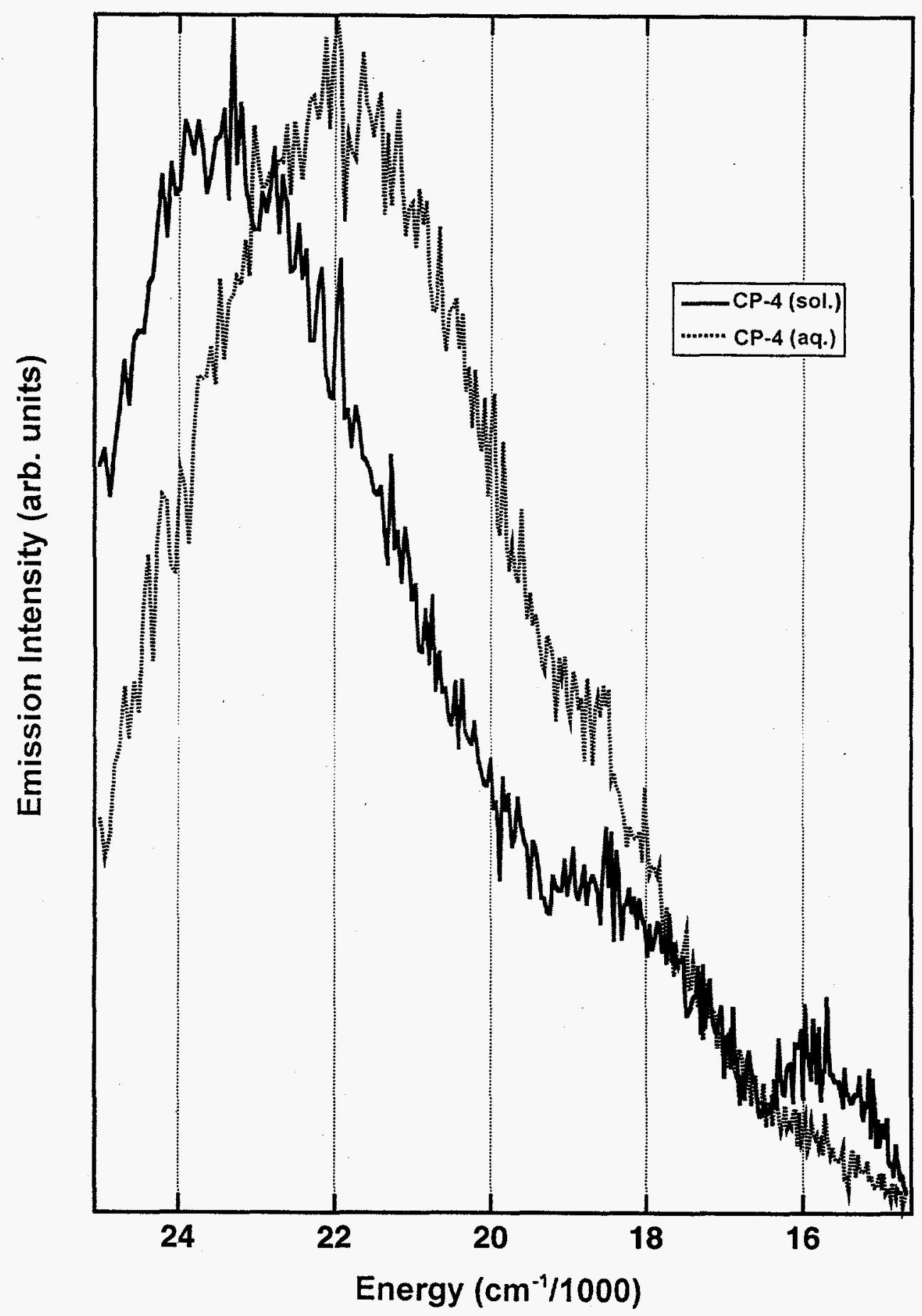




\section{Summary}

In this study, a number of techniques were used to identify the speciation of various migrating radionuclides in a mature, well-characterized low-level waste-disposal facility located in a humid environment. Although the current investigation should not be considered exhaustive, it offers much evidence to support the contention that naturally occurring macromolecules are largely responsible for the facilitated transport of radionuclides via organo-metallic complexation processes. These findings are particularly relevant to decisions involving groundwater remediation and contaminant-retention activities at many existing or projected disposal facilities around the world.

Two low-level waste sites at the Chalk River Facility were studied: the Chemical Pit (within the Liquid Dispersal Area) and Waste Management Area C. The history of waste disposal, trench construction, local geology, and hydrology of these sites was discussed in some detail and, to establish a geochemical baseline for these areas, the results of groundwater analyses performed before this study were presented.

During the course of this study, these waters were observed to be slightly acidic and oxidizing in nature, and their redox environments varied substantially from both a spatial and temporal perspective, possibly due to the presence of humic and fulvic acids. Anion chromatography results were representative of the known anthropogenic and meteoric inputs of this region, and the identified trace elements were found to reflect the mineralogy of the aquifer medium. Anionic radionuclides - suspected of being organoradionuclide complexes - were the most prevalent charged species in these waters (a notable exception, however, is cationic ${ }^{90} \mathrm{Sr}$ at the Chemical Pit), and some evidence exists that suggests inter-charged-species exchange may be occurring to a limited degree along the groundwater flow path. First-order $\mathrm{K}_{d} \mathrm{~s}$ for ${ }^{106} \mathrm{Ru},{ }^{60} \mathrm{Co}$, and ${ }^{90} \mathrm{Sr}$ were determined using measured activity levels from compositesoil and pore-water collected down-gradient from the Chemical Pit. However, only the Ru radioactivity distribution coefficient was consistent with previously reported contaminant mobilities (see Section 3.3 of this report). The determined $\mathrm{Co}$ and $\mathrm{Sr} \mathrm{K}_{d} \mathrm{~s}$, on the other hand, were respectively lower and higher than values represented in the literature for the Chalk River Site, suggesting the need for further investigation in this regard.

Hollow-fiber ultrafiltration of waters sampled downgradient from the Chemical Pit, which was intended to fractionate migrating radionuclide species as a function of molecular or particulate size, generated results that were not consistent over time. In 1993, for example, the highest concentration of observed radionuclides existed in the smallest size fraction $(<1 \mathrm{~nm})$, and abundances were seen to decrease with increasing particle size. Membrane ultrafiltration studies at this time confirmed these results. This could be interpreted as a manifestation of the natural fragmentation and filtration of organo-radionuclide species (i.e., humic and fulvic complexes) as they migrate through the aquifer medium. In contrast, the 1994 results indicate that, in the near-field region, radionuclides predominate in the largest size fraction $(10 \mathrm{~nm}-450 \mathrm{~nm})$ and decrease with decreasing particle size. A large-volume effluent discharge to the Chemical Pit, which occurred before this sampling effort, may have led to the resuspension of some larger species and these disparate results. In the far field, observed radionuclides in 1994 exhibit highly variable behaviors, and, therefore, their interpretations are uncertain. These varied results, however, may represent a snapshot of overlapping phenomena associated with long-term, steadystate conditions and the aforementioned discharge event. A recurring species in the 3-to-5-nm size range was identified in each sample and may be indicative of persistent, stable fragments of natural macromolecules complexed with radionuclides. Particle-size analyses determined the presence of material in near- and far-field Chemical Pit waters with particulate matter ranging from $\sim 2,500 \mathrm{~nm}$ to less than $10 \mathrm{~nm}$ in size. This range corresponds with the anticipated sizes of humic (larger) and fulvic (smaller) macromolecules and the fragments thereof.

Anion-exchange chromatography led to the identification of five to eight individual ${ }^{60} \mathrm{Co}$ species in waters drawn from the Chemical Pit plume, and there appears to be some degree of exchange between or evolution of these species during migration. Gel-exclusion chromatography results indicate that a majority of the radionuclide species fall within a 100-to-1,800-MW size range, which may be representative of whole and fragmented humic and fulvic acid molecules or man-made chelating agents (EDTA, etc.). Ultraviolet absorbance of selected fractions of the aforementioned chromatograms identified two separate organic species that exhibit functional groups commonly associated with humic material, thereby providing further support for the presence of organically complexed radionuclides. Liquid Chromatography/Mass Spectrometry also indicated that high-molecular-weight (>500 MW), polymeric material was present in near-field Chemical Pit waters.

A number of optical spectroscopic techniques were used to further characterize the nature of the migrating radionuclide species, although not all applied techniques generated equally viable results due to limitations associated with relatively low analyte concentrations and the unavailability of "standards" for naturally occurring humic material. Nonetheless, substantial evidence was obtained via these spectroscopic investigations for the presence of humic 
substances in waters sampled downgradient of the Chemical Pit. The greatest abundance of these species is found in the near field, and concentrations apparently decrease somewhat with distance from the point of dispersal. Their continuous presence along the plume axis and known cation-complexing capabilities strongly suggest that these naturally occurring macromolecules are responsible for the enhanced transport of radioactive contaminants at this site. Decreasing humic concentrations along the groundwater flowpath may be a manifestation of the natural filtering process afforded by the aquifer medium, although this would not preclude the continued migration of relatively small organo-radionuclide complexes, such as the fragments of once-larger macromolecular species.

This study has shown, through the use of multiple, state-ofthe-art methods, the consistent relationship between migrating radionuclides and naturally occurring humic and fulvic materials in CRL groundwater. Their ubiquitous presence in sampled waters, their substantial capacity for the complexation of cationic radionuclides under the existing conditions, and their general lack of attraction for most mineral surfaces in the aquifer medium suggest that these species are primarily responsible for facilitating the transport of contaminants in this region.

As the CRL site serves as a viable model for low-level waste repositories in humid environments, the results of this investigation have far-reaching implications in the fields of facility design, maintenance, and remediation. For example, the migration of radionuclides via complexation with humic species might be controlled (i.e., enhanced or retarded) by manipulating groundwater $\mathrm{pH}$ in systems already containing such material, or inexpensive, manmade analogue solutions may be produced in bulk for supporting pump-and-treat activities to strip contaminants from the subsurface. 


\section{References}

Boggs, S., D. Livermore, and M.G. Seitz. 1985. Humic Substances in Natural Waters and Their Complexation with Trace Metals and Radionuclides: A Review.

ANL-84-78, Argonne, Illinois.

Cabaniss, S.E., and M.S. Shuman. 1988.

"Fluorescence Quenching Measurements of Copper-

Fulvic Acid Binding." Anal. Chem. 60:2418-2412.

Champ, D.R., J.L. Young, D.E. Robertson, and K.H. Abel. 1985. "Chemical Speciation of Long-Lived Radionuclides in a Shallow Groundwater Flow System." Water Poll. Res. J. Canada 19(2).

Choppin, G.R. 1988. "Humics and Radionuclide Migration." Radiochim. Acta 44/45:23-28.

Ewald, M., C. Belin, and P. Berger. 1983. "Corrected Fluorescence Spectra of Fulvic Acids Isolated from Soil and Water." Environ. Sci. Technol. 17:501-504.

Florence, T.M. 1982. "The Speciation of Trace Elements in Waters." Talanta 29:345-364.

Jensen, B.S., and H. Jensen. 1988. "Complex Formation of Radionuclides with Organic Ligands Commonly Found in Groundwater." Radiochim. Acta 44/45:45-49.

Killey, R.W.D., and J.H. Munch. 1984. Subsurface Contaminant Transport from the Liquid Disposal Area, CRNL: (I) Hydrogeology and Tritium Contamination near the Chemical Pit. AECL-7691, Atomic Energy of Canada Limited.

Killey, R.W.D., J.O. McHugh, D.R. Champ, E.L. Cooper, and J.L. Young. 1984. "Subsurface Cobalt-60 Migration from a Low-Level Waste Disposal Site." Environ. Sci. Technol. 18:148-157.

Killey, R.W.D., and J.F. Mattie. 1993. Carbon-14 in the Vicinity of Waste Management Area C: Results of a Scoping Study. AECL-10795, Atomic Energy of Canada Limited.

Killey, R.W.D., and J.H. Munch. 1993. Performance of the Impermeable Cover at Area C - Status to 1992. TR-506, Atomic Energy of Canada Limited.

Killey, R.W.D., R.R. Rao, and S. Eyvindson. 1993. Radiocarbon Speciation and Distribution in an Aquifer Plume and Groundwater Discharge Area, Chalk River, Ontario. RC-1135, Atomic Energy of Canada Limited.
Levesque, M. 1972. "Fluorescence and Gel Filtration of Humic Compounds." Soil Sci. 113(5):346-353.

Lieser, K.H., B. Gleitsmann, S. Peschke, and T.H Steinkopff. 1986. "Colloid Formation and Sorption of Radionuclides in Natural Systems." Radiochim. Acta 40:39-47.

Lieser, K.H., A. Ament, R. Hill, R.N. Singh, U. Stingl, and B. Thybusch. 1990. "Colloids in Groundwater and Their Influence on Migration of Trace Elements and Radionuclides."

Radiochim. Acta 49:83-100.

McCarthy, J.F. 1988. Role of Colloidal Particles in the Subsurface Transport of Contaminants. DOE/ER-0384, U.S. Department of Energy, Washington, D.C.

McCarthy, J.F., and J.M. Zachara. 1989. "Subsurface Transport of Contaminants.” Environ. Sci. Technol. 23:496-502.

Patterson, R.J., and T. Spoel. 1981. "Laboratory Measurements of the Strontium Distribution Coefficient for Sediment from a Shallow Sand Aquifer." Water Resour. Res. 17(3):513-520.

Pickens, J.F., R.E. Jackson, and K.J. Inch. 1981. "Measurement of Distribution Coefficients using a Radial Injection DualTracer Test." Water Resour. Res. 17(3):529-544.

Ramsay, J.D.F. 1988. "The Role of Colloids in the Release of Radionuclides from Nuclear Waste." Radiochim. Acta 44/45:165-170.

Robertson, D.E., and R.W. Perkins. 1975. "Radioisotope Ratios in Characterizing the Movement of Different Physical and Chemical Species through Natural Soils." In: Isotope Ratios as Pollutant Source and Behavior Indicators, International Atomic Energy Agency, Vienna, Austria.

Robertson, D.E., M.P. Bergeron, D. Holford, K.H. Abel, C.W. Thomas, D.A. Myers, D.R. Champ, R.W.D. Killey, D.L. Moltyaner, J.L. Young, and T. Ohnuki. 1989. Demonstration of Performance Modeling of a Low-Level Waste Shallow-Land Burial Site. NUREG/CR-4879 vol. 2, U.S. Nuclear Regulatory Commission, Washington, D.C.

Summers, R.S., P.K. Cornel, and P.V. Roberts. 1987.

"Molecular Size Distribution and Spectroscopic Characterization of Humic Substances." Sci. Total Environ. 62:27-37.

Warwick, P., A. Hall, P. Shaw, J.J.W. Higgo, G.M. Williams, B. Smith, D. Haigh, and D. Noy. 1991. "The Influence of Organics in Field Migration Experiments (Part 2)." Radiochim. Acta 52/53:465-471. 
Williams, G.M., J.J.W. Higgo, M.A. Sen, W.E. Falck, D.J. Noy, G.P. Wealthall, and P. Warwick. 1991. "The Influence of Organics in Field Migration Experiments (Part 1)." Radiochim. Acta 52/53:457-463.

Wobber, F.J. 1991. Subsurface Science Program:

Program Overview and Research Abstracts. DOE/ER0432, U.S. Department of Energy, Washington, D.C. 


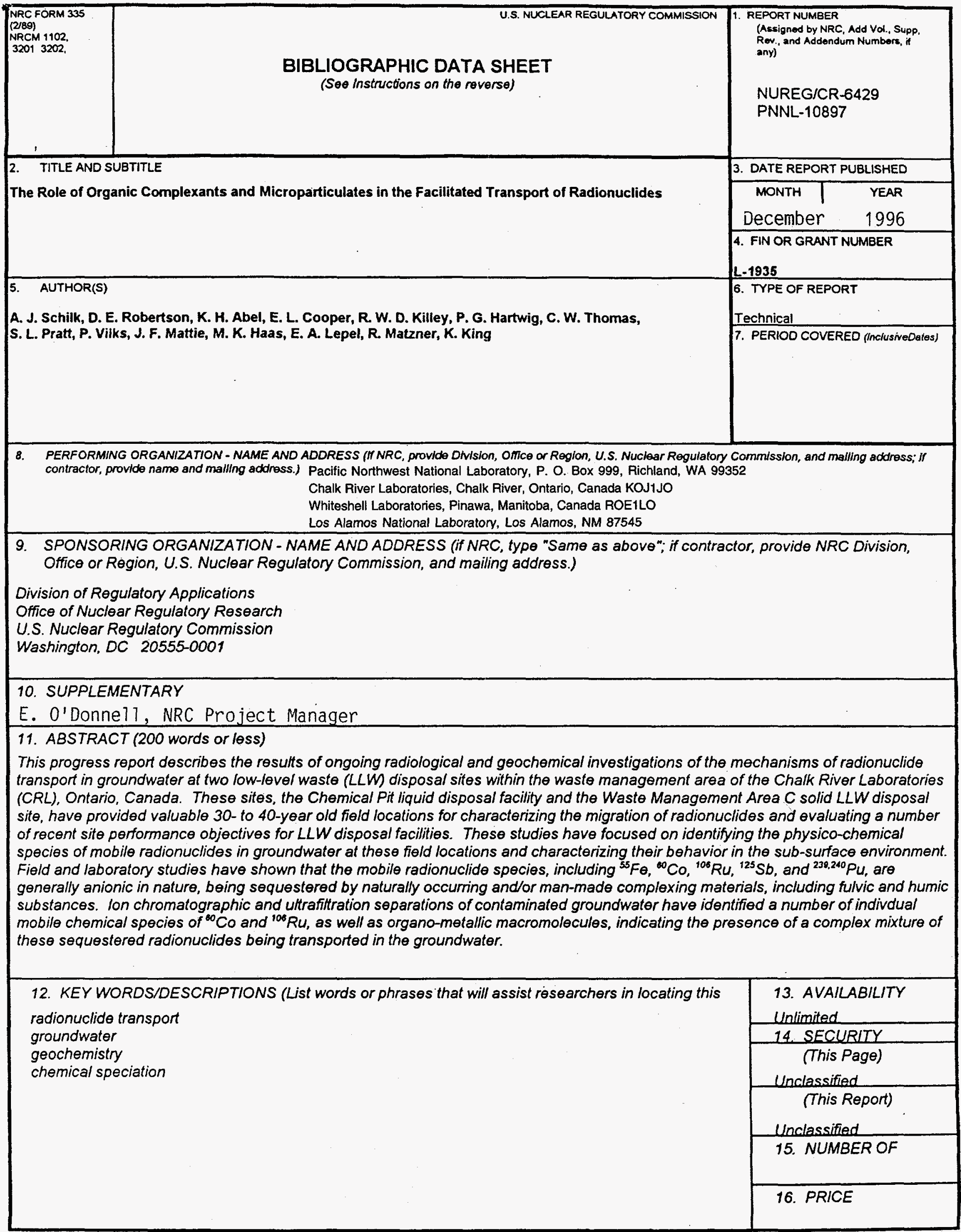

